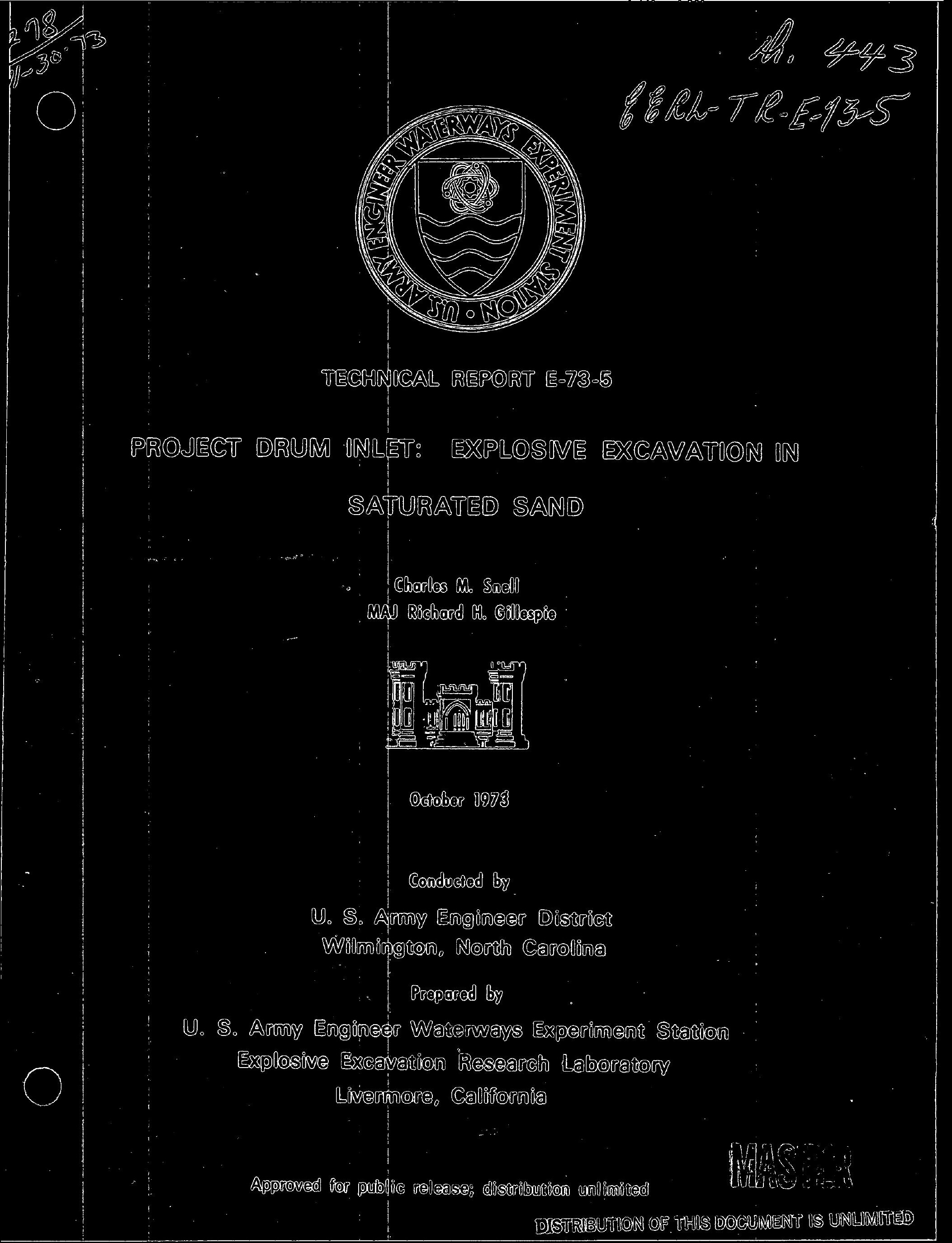


Destroy thiిs repor when no longer needed。

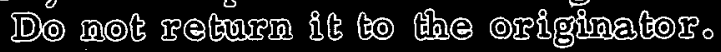

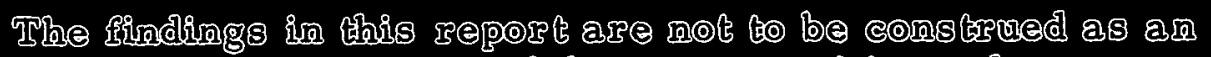

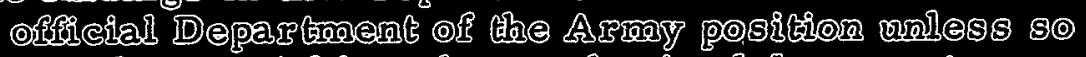
desi̊gnated by other authorized doenreent.

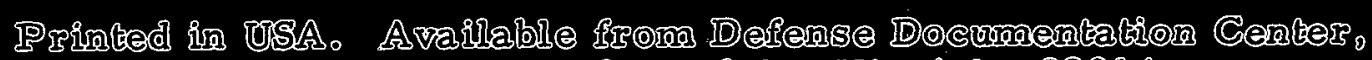

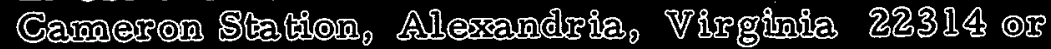

National The

U. S。 Departiont of Cornoerce

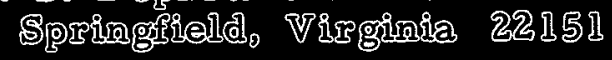

$\therefore \infty$ 


\section{DISCLAIMER}

This report was prepared as an account of work sponsored by an agency of the United States Government. Neither the United States Government nor any agency Thereof, nor any of their employees, makes any warranty, express or implied, or assumes any legal liability or responsibility for the accuracy, completeness, or usefulness of any information, apparatus, product, or process disclosed, or represents that its use would not infringe privately owned rights. Reference herein to any specific commercial product, process, or service by trade name, trademark, manufacturer, or otherwise does not necessarily constitute or imply its endorsement, recommendation, or favoring by the United States Government or any agency thereof. The views and opinions of authors expressed herein do not necessarily state or reflect those of the United States Government or any agency thereof. 


\section{DISCLAIMER}

Portions of this document may be illegible in electronic image products. Images are produced from the best available original document. 
TID-4500, UC-35

Peaceful Applications of Explosions

\title{
TECHNICAL REPORT E-73-5 PROJECT DRUM INLET: EXPLOSIVE EXCAVATION IN SATURATED SAND
}

\author{
CHARLES M. SNELL
}

MAJ RICHARD H. GILLESPIE

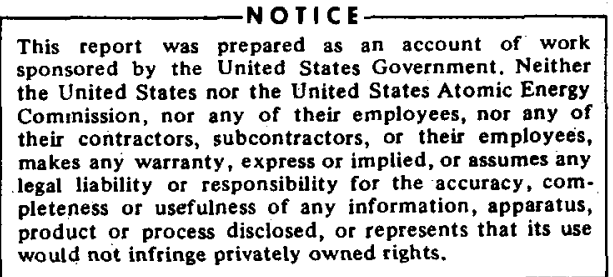

Conducted by

U.S. ARMY ENGINEER DISTRIC'T WILMINGTON, NORTH CAROLINA

\section{Prepared by}

U.S. ARMY ENGINEER WATERWAYS EXPERIMENT STATION EXPLOSIVE EXCAVATION RESEARCH LABORATORY

LIVERMORE, CALIFORNIA

MS. date: August 1973

This document is

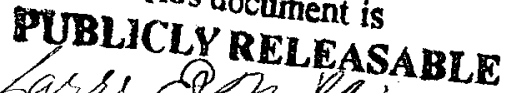

Authorizing Oficial lame

1: $08 / 09 / 2$

$$
-i-
$$

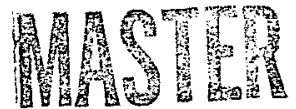




\section{Preface}

This report was prepared by the Explosive Excavation Research Laboratory (EERL) * of the U.S. Army Engineer Waterways Experiment Station (USAEWES). The Drum Inlet Project was executed and funded under the auspices of the Wilmington District, Corps of Engineers. EERL provided technical assistance and advice during the explosive excavation phase of the project. Technical programs related to the explosive detonation were implemented by EERL, with support from the Wilmington District. Results of these programs are presented in this report.

COL A. C. Castango was Distrıct Engineer of the Wilmington District, Corps of Engineers, and Mr. C. D. (Don) Carmen, Jr., was the district's project engineer and coordinator for Drum Inlet. COL E. Peixotto was the Director of the Waterways Experiment Station during project design and execution and during the preparation of this report. The Directors of EERL were COL W. E. Vandenberg, LTC R. L. LaFrenz, and LTC R. R. Mills, Jr.

\footnotetext{
Formerly known as the USAEWES Explosive Excavation Research Office (EERO), from 1 August 1971 until 4 April 1972, and before that as the USAE Nuclear Cratering Group (NCG).
} 


\begin{abstract}
Seasonal storms during February of 1971 completely closed the Drum Inlet navigation channel through the Outer Banks off the North Carolina coast. This channel is highly useful to commercial and sport fishing industries in the Carteret County vicinity of North Carolina, and is vital to maintenance of the ecological balance in the inland Core Sound waters. To reopen Drum Inlet, an alignment about 2.1 miles south of the original location was selected. A contract dredge excavated a channel from the inland Core Sound waterway to and part way through the Outer Banks. The final $385-\mathrm{ft}-$ long section of sand separating the Core Sound from the Atlantic Ocean was excavated with large explosive charges. This report describes the explosive excavation of that portion of the channel. Twenty-two separate canisters, each containing 1 ton of aluminized ammonium-nitrate slurry blasting agent, were emplaced in two rows. All charges were detonated simultaneously at 1327 hours, 23 December 1971. The detonation successfully removed the sand barrier, forming a continuous channel over $80 \mathrm{ft}$ in width. This channel subsequently washed out to a width of about $1000 \mathrm{ft}$ and was used as an access route to the Raleigh Bay fishing grounds. The Drum Inlet project demonstrated the practicality of explosive channel excavation in saturated sand under the special conditions encountered at this site.
\end{abstract}




\section{Contents}

PREFACE

ABSTRACT

CONVERSION FACTORS

1. INTRODUCTION

2. EXPLOSIVE EXCAVATION IN SATURATED AND SUBMERGED

MEDIA: PREVIOUS EXPERIENCE

3. PROJECT HISTORY

4. PROJECT DESIGN

5. CONSTRUCTION AND EXECUTION

6. DETONATION PHENOMENOLOGY

7. EXCAVATION RESULTS

8. TECHNICAL PROGRAM RESULTS

9. SUMMARY AND CONCLUSIONS

REFERENCES

\section{FIGURES}

1 The North Carolina coast photographed from Apollo 9

2 North Carolina coast in the vicinity of Drum Inlet and the Core Banks

Aerial photograph showing the old Drum Inlet

Aerial photograph showing the old Drum Inlet vicinity of the Outer Banks after closure of the inlet (taken 11 Feb. 1971)

Mosaic compiled from aerial photographs of Drum Inlet and excavation cut vicinity

Preshot and postshot photographs of an eight-charge simultaneous modeling detonation in saturated sand

Contours of the crater excavated by an eight-charge simultaneous double-row modeling detonation in saturated sand

Contours of the crater excavated by a six-charge delayed double-row modeling detonation in saturated sand

Preliminary design plans for dredging and excavation of the Drum Inlet channel, September 1971

Side view (cross section) and overhead view of final charge emplacement design for Drum Inlet

Canister design and priming assembly

Canister end-seal details

Charge emplacement procedures

Ground level sequence view of the detonation as seen from a range of about $1500 \mathrm{ft}$

Long-range sequence view of the detonation, photographed from the beach approximately 2.5 miles away

Sequence view of the detonation and cloud taken from a helicopter flying on the Core Sound side of the Outer Banks

Early-time postdetonation photographs of Drum Inlet channel showing offshore lip and islets near center of crater 
FIGURES (continued)

TABLES

Approximate postshot crater contours, based on visual estimates

Preshot and postshot views of the Outer Banks area and the excavated Drum Inlet channel

Postshot views of the Drum Inlet channel, 23 December 1971

Postshot views of the Drum Inlet channel immediately after the shot and 19 days later

Cloud dimensions at very late time $\left(+35.0^{\circ} \mathrm{sec}\right) \cdot$

Base cloud radius off ends of row as a function of time

Height of base cloud and base cloud plume as functions of time

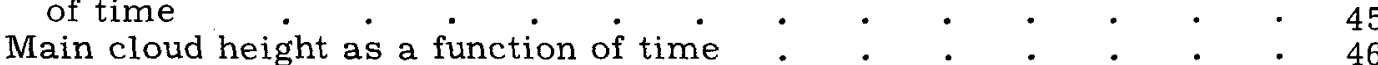

Early-time mound and water plume growth, charges 1 through 8

Early-time stem ejection and plume development, charges 1 through 8

SGZ peak vertical spall velocity, $\mathrm{V}_{0}$, as a function of scaled depth of burial, dob, for events in saturated media, moist sand, and saturated media overlain by water

SGZ peak vertical spall velocity as a function of scaled depth of burial, for sand and concrete

Velocity ratio $\left(\mathrm{V} / \mathrm{V}_{0}\right)$ as a function of dimensionless slant range from shot point squared, (D/S $)^{2}$, for charges 5 , 6 , and 7

Estimated free-field particle velocities as a function of range, for AANS explosive in saturated sand

Sample trajectories of high-velocity ejecta, labeled with the ejecta particle number and the approximate velocities

Charge locations, charge depths, row separations, and intercharge spacing for the Drum Inlet double-row detonation

Ground-level photographic coverage of the Drum Inlet

Approximate stabilized cloud dimensions for Drum Inlet and comparable 1-ton single-charge detonations near optimum depth of burial

Measured sand-surface peak vertical spall velócities and spall velocity profiles for the Drum Inlet detonation, charges 3 through 7

Sand plume (stem vent) ballistic ejection velocities for the Drium Inlet detonation, charges 3 through 6

Measured radial water plume velocities for the Drum Inlet detonation; charges 1 and 8

Predicted and observed péak water spall velocities above charges 1 and $8^{\circ}$

Measured late-time ejecta velocities perpendicular to the camera bunker line of sight for the Drum Inlet detonation 


\section{Conversion Factors}

British units of measurement used in this report can be converted to metric units as follows.

\begin{tabular}{|c|c|c|}
\hline Multiply & By & To obtain \\
\hline inches & 2.54 & centimeters \\
\hline feet & 0.3048 & meters \\
\hline cubic feet & 0.02832 & cubic meters \\
\hline cubic yards & 0.764555 & cubic meters \\
\hline pounds & 0.4535924 & kilograms \\
\hline pounds per square inch & 0.00689476 & meganewtons per square meter \\
\hline pounds per cubic foot & 16.02 & kilograms per cubic meter \\
\hline Fahrenheit degrees & $-^{\mathrm{a}}$ & Celsius or Kelvin degrees \\
\hline foot-pounds & 0.138255 & meter-kilograms \\
\hline pounds per square inch (psi) & 69.0 & millibars \\
\hline
\end{tabular}

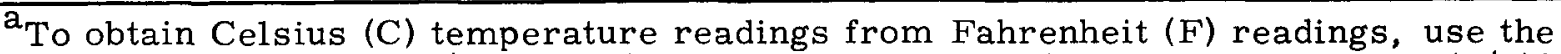
following formula: $C=(5 / 9)(F-32)$. To obtain Kelvin $(K)$ readings, use: $K=(5 / 9)(F$ $-32)+273.15$
}

The contents of this report are not to be used for advertising, publication, or promotional purposes. Citation of trade names is intended to describe the experimental setup, and does not constitute an official endorsement or approval of the use of such commercial products. 


\section{PROJECT DRUM INLET: EXPLOSIVE EXCAVATION IN SATURATED SAND}

\section{Introduction}

\section{Purpose}

This report documents the explosive excavation phase of Project Drum Inlet, the reopening of Drum Inlet navigation channel through the Outer Banks off the North Carolina coast. The design, implementation, and technical program results of the explosive event are described. A brief summary of the origin, history, and overall results of the project is also included.

\section{Background}

The eastern coastal areas of North Carolina are separated from the Atlantic Ocean by a great sand barrier reef known as the Outer Banks. * This reef consists of a chain of islands penetrated by several temporary or semipermanent inlets of various sizes. The inland waterways enclosed by the reef are called "sounds." The inlets provide navigational access to the sounds, and interchange of ocean and sound waters. Most of the smaller inlets are not dynamically stable over long periods of time, and often undergo rapid changes in location, size and shape, or complete closure. The Drum Inlet channel, located in the Carteret County vicinity of North Carolina, was closed as a result of seasonal storms during February of 1971. This inlet was used as a short route to Raleigh Bay by many com-

\footnotetext{
"See Fig. 1, the North Carolina coast photographed from Apollo 9.
}

mercial and sport fishing craft. In addition, disappearance of the inlet interrupted tidal communication between the ocean and the inland waterway (known as the Core Sound), threatening a reversal of favorable environmental conditions within the sound. Therefore, a project was initiated to create a new inlet near the site of the old one. The Wilmington District of the U.S. Army Corps of Engineers was responsible for designing and coordinating the, project. A navigation channel was excavated to a depth of $7 \mathrm{ft}$ within the sound waters and part way through the Outer Banks by a conventional dredge. Due to the high risk of severe damage to the dredging plant, it was deemed unsafe to dredge the last section of sand separating the sound from the ocean, so an explosive excavation event was designed to complete the channel. The Explosive Excavation Research Laboratory provided the charge emplacement design and technical assistance for this portion of the project. Design, execution, and results of the detonation are discussed in this report. Other participating agencies, involved with the study of inlet dynamics or the ecological aspects of the project, included the Hydraulics Laboratory of Waterways Experiment Station (WES), the Coastal Engineering Research Center (CERC), and the National Park Service. Results of their investigations will be reported separately by the individual participants. 


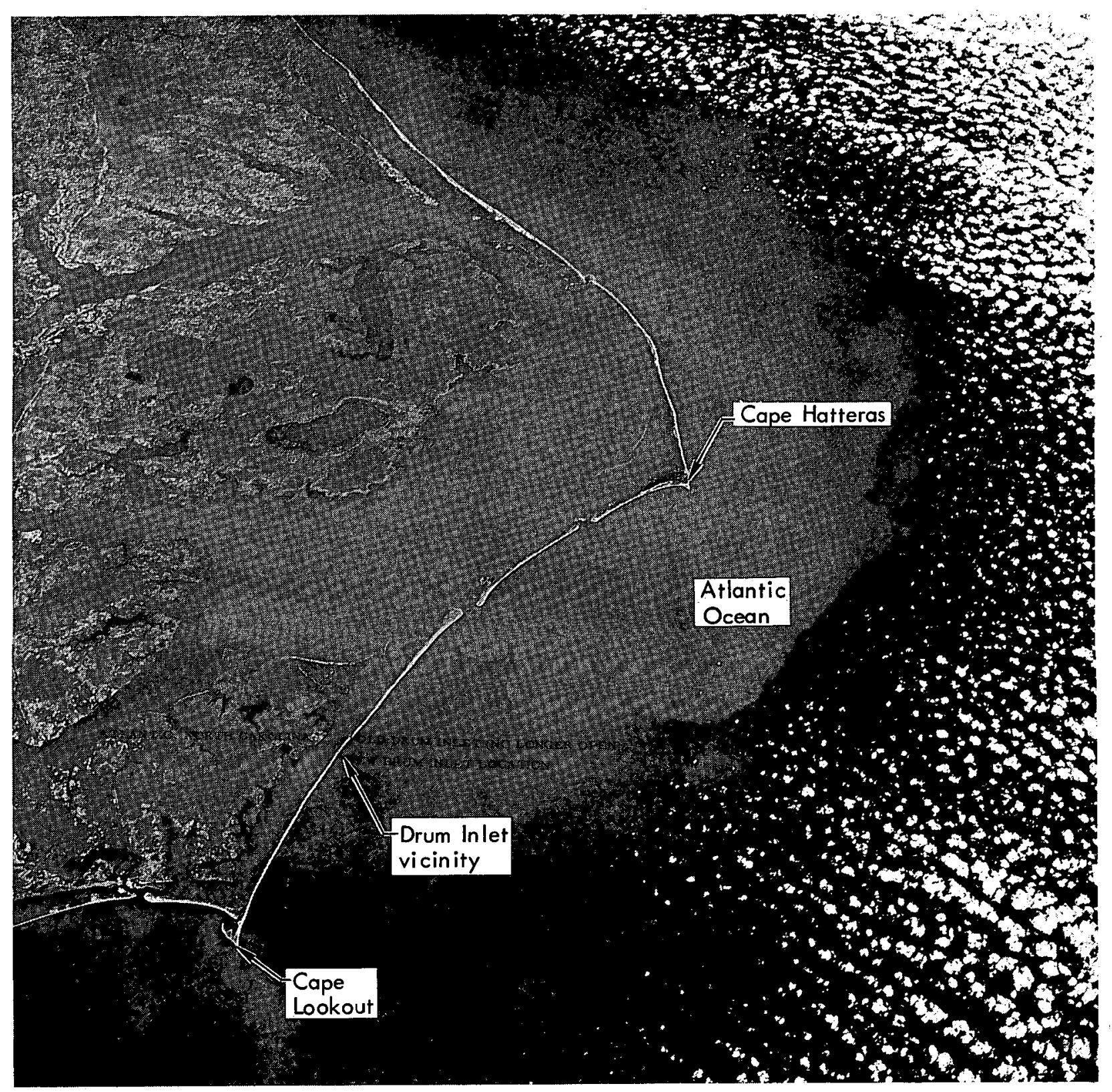

Fig. 1. The North Carolina coast photographed from Apollo 9.

\section{Technical Programs}

Technical programs were implemented by EERL to study the effects of the Drum Inlet event. The main goals of these programs were as follows: (1) to verify proper detonation of all charges, (2) to photographically investigate crater formation mechanisms in saturated sand, (3) to measure sand-surface and watersurface peak spall velocities and velocity profiles, (4) to observe growth and stabilized dimensions of the dust cloud, (5) to obtain approximate ejecta velocities and ranges, and (6) to evaluate initial crater dimensions and early-time scouring or washout effects (full-scale technical programs in these areas were not possible due to the nature of the construction project). Results of the above investigations are discussed in this report. 


\section{Explosive Excavation in Saturated and Submerged Media: Previous Experience}

During the past four years, the Explosive Excavation Research Laboratory has been engaged in the development and application of the technology of civil engineering excavation with large conventional explosive charges. Underwater excavation is often one of the most expensive activities involved in civil works construction projects; thus, this area offers many opportunities for application of explosive techniques to reduce costs. The use of arrays or rows of large charges is particularly advantageous because relatively few emplacement holes are needed and a large volume of material can be excavated rapidly with a single detonation. Some of the potential benefits include: (1) decreased cost, (2) speed of construction, (3) decreased environmental damage of a single event (as opposed to extensive conventional excavation activities or multiple small-scale blasting), (4) applicability to time-limited or emergency project situations, and (5) applicability to projects which would be difficult or dangerous to accomplish by conventional methods.

In addition to the possible advantages, explosive excavation in a saturated underwater environment also presents a number of new technical and design problems: The material properties and cratering mechanisms for saturated media may differ from those encountered in most dry-land applications. The presence of an overlying water layer affects shock wave transmission, reflection, and cratering dynamics. Finally, the postshot material properties, fallback dynamics, crater stabilization mechanisms, water washback, and water flow effects may modify the size and shape of the final crater. Some of these factors are not yet fully understood, but they are quite important to the study and design of underwater excavation events.

References 1 through 11 document prior data and experience pertinent to explosive excavation in wet and dry sand, saturated media, and saturated submerged media. The following paragraphs summarize the chief water-layer effects observed for underwater cratering in saturated sand.

During small-scale model tests in submerged saturated sand, ${ }^{9}$ crater dimensions and crater shapes underwent substantial and continuous changes for shallow to moderate water depths, $0<\mathrm{D}_{\mathrm{w}} / \mathrm{D}_{\mathrm{m}}$ $<0.6$ (where $D_{w}=$ water layer depth, and $\mathrm{D}_{\mathrm{m}}=$ depth of charge burial in the cratering medium), The most sensitive region was at shallow water depths, $0<\mathrm{D}_{\mathrm{w}} / \mathrm{D}_{\mathrm{m}}$ <0.2. Within this region, crater depths decreased rapidly with increasing waterlayer depth, while crater radius increased sharply, and crater volume decreased slightly. Crater lip heights also decreased dramatically, and the lips almost disappeared at $\mathrm{D}_{\mathrm{w}} / \mathrm{D}_{\mathrm{m}} \approx 0.1$. These facts strongly indicate that washback is the major factor in controlling the final shape of underwater craters in sand. The washback wave is responsible for triggering slope failure, slumping, and radial flow of material from the heaviest 
initial fallback location (lips) toward the center of the crater. These mechanisms, in turn, account for the broad, shallow craters formed. Washback overtops and largely destroys the crater lips at shallow depths $\left(D_{\mathrm{w}} / \mathrm{D}_{\mathrm{m}}\right.$ values of $\left.0.1-0.2\right)$, and the lips no longer protrude above the water surface for $\mathrm{D}_{\mathrm{w}} / \mathrm{D}_{\mathrm{m}}>0.2$. Thus, crater profiles are most sensitive to the effects of washback and slope failure for shallow overlying water layers. At greater depths, $D_{w} / D_{m} \gtrsim 0.4$, crater radius and depth both decrease slowly with increasing water depths. For $\mathrm{D}_{\mathrm{w}} / \mathrm{D}_{\mathrm{m}} \approx 1$, the crater radius is reduced to about 0.95 times the corresponding value for equivalent craters in sand with no water overburden, crater depth decreases to about 0.35 times the normal value, and crater volume decreases to about 0.32 times the normal value. The craters remain shallow and flattened in shape. The lip height increases slightly at $\mathrm{D}_{\mathrm{w}} / \mathrm{D}_{\mathrm{m}}$ values greater than 0.1 to 0.2 , indicating that washback does not completely remove lips at water depths sig- nificantly greater than the initial overtopping depth.

Still another interesting effect came to light during the modeling experiments. For a given overlying water depth, the "optimum" depth of charge burial in sand required to produce the largest crater radius often differed from the optimum depth required to produce the largest crater depth. This effect has not been previously observed in dry-land cratering experiments and was not apparent in the underwater modeling data where a concrete mix was used as the medium. ${ }^{10}$ It is closely related to the complex mechanisms of washback and slope failure, which decrease crater depth but first increase and then decrease crater radius with increasing water depth. The relationship between burial depth and crater dimensions is evidently a complicated function of water depth and washback velocity, as well as of the density, strength, and postshot particle size of the cratering medium.

\section{Project History}

That portion of the Outer Banks bounded by Cape Hatteras on the north and Cape Lookout on the south is penetrated by four inlets: Hatteras, Ocracoke, Swash, and Drum. Another major inlet, Oregon, is located north of Cape Hatteras, and the Beaufort Inlet is located west of Cape Lookout and southwest of Drum Inlet. Various of these inlets are used by commercial shipping, commercial fishing craft, sport fishing vessels, and recreational craft. Figure 2 is a map of the
North Carolina coastal area; the old Drum Inlet site is located about 20 miles southwest of Ocracoke Inlet and 24 miles northeast of Cape Lookout. The section of the Outer Banks near this site is uninhabited and not accessible except by water. Thus, the channel is important to fishing and navigation in the vicinity. Adjacent coastal communities include Atlantic (about 3 miles west of the old inlet site) and Sealevel. Records show that other inlets of the same name existed 


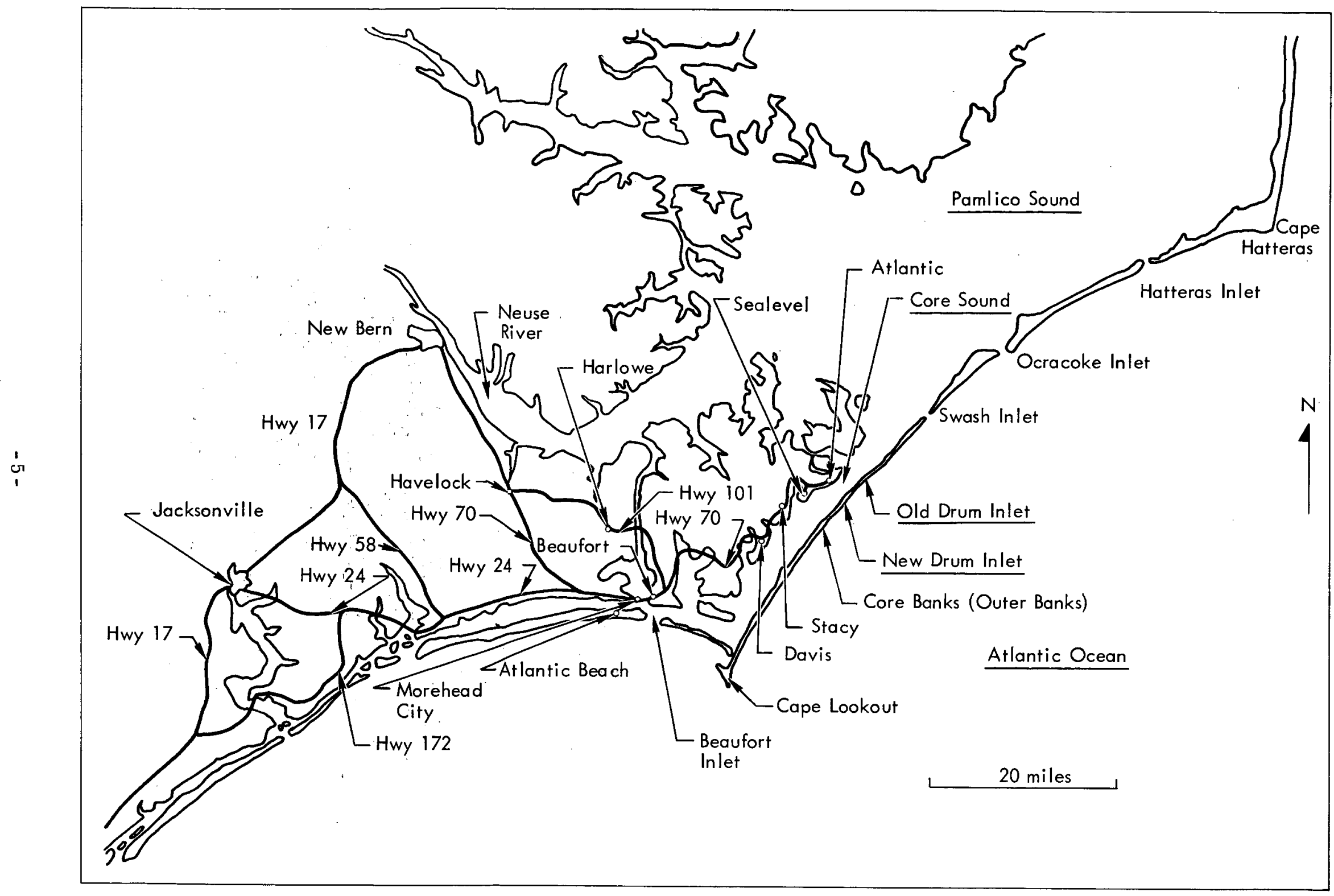

Fig. 2. North Carolina coast in the vicinity of Drum Inlet and the Core Banks. 
near this location in 1799 and 1899. It is believed that these inlets were opened by the action of storm-driven waters and closed by littoral drift processes. ${ }^{12-14}$

The most recent natural Drum Inlet was opened during the hurricane of September 1933, when high waters overtopped a low section of the reef. Hydraulic forces excavated a channel up to $2200 \mathrm{ft}$ wide at high tide and $10 \mathrm{ft}$ deep at the deepest point. The depth subsequently increased to $17 \mathrm{ft}$, and the controlling (shallowest) depth over the ocean bar outside the inlet was about $6.5 \mathrm{ft}$ at mean low water. The inland waterway or Core Sound at the Drum Inlet location has a total width of about 2.5 miles. 15

The tidal range at the old Drum Inlet was about $3.8 \mathrm{ft}$ at the ocean entrance and $2.5 \mathrm{ft}$ on the Core Sound side, with a maximum differential of $1.3 \mathrm{ft}$. No perceptible astronomical tide occurs at Atlantic on the mainland, but winds may lower the water level in the Core Sound by $1 \mathrm{ft}$ or raise it by $7 \mathrm{ft}$ above mean stage during hurricanes. Prevailing winds are from the southwest. Severe northeasters strike with little warning once or twice a year, and hurricanes occur about once every two years on the average. The amount of material carried by the littoral drift is dependent on tidal flow, wave energy, and wave direction. Precise statistics are not available for Drum Inlet, but the total quantity of material moving in the near-shore zone has been estimated at $4-$ to $-5 \times 10^{5} \mathrm{yd}^{3} /$ yr. ${ }^{14,15}$ Drift rates may vary between zero and $5000 \mathrm{yd}^{3} /$ day. Wave energy approaching along directions conducive to littoral transport reaches a maximum during the winter months, and drift rates and shoaling are expected to be most severe at that time. While the old inlet was open, a large quantity of fine littoral material was carried through the channel by flood tides, sustaining extensive shoals which extended 3000 to $4000 \mathrm{ft}$ into the Core Sound. Coarser material tends to be spoiled out of an inlet by ebb currents and returned to the littoral transport zone. 15

In spite of the large amount of littoral transport, Drum Inlet remained in a state of dynamic equilibrium for nearly twenty years. A controlling depth of about $7 \mathrm{ft}$ at the ocean bar was maintained from 1940 until 1953. Drum Inlet subsequently migrated $2400 \mathrm{ft}$ to the southwest. Most of this movement occurred during the period from 1954 to 1960 , and was probably caused by five hurricanes which passed within 50 miles of the inlet. The controlling depth decreased steadily to about $3 \mathrm{ft}$. Little vessel traffic was possible after 1958. Figure 3 is an aerial photograph of the inlet ${ }^{15}$ taken in March 1962. The shallow ocean bar outside the inlet is clearly visible, as are the shoals extending some $4000 \mathrm{ft}$ into the Core Sound. Drum Inlet was temporarily open to small craft navigation during the 1960s, but shoaling processes again intervened. The inlet finally became impassable in December 1970. Then seasonal storms during February 1971 closed the passage completely. 12,13 Figure 4 depicts the inlet location shortly after closure occurred (aerial photograph courtesy of the Wilmington District, Corps of Engineers). The ocean bar near the seaward side of the reef and the shoals within the sound are again apparent. 


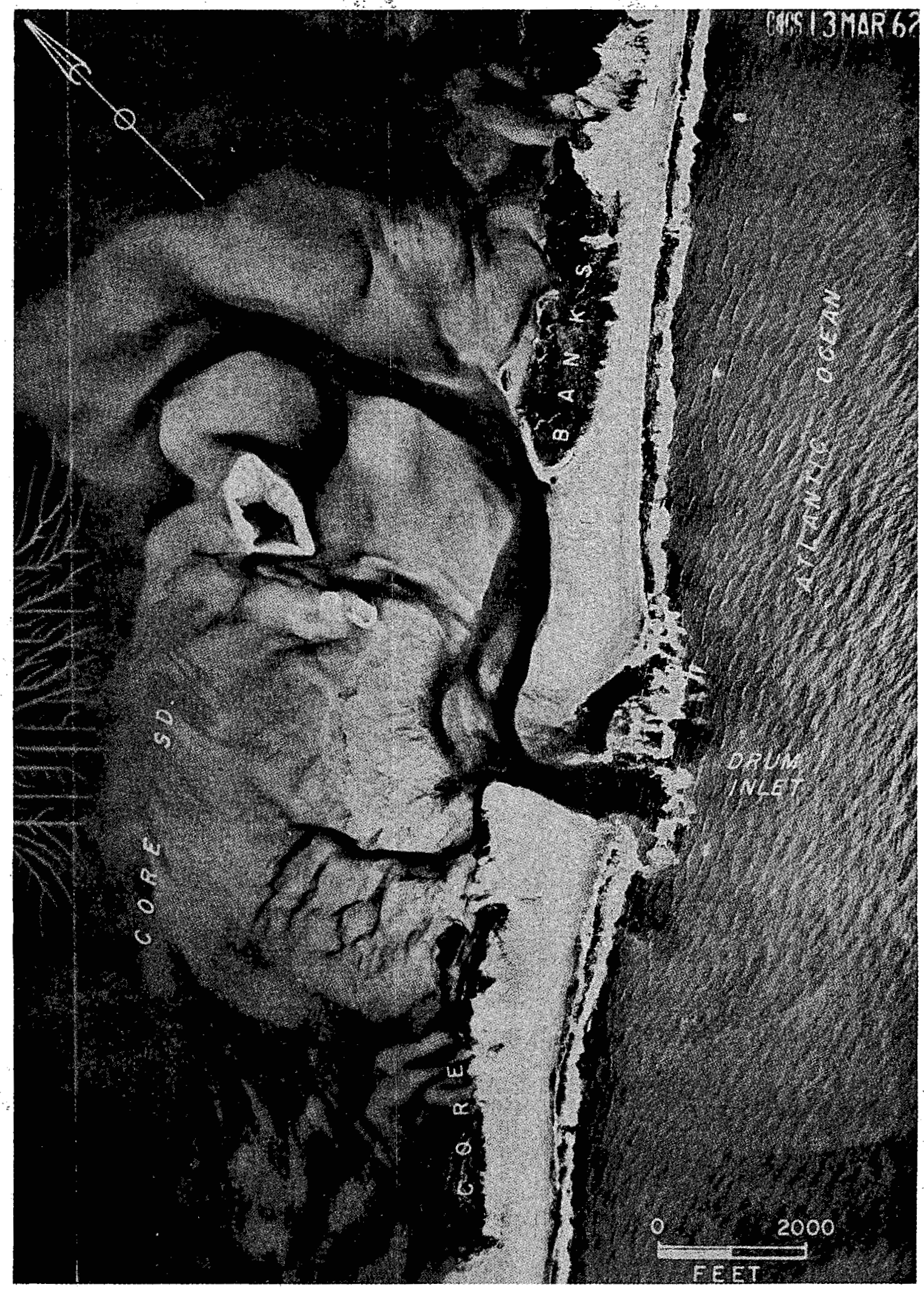

Fig. 3. Aerial photograph showing the old Drum Inlet. 


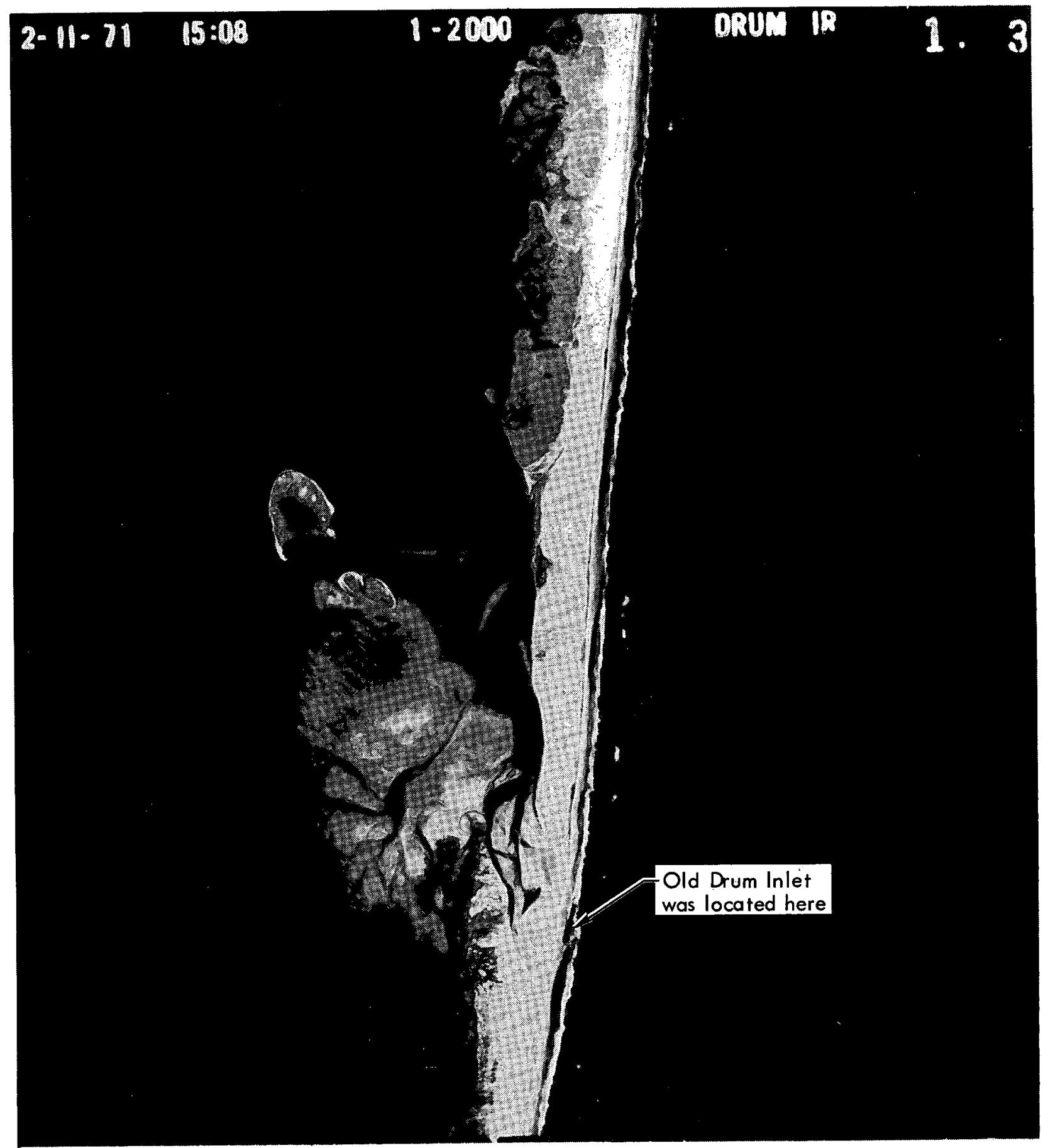

Fig. 4. Aerial photograph showing the old Drum Inlet vicinity of the Outer Banks after closure of the inlet (taken 11 Feb. 1971). 
The tributary area around Drum Inlet extends for a radius of 45 miles, and had a population of about 35,000 in 1960 . The region is largely rural; its economy is dependent on farming, commercial fisheries, and tourism for sport fishing. Navigation interests in the Carteret County vicinity were understandably perturbed about the loss of the inlet. Commercially valuable species of fish and mollusks are taken in an area of Raleigh Bay extending approximately 10 miles on either side of Drum Inlet and 25 miles offshore into the Atlantic Ocean. This region is an active fishery during the period of mid-September to mid-May, when some species of fish migrate along the coast. Calico scallop beds have also been intermittently productive in recent years. Recently, sport fishing has emerged as an economically significant activity. Access to the fishing grounds via Ocracoke Inlet or Beaufort Inlet entails a much longer round trip. Thus, activities are restricted and operating expenses are increased due to the greater transit distance. Small craft may also be unable to participate except in ideal weather because no harbor of refuge is immediately available. Planning studies conducted prior to the Drum Inlet project showed that reopening and stabilizing the inlet would produce the following benefits $^{15}$ : (1) decreased travel time to Raleigh Bay for fishermen who base their vessels at harbors along the Core Sound;

(2) increased catches of seafood due to quick, easy access to the fishing grounds;

(3) decreased vessel operating costs;

(4) decreased spoilage of sea scallops and other catches during the shorter return trip; and (5) quick access to a harbor of refuge for recreational and sport fishing craft in the event of sudden squalls or storms. Cost-benefit analyses demonstrated that the project would exert a favorable effect on the overall economic development of the area. A small-scale channel improvement and maintenance project was considered justifiable on the basis of economic factors.

In addition to the commercial advantages, the reopening of Drum Inlet also offered environmental benefits. Interruption of the interchange of ocean and sound waters decreased the salinity balance within the Sound and threatened the native shellfish population. The salinity balance could be restored and the favorable environmental conditions prevalent since 1933 could be maintained only by constructing a new inlet. Thus, the Corps of Engineers found itself in the position of being pressed by environmentalists to carry out a project. ${ }^{12}$

After obtaining initial approval for the project, it was necessary to select a suitable site and construction method. The basic design concept involved dredging a navigation chạnnel in the Core Sound waterway, breaching the Outer Banks, and, hopefully, restoring the state of dynamic equilibrium of the inlet which prevailed prior to 1954 . Drum Inlet's location within an area proposed for addition to the Cape Lookout National Seashore prompted coordination with the National Park Service, U.S. Department of the Interior. Accordingly, the Wilmington District received the recommendations of Dr. Paul Godfrey, Professor of Botany at the University of Massachusetts and Research Biologist for the National Park Service. Dr. Godfrey 
suggested that the new Drum Inlet be opened about 2 miles southwest of the old location. Subsequently, a thorough study was conducted to determine the most favorable location for a new channel. Various sites were evaluated on the basis of costs, design considerations, and environmental impact. A location in the proximity of the original inlet was initially considered, but the alignment suggested by Dr. Paul Godfrey, 2.1 miles southwest of the old location, was finally adopted. The reef is only $1000 \mathrm{ft}$ wide at this point, which makes it a probable site for a natural storm breach. ${ }^{12}$ Figure 5 is an aerial photograph mosaic which shows the approximate locations of the old inlet and the new channel alignment (courtesy of the Wilmington District, Corps of Engineers). The site selected avoids the large quantity of littoral drift material deposited in the sound near the closed inlet. In addition, salt marsh grass (Spartina alterniflora) is naturally seeding at the old location; the site provides a nursery habitat for marine organisms, and presents a valuable opportunity to study reef and island formation at closed inlets. It was not disturbed during construction operations.

Plans called for dredging a channel 1.8 miles long by $7 \mathrm{ft}$ deep by $150 \mathrm{ft}$ wide at design depth in the Core Sound, extending from the major north-south waterway connecting Pamlico Sound and Beaufort Harbor to the Outer Banks. A final cut $9 \mathrm{ft}$ deep by $150 \mathrm{ft}$ wide would then be opened through the Outer Banks. The 9 -ft depth at the inlet was necessary in order to allow for wave action affecting navigation over the ocean bar. The required dredging operation was straight- forward. The only unconventional aspect of the project was the removal of the final material plug between the Core Sound and the ocean. Inlet breaching with a hydraulic dredge presents unacceptable hazards to the dredging plant. ${ }^{12}$ It was judged that dredging should not be conducted closer than $75 \mathrm{ft}$ to the mean. high water line on the ocean side of the Banks. An alternative excavation method was required for the last section of the cut, and excavation by explosive techniques was believed to be the most feasible plan to accomplish this part of the project.

The use of explosives for inlet excavation was first suggested during 1969 , when a channel improvement program at Oregon Inlet was being designed. The Oregon Inlet project was far more extensive than Drum Inlet, but conditions did not favor explosive applications. A fixedspan concrete piling highway bridge passed about $5000 \mathrm{ft}$ from certain parts of the site. Therefore, very large scale detonations were excluded. Drum Inlet presented a far more favorable opportunity. First of all, the entire design was somewhat unusual and untested. Experience with the maintenance of dredged channels at relatively shallow coastal inlets was lacking; initial analyses of the project were based on the assumption that the channel would remain open at design depth throughout the fishing season, after a single annual dredging during the September-October period. Earlier data were contradictory. Some dredged channels at unprotected inlets required supplementary dredging up to two or three times a year. Channel life may also depend on storm frequency. Thus, 


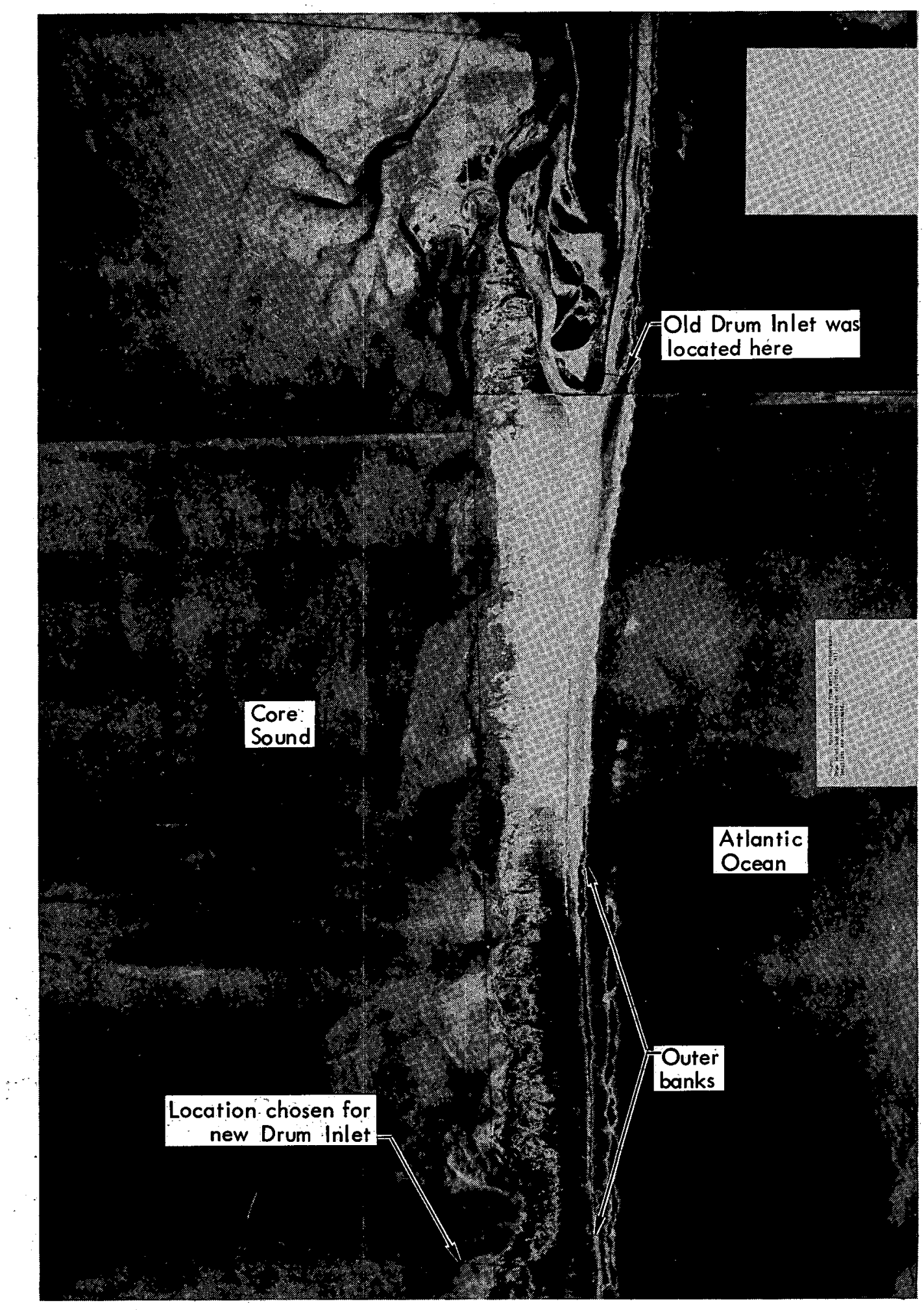

Fig. 5. Mosaic compiled from aerial photographs of Drum Inlet and excavation cut vicinity. All locations are approximate. 
the project was avowedly experimental in nature, and provided an appropriate chance for testing a new construction method. In addition, there were no structures or other safety hazards within thousands of feet of the site. This fact eliminated concern about possible damage effects of a detonation in a new medium. From the standpoint of environmental effects, the benefits of the project were considered greater than any slight harm which might result from the explosive excavation event. Furthermore, test probings at the site demonstrated that the local material consisted entirely of fineto-medium-grain sand and broken shell, with some regions of hard-packed sand beginning at 9 to $11 \mathrm{ft}$ below mean low water (MLW); thus, inexpensive water jetting techniques could be used to emplace charges. Finally, the evolving project design virtually required instantaneous removal of the final sand plug by a large-scale detonation. Project situation, safety, environmental factors, costs, and design requirements all indicated that explosive excavation was the best available method.

The Wilmington District of the Corps of Engineers was responsible for overall project design, but since the District personnel did not have previous experience with large-charge explosive excavation, design assistance was requested from EERL. Further support was elicited from the Corps of Engineers Water- ways Experiment Station (EERL's parent organization), the Coastal Engineering Research Center (CERC), the National Park Service, and the North Carolina State Department of Fisheries. Review and comment were also sought from concerned state and federal agencies for incorporation in the Environmental Impact Statement. Information related to tidal flow characteristics, inlet stability, and bio-environmental effects was provided by $\mathrm{CERC}$ and the Waterways Experiment Station.

After reviewing project plans, scientists recommended that dredge spoil material be emplaced on the Core Sound side of the Outer Banks, just north of the inlet mouth. This procedure would serve to widen the reef and create an intertidal zone suitable for artificial seeding of salt marsh grass. Thus, the reef and inlet could be stabilized and a useful biological habitat could be established. The seeding program was implemented under the direction of Dr. W. W. Woodhouse of North Carolina State University; salt marsh grass was planted over parts of the 30-acre dredge spoil area during the spring of $1972{ }^{12}$ Preliminary results through December 1972 indicate that the experiment was highly successful. Further studies are now in progress. This investigation could produce valuable data on the stabilization and use of spoil areas, with broad potential application to a variety of Corps of Engineers navigation projects.

\section{Project Design}

The major task assigned to EERL during the Drum Inlet Project was to provide design specifications and monitoring for the explosive excavation contract. The 
Wilmington District requested that the explosive excavation be designed to produce a channel $80 \mathrm{ft}$ in width at a controlling depth of $6 \mathrm{ft}$ below mean low water (Atlantic Datum). In order to achieve the desired depth throughout the channel, a section of sand $470 \mathrm{ft}$ in length had to be removed (distance from the end of the dredge cut to a water depth of $6 \mathrm{ft}$ on the ocean side of the reef). Beach erosion and charge emplacement difficulties subsequently reduced the length of the planned explosive cut to $385 \mathrm{ft}$ (see below). The channel design width and depth were selected to provide ample working room for the Corps of Engineers sidecast dredge Merritt, which could then safely enter the channel and excavate to any desired project dimensions if further excavation were needed.

Design width of the Drum Inlet channel was large relative to the depth. Hence, it was necessary to utilize two separate rows of explosive charges. The weight of explosive per charge required for a single-lift cratering cut depends primarily on the depth of the cut, $D_{a}$. The greatest excavation depth at the highest part of the reef was $13 \mathrm{ft}$ ( $6 \mathrm{ft}$ below MLW, plus $7 \mathrm{ft}$ of sand above water level). Approximately 1 ton of explosive, emplaced at optimum burial depth, is needed to produce a crater depth of $13 \mathrm{ft}$. Therefore, 1-ton explosive charges were selected. Smaller charges could have been used in the shallow portions of the cut; however, for reasons of convenience in construction and emplacement, it was decided to use 1-ton charges throughout the cut. The emplacement configuration was then modified so as to achieve the desired dimensions at all locations.
The predicted crater sizes and emplacement parameters used in the Drum Inlet design were based on a combination of dry-land data for single-charge and row-charge craters in alluvium (6oil), ${ }^{16-18}$ and small-scale modeling tests for craters in submerged media and sand. $6,7,9,19-22$ As an example of the design procedure, consider those charges emplaced under the deepest part of the sand layer, near the center and Core Sound end of the channel. A crater depth of $13 \mathrm{ft}$ was required. Since previous experience with large charges in saturated sand was lacking, a slightly conservative design depth of $15 \mathrm{ft}$ was adopted. Singlecharge apparent crater dimensions ${ }^{*}$ for alluvial material were chosen as the fundamental design input. These dimensions are normally expressed as "scaled" values; i.e., in units of $\mathrm{ft} / \mathrm{ton}^{1 / 3}$. Since only 1-ton charges were included in the design, scaled dimensions in $\mathrm{ft} /$ ton $^{1 / 3}$ are equivalent to actual dimensions. Previous experiments in alluvium used TNT explosives. Therefore, an increase of $10 \%$ in the empirical single-crater dimensions was made to allow for the better cratering efficiency of aluminized slurry explosive relative to TNT. The following single-charge dimensions, applicable to 1 -ton charges, were adopted:

$$
\begin{gathered}
\mathrm{R}_{\mathrm{a}}=28 \mathrm{ft} \begin{array}{c}
\text { (apparent crater radius at } \\
\text { the level of the preshot } \\
\text { ground surface), }
\end{array} \\
\mathrm{D}_{\mathrm{a}}=13 \mathrm{ft} \text { (apparent crater depth), }
\end{gathered}
$$

\footnotetext{
*Apparent crater dimensions are measured from the preshot ground surface to the final excavated postshot surface formed by the ejecta, fallback, and washback material deposited in the crater.
} 


\section{$\mathrm{DOB}_{\text {opt }}=16 \mathrm{ft}(\mathrm{DOB}=$ depth of burial to
the center of the charge, measured from preshot ground surface; DOB opt = optimum depth of burial for maximizing crater dimensions).}

The "optimum" DOB of $16 \mathrm{ft}$ is slightly shallower than true optimum depth in dry alluvium.

The spacing of charges in a row is dependent on the required depth of the cut and on the single-charge crater dimensions. In this case, a design depth of $15 \mathrm{ft}$ is desired, but the single-charge depth is only $13 \mathrm{ft}$. In order to overcome this difficulty, it is necessary to make use of the "enhancement" phenomenon, or increase in crater dimensions which occurs when charges in a row are spaced progressively closer together. ${ }^{16,17}$ The amount of linear size enhancement needed is the ratio of the design depth to the expected single-charge depth:

$$
\text { enhancement }=\mathrm{e}=\frac{15}{13} \approx 1.15 \text {. }
$$

In other words, the single-charge crater dimensions must be enhanced by a factor of 1.15 to achieve the design dimensions. Empirical laws governing enhancement have been derived on the basis of rowcharge experiments in dry-land media. The relationship which determines the charge spacing that is needed to achieve a given enhancement is

$$
\frac{\mathrm{S}}{\mathrm{R}_{\mathrm{a}, \mathrm{opt}}}=\frac{1.4}{\mathrm{e}^{2}}
$$

where

$$
S=\text { intercharge spacing in a row, }
$$

$$
\begin{aligned}
& \mathrm{R}_{\mathrm{a}, \mathrm{opt}}=\begin{array}{r}
\text { radius of the optimum single- } \\
\text { charge crater (optimum depth }
\end{array} \\
& \text { of burial), } \\
& \mathrm{e}=\text { enhancement. }
\end{aligned}
$$

For the sample design,

$$
\frac{\mathrm{S}}{\mathrm{R}_{\mathrm{a}, \mathrm{opt}}}=\frac{1.4}{1.15^{2}}=1.06,
$$

and, since the optimum radius is $28 \mathrm{ft}$,

$$
\mathrm{S}=28 \mathrm{ft} \times 1.06=29.6 \mathrm{ft} \approx 30 \mathrm{ft} .
$$

The DOB ${ }_{\text {opt }}$ must likewise be increased by the linear enhancement factor, e, so

$$
\mathrm{DOB}=1.15 \times 16 \mathrm{ft}=18.4 \mathrm{ft} \approx 18 \mathrm{ft} .
$$

Separation of the rows in a double-row array is determined from designs which have proved successful in producing flat and uncusped craters in dry-land media. The separation normally used is 1.4 times the half-width (or enhanced crater radius) of a single row. The enhanced radius for the current design is

$$
\mathrm{e} \times \mathrm{R}_{\mathrm{a}}=1.15 \times 28 \mathrm{ft} \approx 32 \mathrm{ft} \text {. }
$$

Therefore,

Inter-row separation $=1.4 \times 32 \mathrm{ft}$

$$
\approx 44 \mathrm{ft}
$$

The above design parameters were applied in the deepest portion of the cut, but the depth of burial was decreased slightly from the calculated $18 \mathrm{ft}$ in order to increase material ejection velocities. This expedient was adopted because of the unknown cratering properties of saturated sand; it was hoped thereby to avoid any 
deeper-than-optimum burial and consequent excessive fallback or washback of material into the crater. This modification was not expected to significantly affect the crater radius or the spacings, since the crater radius curve is relatively flat (does not change rapidly with depth) near optimum depth of burial.

The required cut depth decreases toward the ocean edge of the reef. Overexcavation was not considered desirable, since it might cause unpredictable destabilization and washback effects. Hence, the depth of burial was decreased to less than optimum, and the intercharge spacing within each row was increased (in order to decrease enhancement effects and crater dimensions). Emplacement parameters were selected so as to reduce crater depths to the desired values at all locations. The design at the ocean end of the cut was based primarily on judgment since large-scale cratering experience for saturated sand overlain by water was not available. The inter-row separation also had to be decreased slightly because shallow charges at wider intercharge spacing produce a smaller crater radius (i.e., the crater half-width for each row is smaller, so the rows have to be placed closer together in order to avoid cusping between rows). Analysis of the predicted crater profile by standard design techniques showed that a channel width of $80 \mathrm{ft}$ should be maintained in spite of the smaller dimensions and closer inter-row separation. The final design at the ocean end of the cut called for charges at a burial depth of 7 to $9 \mathrm{ft}$, with an intercharge separation of $39 \mathrm{ft}$ and an interrow separation of $36 \mathrm{ft}$.
In order to check the Drum Inlet design, a series of small-scale modeling tests was performed. These experiments, conducted at the Site 300 facility of the Lawrence Livermore Laboratory, consisted of three double-row events utilizing 1-1b C-4 charges in saturated sand (density $\approx 1.9-2.1 \mathrm{~g} / \mathrm{cm}^{3}$ ). A shallow water basin was located adjacent to but beyond the ends of the rows. The first two events were uniform double rows of four charges per row, detonated simultaneously. The third event used a uniform double row of three charges per row; the two middle charges were initiated first, and the four charges at the ends of the rows were detonated $3 \mathrm{msec}$ later. No test with inter-row delays was attempted, nor was any effort made to model the shallowly buried submerged charges at the ocean end of the cut. All of the events were designed to simulate (at $1-1 b$ scale) the deeply buried charges near the center of the Drum Inlet rows. The depth of burial was constant for all charges, at approximately $1.4 \mathrm{ft}$ below the sand surface (equivalent to a 1-ton scaled depth of $18 \mathrm{ft} / \operatorname{ton}^{1 / 3}$ ), This depth was chosen as the optimum for 1-1b C-4 modeling events in saturated sand. For comparison, the optimum depth of burial in saturated concrete is $1.1 \mathrm{ft}$, and the optimum depth in saturated sand overlain by a deep water layer $\left(D_{w} / D_{m}>0.3\right)$ is about $1.0 \mathrm{ft}$. The intercharge spacing within each row was $2.5 \mathrm{ft}\left(32 \mathrm{ft} / \operatorname{ton}^{1 / 3}\right)$, and the inter-row separation was $3.5 \mathrm{ft}\left(44 \mathrm{ft} / \operatorname{ton}^{1 / 3}\right)$.

Typical results of modeling tests are shown in Figs. 6 through 8 . Figure 6 presents a preshot view of the test pit prior to one of the simultaneous double rows, and a postshot view of the crater 

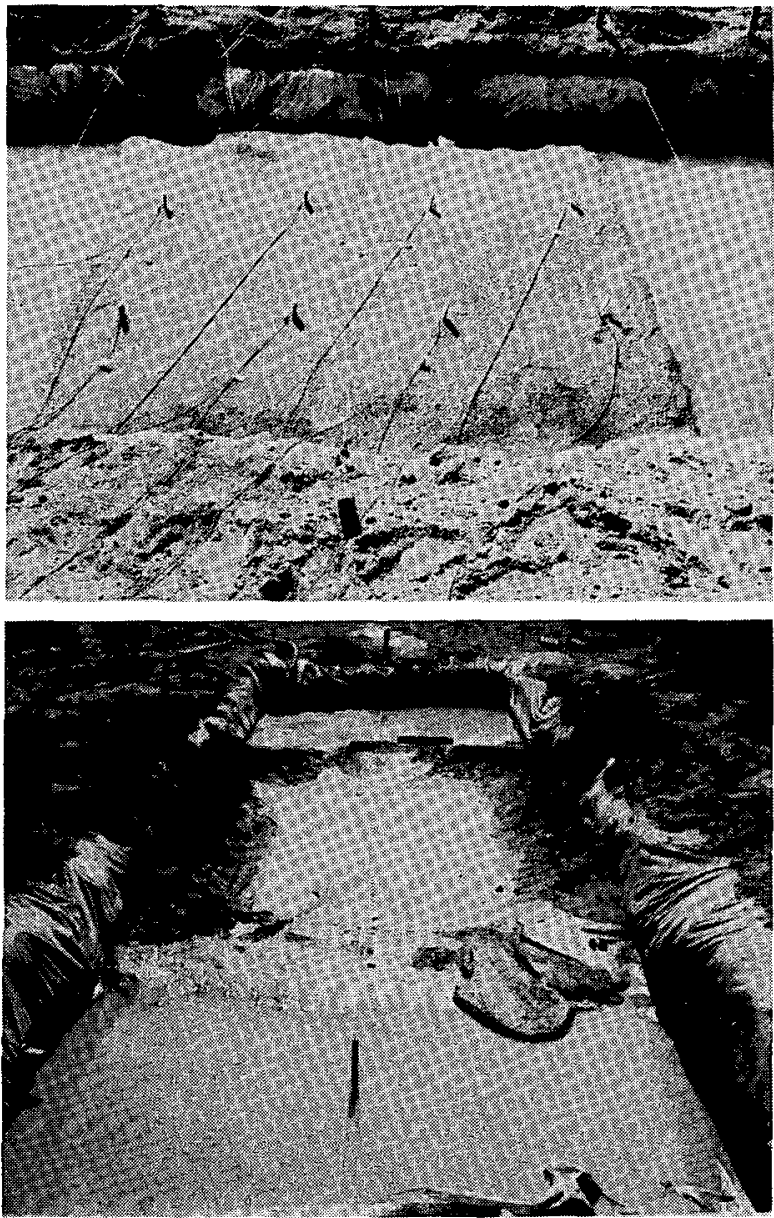

Fig. 6. Preshot and postshot photographs of an eight-charge simultaneous modeling detonation in saturated sand. Upper photo: looking across the width of the rectangular test pit at the array of eight emplaced 1-lb charges. Lower photo: looking along the length of the pit at the results of the detonation.

filled with water. Figure 7 gives preshot and postshot sand-surface profiles for this event, along the central axis between the two rows and along a typical cross section perpendicular to the axis. Figure 8 depicts the corresponding contours for the delayed double row. The $3-\mathrm{msec}$ delay had no significant effect upon the overall crater contours. Note that there was a small center mound between the rows for the delayed detonation, but this mound was less evident or absent in most of the cross-sectional profiles for the two simultaneous double-row experiments. The crater depths near the center of the cut varied from 0.9 to $1.67 \mathrm{ft}$; this is equivalent to a 1 -ton scaled crater depth of 11 to $21 \mathrm{ft} /$ ton $^{1 / 3}$. The required depth at the center of the Drum Inlet cut was 13 to $15 \mathrm{ft}$ ( 6 to $8 \mathrm{ft}$ below water level). Typically, the cross-sectional prism widths and depths (below the sand surface) were equivalent to scaled dimensions of 80 $\times 9.5 \mathrm{ft} /$ ton $^{1 / 3}$ (simultaneous rows) and $80 \times 11 \mathrm{ft} /$ ton $^{1 / 3}$ (delayed event). Although the modeling configuration was not precisely similar to Drum Inlet, these dimensions would produce a Drum Inlet navigation prism (below water level) of $80 \times 2.5$ to $80 \times 4 \mathrm{ft} /$ ton $^{1 / 3}$. Thus, the model tests created navigation prisms somewhat narrower on the average than the required $80-\mathrm{ft}$ width at the $6-\mathrm{ft}$ design depth. The craters did meet design requirements in certain limited sections, due to the irregular cross sections common among small-scale simulation events.

Since modeling results were somewhat inconclusive, the design adopted for Drum Inlet was based largely on dry-land cratering curves for alluvium, dry-land rowcharge enhancement formulae, and judgment. ${ }^{16}$ Some consideration was also given to the limited underwater cratering data. The design initially consisted of 30 charges, in two 15-charge rows. The charges near the Core Sound end of the rows (deepest part of the cut) were designated for emplacement near optimum depth of burial. Toward the ocean end of the cut, burial depth was decreased, intercharge spacing was increased, and 


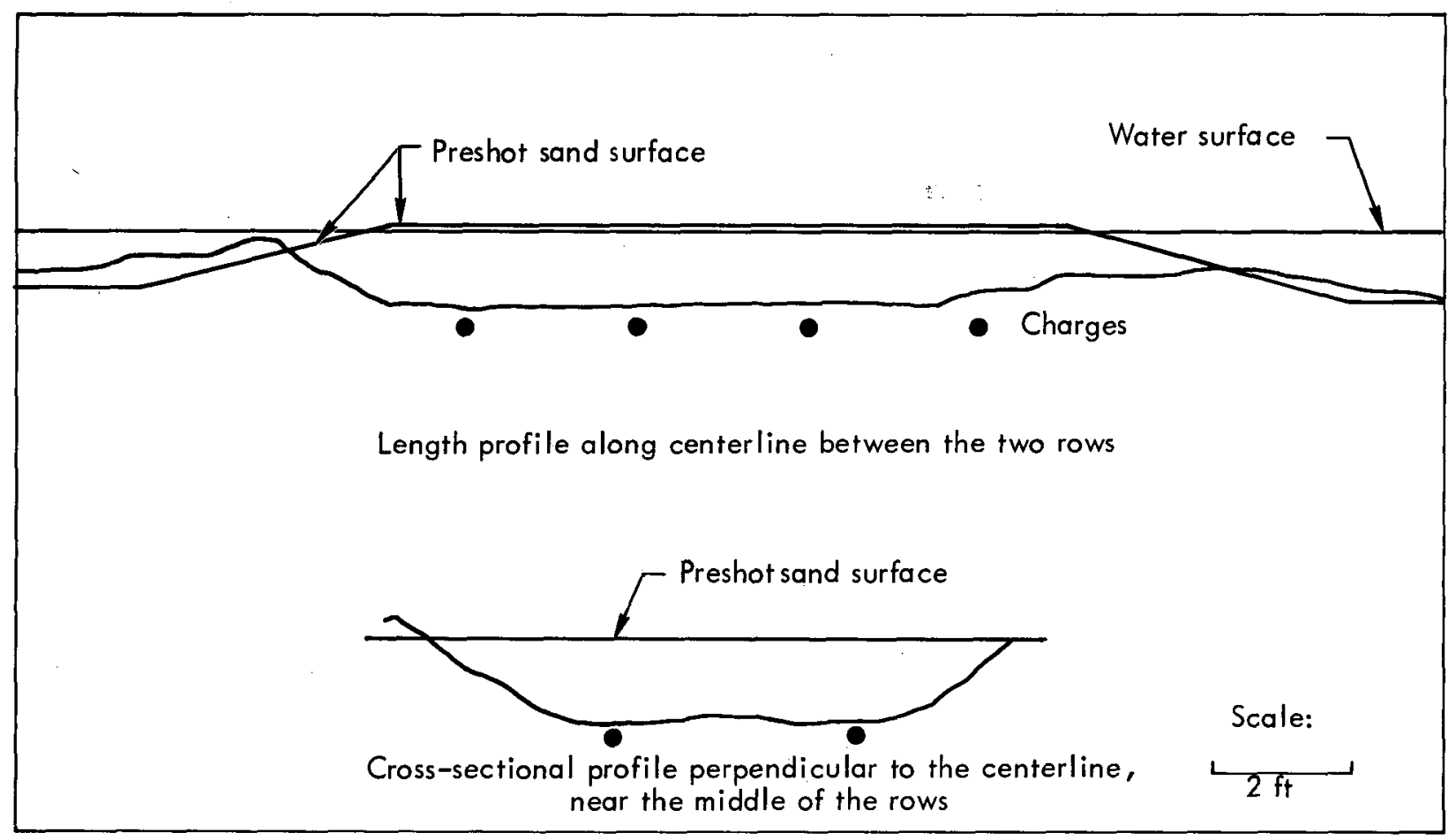

Fig. 7. Contours of the crater excavated by an eight-charge simultaneous double-row modeling detonation in saturated sand (1-lb $\mathrm{C}-4$ charges, depth of burial $=1.4 \mathrm{ft})$.

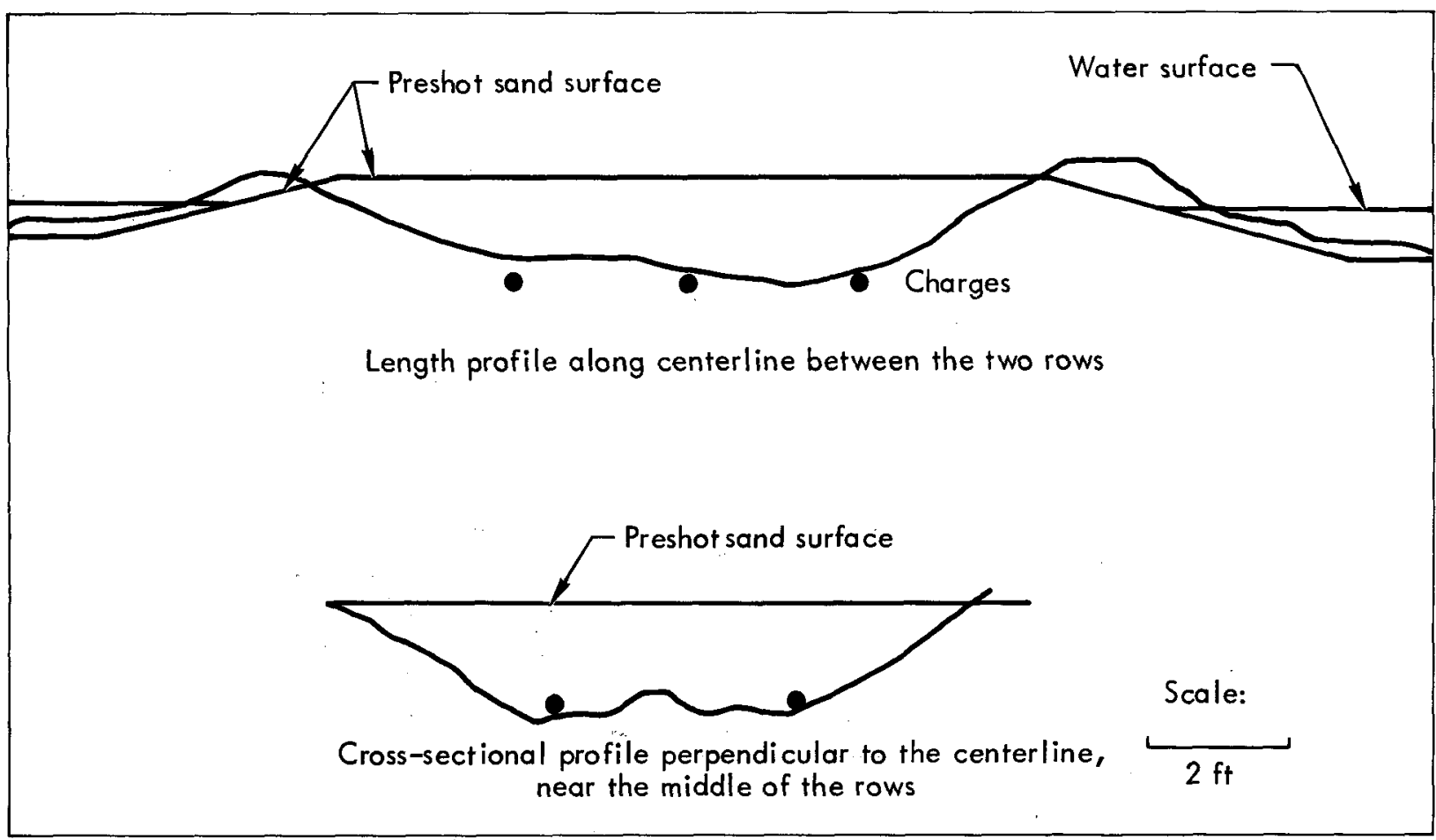

Fig. 8. Contours of the crater excavated by a six-charge delayed double-row modeling detonation in saturated sand $(1-1 b \mathrm{C}-4$ charges, depth of burial $=1.4 \mathrm{ft})$. There was a delay of $3.0 \mathrm{msec}$ between detonation of the two middle charges and the four end charges in the rows. 
the inter-row separation was decreased. Burial depths in sand varied between 17 and $7 \mathrm{ft}$ (to the charge center), and intercharge spacing varied from 30 to $39 \mathrm{ft}$. Prior to charge emplacement, surveys revealed rapid beach erosion on the ocean side of the reef. For this reason, two pairs of charges at the ocean end of the cut were removed from the design. The remaining 26 charges were required to excavate the sand surface contours shown in Fig. 9 (from a preliminary design blueprint, Wilmington District, Corps of Engineers). The upper drawing shows an overhead view of the cut vicinity and charge locations (dredge cut at top, Atlantic Ocean below). The lower drawing presents a cross-section view of the reef material to be excavated (dredge cut at left, Atlantic Ocean at right; vertical scale exaggerated relative to the horizontal scale). Erosion continued on the ocean side of the reef, and two more pairs of charges had to be discarded due to emplacement difficulties in the surf zone, leaving a total of 22 charges in two 11-charge rows. Figure 10 depicts the final emplacement design. The four pairs of charges eliminated are shown in outline sketch at the ocean (right) end of the rows. The lower drawing presents an overhead plan view of the two rows. The upper drawing gives a cross-section profile through the reef (dredge cut at left); the heavy black contour is the final preshot survey of the sand surface (14 December 1971, nine days before the shot). Note that the last two pairs of charges eliminated were at a water depth of about $4 \mathrm{ft}$, less than the 6-ft design depth. Emplacement parameters for the 22 charges are summarized in Table 1
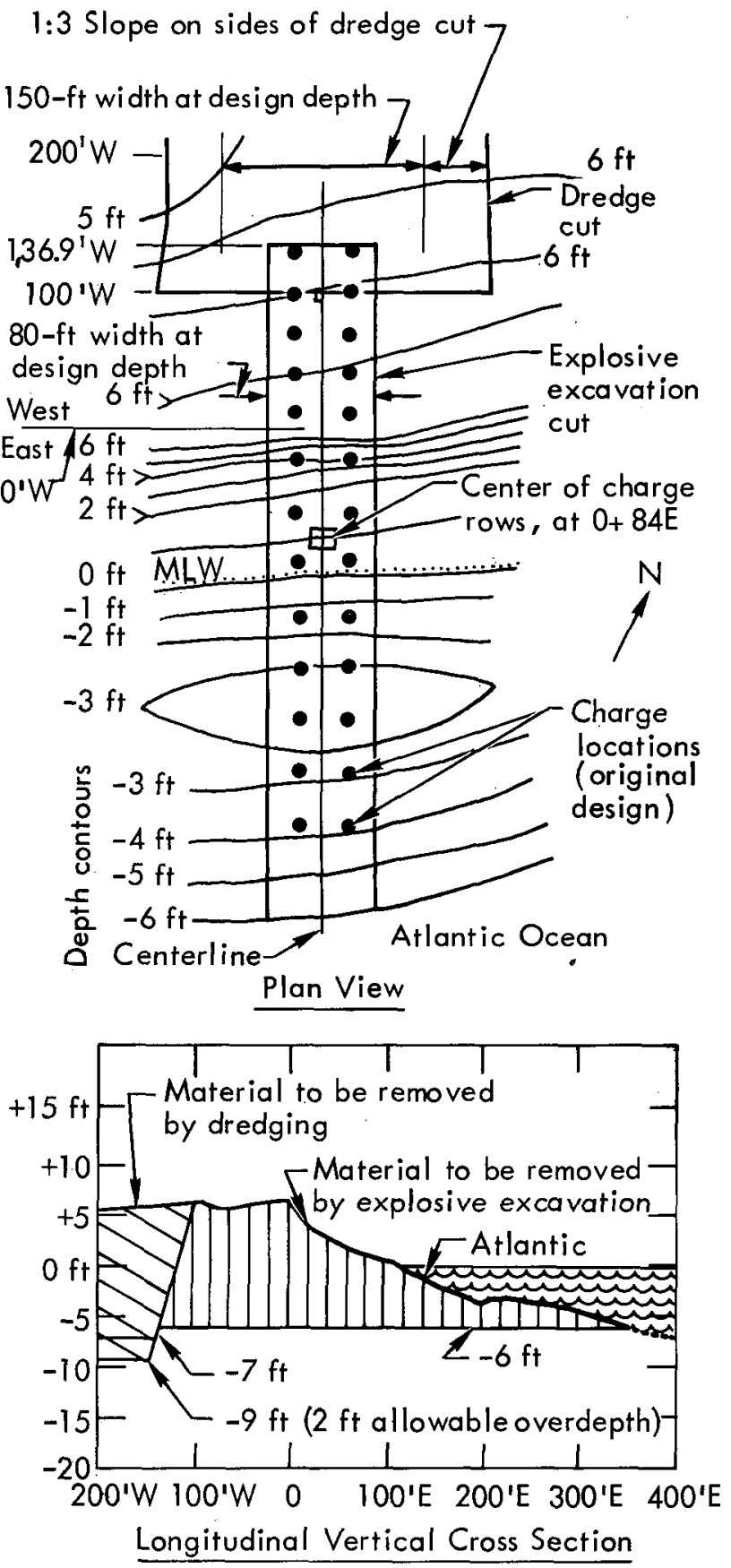

Fig. 9. Preliminary design plans for dredging and excavation of the Drum Inlet channel, September 1971 .

(charges are designated as $1 \mathrm{a}-\mathrm{b}$, at the Core Sound end of the channel, through $11 a-b$, at the ocean end; emplacement parameters for each $a-b$ charge pair in the two rows are identical). 

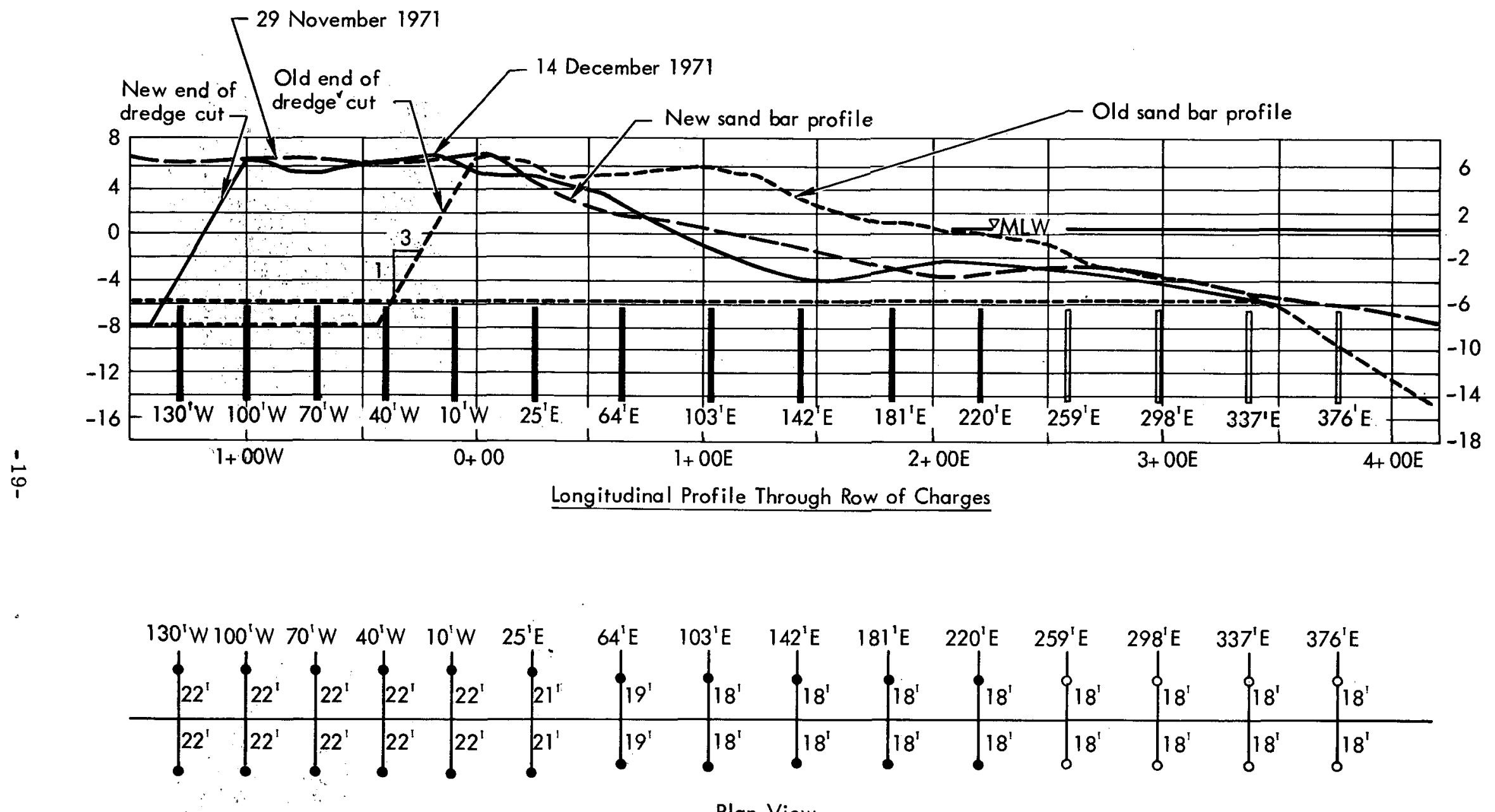

Fig. 10. Side view (cross section) and overhead view of final charge emplacement design for Drum Inlet. Each cylindrical charge contained 1 ton of aluminized ammonium-nitrate slurry blasting agent. 
Table 1. Charge locations, charge depths, row separations, and intercharge spacing for the Drum Inlet double-row detonation (see Fig. 10).

\begin{tabular}{|c|c|c|c|c|}
\hline Charge pair ${ }^{a}$ & $\begin{array}{l}\text { Charge pair } \\
\text { position } \\
\text { (ft from } \\
\text { ocean end) }\end{array}$ & $\begin{array}{c}\text { DOB to center } \\
\text { of charge } \\
(\mathrm{ft})^{\mathrm{b}}\end{array}$ & $\begin{array}{c}\text { Between- } \\
\text { row } \\
\text { separation } \\
\text { (ft) }\end{array}$ & $\begin{array}{l}\text { Within-row } \\
\text { charge } \\
\text { separation, } \\
\text { between } \\
\text { successive } \\
\text { pairs (ft) }\end{array}$ \\
\hline $\begin{array}{l}\text { 11a-b (ocean } \\
\text { end of row) }\end{array}$ & 0 & $8+3^{c}$ & 36 & 39 \\
\hline $10 a-b$ & 39 & $7-1 / 2+3-1 / 2^{c}$ & 36 & 39 \\
\hline $9 a-b$ & 78 & $7+4^{c}$ & 36 & 39 \\
\hline $8 a-b$ & 117 & $9+2^{c}$ & 36 & 39 \\
\hline $7 a-b$ & 156 & $13(+0)$ & 38 & 39 \\
\hline $6 a-b$ & 195 & $15-1 / 2(+0)$ & 42 & 35 \\
\hline $5 a-b$ & 230 & $16-1 / 2(+0)$ & 44 & 30 \\
\hline $4 a-b$ & 260 & $16-1 / 2(+0)$ & 44 & 30 \\
\hline $3 a-b$ & 290 & $15-1 / 2(+0)$ & 44 & 30 \\
\hline $2 a-b$ & 320 & $17(+0)^{\mathrm{d}}$ & 44 & 30 \\
\hline $\begin{array}{l}\text { 1a-b (Core sound } \\
\text { end of row) }\end{array}$ & $350^{\mathrm{e}}$ & $7+4^{c}$ & 44 & 30 \\
\hline
\end{tabular}

${ }^{a}$ Each charge was 1 ton of aluminized ammonium-nitrate slurry, emplaced upright in an 8-ft-high cylindrical canister.

${ }^{\mathrm{b}}$ Assuming charge centers are $11 \mathrm{ft}$ below MLW.

${ }^{c}$ Charges $1 a-b$ and $8 a-b$ through $11 a-b$ were emplaced at locations where the sand surface was below MLW level. The second number represents the water depth (in feet) overlying the sand surface.

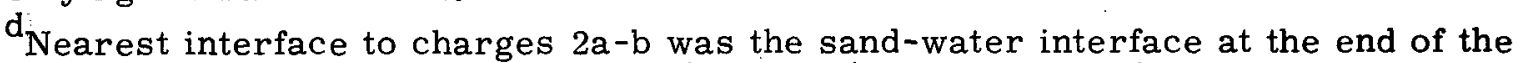
dredge cut, located approximately 6-1/2 to 8-1/2 ft (diagonally) away from the charges.

e Four disposal charges were detonated underwater, in the dredge cut; these charges were located about 110 to $175 \mathrm{ft}$ off the end of the row (beyond chargès 1a-b).

\section{Construction and Execution}

The Drum Inlet Project was executed under two contracts. The first covered dredging of a 1.8-mile channel from the Core Sound waterway to and part way through the Outer Banks. This task was carried out by the contract dredge Clarendon and required 40 days (cost $\$ 168,000$ ). Almost 400,000 cubic yards of material was removed and placed in the designated spoil area, creating a potential marsh site of about 30 acres. ${ }^{12}$ Dredging was completed by 20 November 1971 so that explosive emplacement operations could begin.

The explosive excavation phase of Project Drum Inlet was executed under a separate contract. This contract included construction of the project office, explosive storage, assembly and handling facilities, surface markers, camera 
bunker, firing bunker, and all required operational support. The major portion of the contract consisted of emplacing and firing thirty 1 -ton ammonium-nitrate slurry charges." The contract was let and administered by the U.S. Army Engineer District, Wilmington, North Carolina, with the Explosive Excavation Research Laboratory providing design and technical advice on the specifications, planning, and execution. This contract was awarded to the JERAC Corporation, San Diego, California (cost $\$ 47,050$ ).

\section{Blasting Agent}

The blasting agent specified for use on Project Drum Inlet was an aluminized ammonium-nitrate slurry. The selection of the slurry blasting agent for the project was based on the following criteria:

1. Minimum emplacement costs and safe handling characteristics (pumpable slurry explosive).

2. Minimum explosive costs consistent with prerequisite detonation properties.

3. Compatibility with wet environment.

4. Density greater than seawater.

5. High excavation capability per unit volume of explosive.

The explosive provided under a competitive bid subcontract was Gulf Slurran 615 , which had the following characteristics:

1. Density: $1.30 \mathrm{~g} / \mathrm{cm}^{3}\left( \pm 0.03 \mathrm{~g} / \mathrm{cm}^{3}\right)$.

2. Underwater gas bubble energy: 650 gram-calories/gram:

3. Detonation velocity: $14,100 \mathrm{ft} / \mathrm{sec}$.

\footnotetext{
"Of this number, 26 charges were included in the final design; 22 of these charges were successfully emplaced in two 11-charge rows, each $350 \mathrm{ft}$ in length (see previous section).
}

4. Capable of detonation after 30 days' immersion in salt water.

5. Nontoxic and nonirritating.

6. Ratio of gram-atoms of available oxygen to gram-atoms of aluminum, $1.0553: 1$.

\section{Primer System}

The explosives were primed with Du Pont HDP\# 1 high-strength nonnitroglycerine boosters capable of initiation by 50 -grain primacord. The $1-1 b$ boosters were threaded on the detonating cord to form a $6-\mathrm{ft}$ primer column. The column was then centered in the explosive charge canister. The detonating cord was Scuf-Flex primacord, 60 grains per foot, with a tensile strength of $300 \mathrm{lb}$ and a diameter of $0.230 \mathrm{in}$. The priming system used in each charge is shown in Fig. 11.

\section{Explosive Canisters and \\ Emplacement Procedures}

The explosive containers used in this project were specifically designed so that the charges could be emplaced in sand by means of a crane and high-pressure water jetting rig. Canisters for the 1-ton charges were constructed of an inner Burke tube $(0.375$-in. concrete column form) and an outer sheet-metal shell. Canister design features are shown in Figs. 11 and 12. End caps were of 2-in. plywood, and were connected by a metal support plate and an 8.5-ft-long 5/8-in. rod centered in the charge and threaded to provide for a hold-down bolt over the upper plywood cap. The rod terminated at the upper end with a lifting eye. The charges were vertically supported during lifting and positioning by a keeper from 


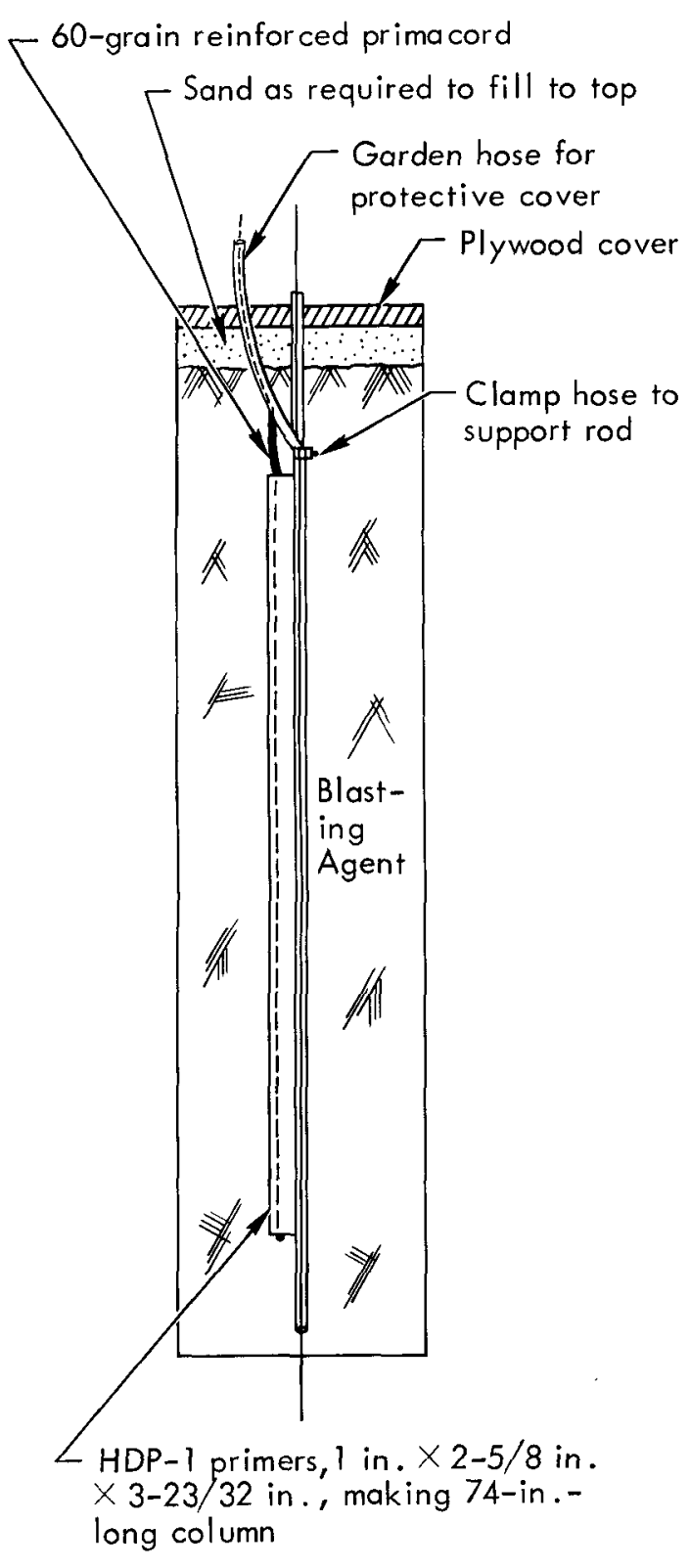

Fig. 11. Canister design and priming assembly.

the lifting eye to a pelican hook on the jetting pipe frame. When a charge was properly positioned and started into the sand, the restraining ring on the pelican hook was unlatched and the charge was jetted down. Figure 13a demonstrates the arrangements for support and emplacement of a canister. Figure $13 \mathrm{~b}$ shows the loaded canisters just prior to emplacement. Each canister was loaded as needed so that there would be a minimum number of primed charges above ground at any time. The procedure applied during loading was as follows: Each empty canister was placed vertically by a 4 -ft loading platform. The necessary blasting agent, detonating cord, and primers were brought from the storage area to the loading platform. The detonating cord was then threaded through the $6-\mathrm{ft}$ primer column and the column was suspended in the canister. Next, the blasting agent was hand-placed in the canister, insuring that the primers remained centered. The 5/8-in. support rod was encased in plastic to cushion it during loading of the primers and blasting agent. For protection against erosion and wave action, the detonating cord was, in turn, threaded through plastic hose. The canister volume was slightly greater than required for 1 ton of explosive. Therefore, upon completion of loading, the canister was topped off with sand and sealed.

During emplacement, a 4-ft-offset batter line was used as a horizontal and vertical control along both charge rows. The line was set at $+8-\mathrm{ft}$ elevation. Each of the charges was brought from the loading area and placed directly over its emplacement site with a ton-and-a-half payloader (Fig. 13a). Once the charge was properly located, the jetting assembly was lowered over the canister. The jetting assembly is shown in Fig. 13c, which depicts a canister being jetted into place. The jetting assembly consisted of three steel I-sections welded to circular collars which would fit around and support the canister. A 3-in. schedule-80 pipe was welded to each of the I-sections 

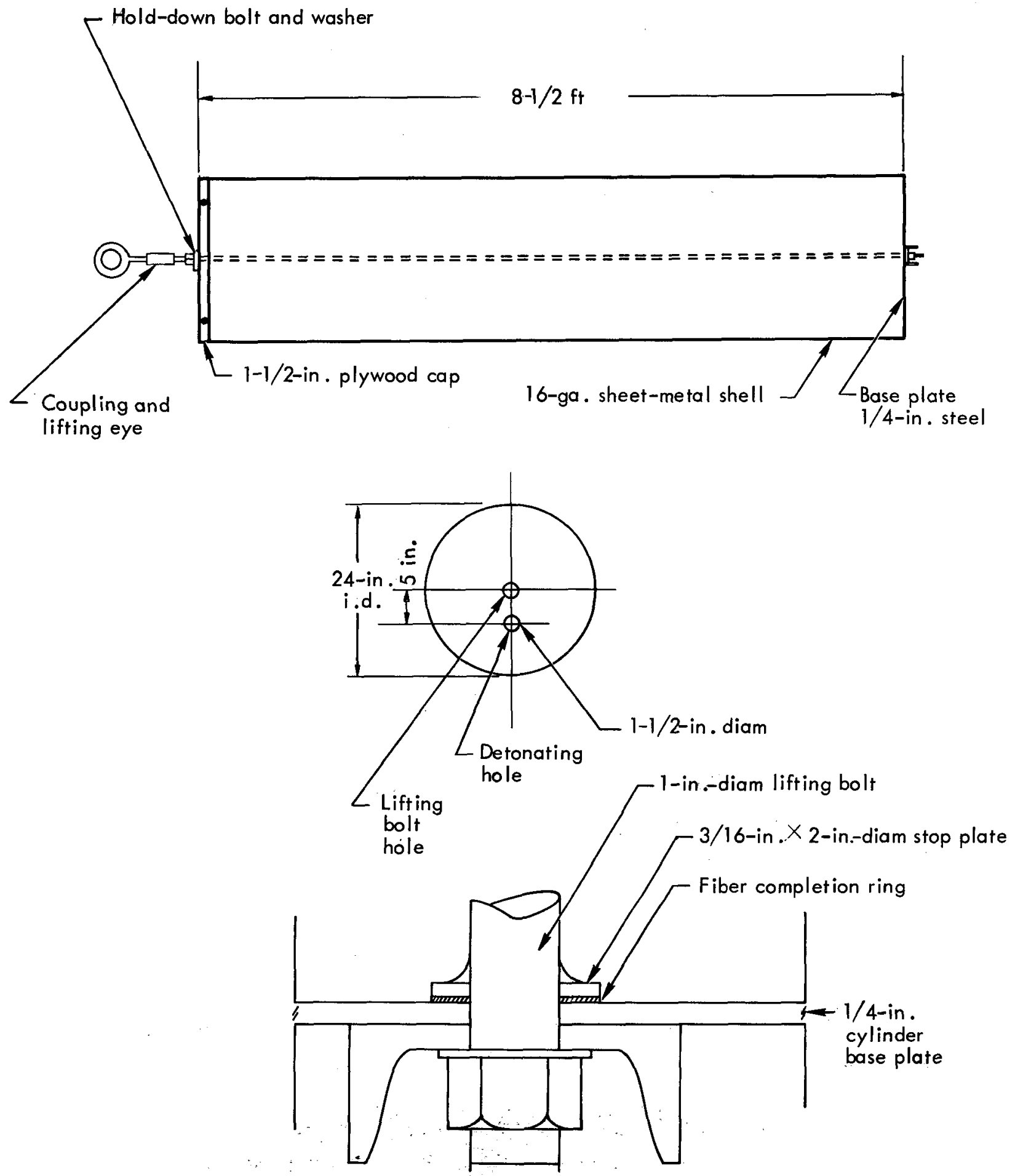

Fig. 12. Canister end-seal details.

and terminated at the lower end in a jetting ring with outlet nozzles. The upper end terminated in a manifold which was connected by a 3 -in. hose to the jetting pump. The jetting pump was rated at $700 \mathrm{gpm}$ at $200 \mathrm{psi}$. The whole assembly was supported by a 5 -ton crane capable of raising and lowering it during jetting 


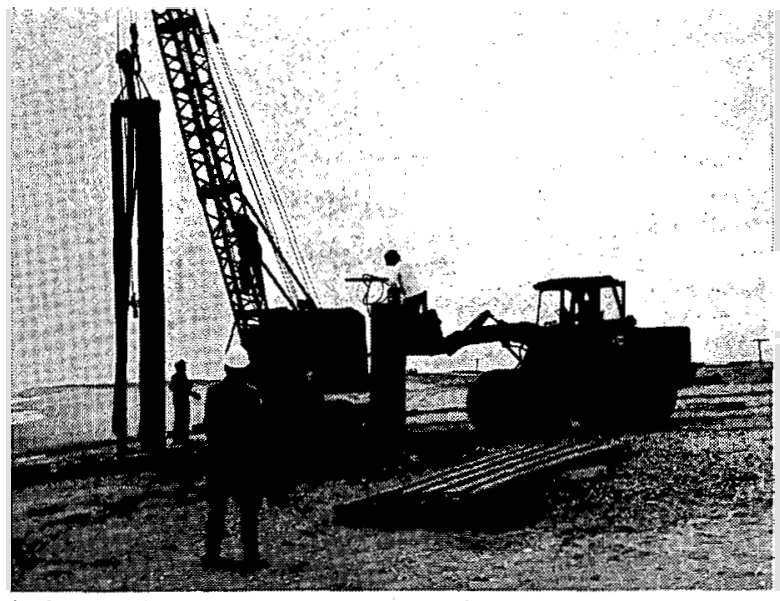

(a) Payloader at right sets charge can ister in place on surface. Jet frame (left) hangs from crane

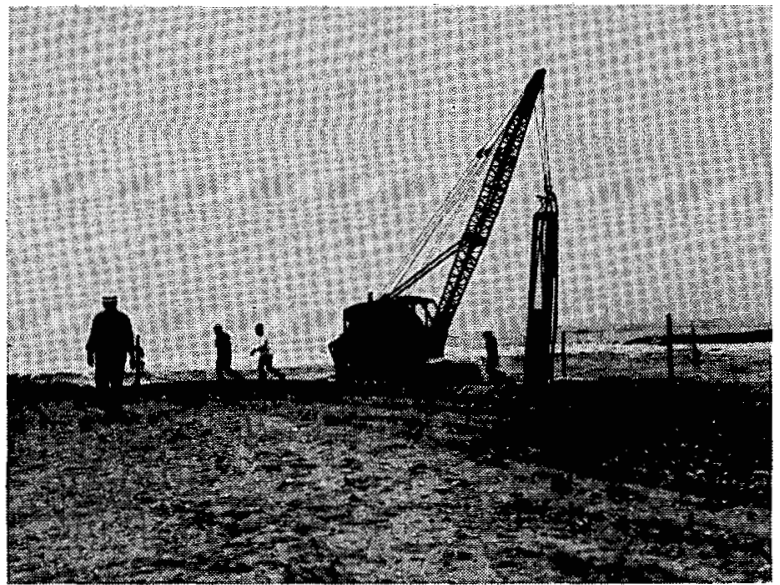

(c) Explosive canister being jetted into place

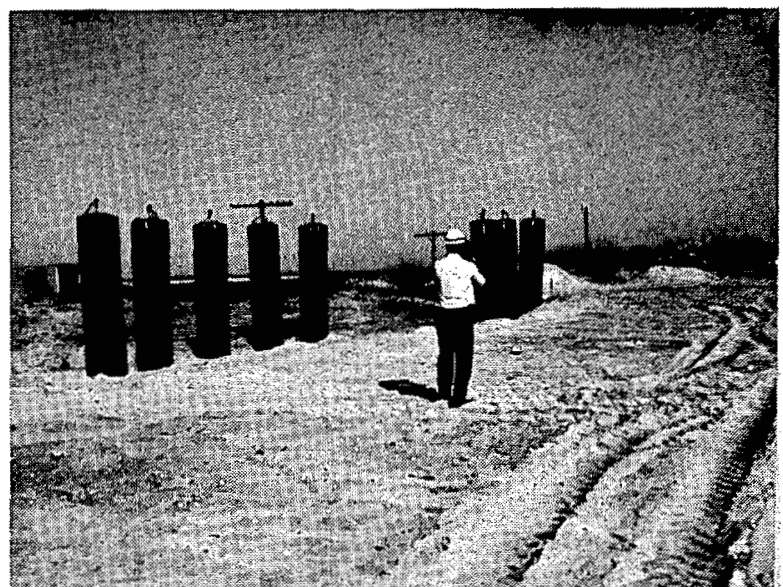

(b) Loaded explosive canisters prior to emplacement

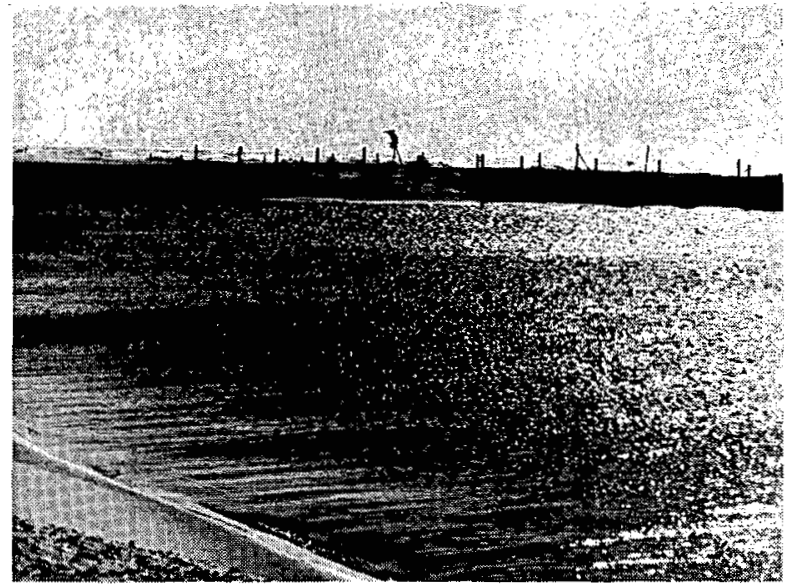

(d) Detonation site after emplacement of the canisters

Fig. 13. Charge emplacement procedures.

operations. Elevation markings were painted along each of the I-sections and a surveyor's transit was used with these markings to accurately position the charge beneath the surface. The procedure followed during jetting was: (1) position and lock the jet assembly over the canister, (2) lift assembly and start the jet pump to insure that the jets are unplugged, (3) lower assembly at a jetting rate of approximately $2 \mathrm{ft} / \mathrm{min}$ until the required depth is reached, (4) unlock assembly and turn off jet pump for approximately $5 \mathrm{sec}$, (5) lift assembly minus canister approximately $2 \mathrm{ft},(6)$ turn on jet pump and slowly retrieve assembly, playing out the detonating cord as the assembly rises. There were some initial problems with both the assembly and the pump. However, once these were resolved, the emplacement of all charges on dry land and those out to a water depth of $4 \mathrm{ft}$ went rapidly. A hydraulic jet pressure of approximately 125 psi was 
sufficient to quicken the sand, and the average emplacement time was about 20 minutes per charge. In order to emplace the last four charges on the seaward side, it would have been necessary to build a pier for the crane. Due to the expected onset of foul weather, incipient beach erosion, and the time delay necessary for pier construction, it was feared that the channel might wash out. Therefore, the final four charges were eliminated from the design and emplaced along the centerline of the dredged portion of the channel (at the Core Sound end of the rows). These charges were detonated underwater in the dredged channel to dispose of the excess explosive.

Elimination of the last two charge pairs presented a high probability of underexcavation, since these charges were located at a water depth of about $4 \mathrm{ft}$ ( $2 \mathrm{ft}$ less than the channel design depth). The last of the actual excavation charges $(11 a-b)$ were emplaced beneath $8 \mathrm{ft}$ of sand and $3 \mathrm{ft}$ of water. The water depth about 25 to $30 \mathrm{ft}$ (or about one crater radius) east of these charges was $3-1 / 2 \mathrm{ft}$. The peak of the crater lip is deposited a few feet beyond the apparent crater radius. Thus, assuming a lip : height of roughly $4 \mathrm{ft}$, one would expect the lip to protrude above water surface level, blocking the ocean exit of the channel. EERL warned District personnel of this possibility; however, engineers on site decided to proceed with the event, in the expectation that natural hydraulic forces would make up for the narrow lip and shallower excavation depths at the ocean end of the channel. Both predictions subsequently proved correct: a narrow offshore lip was observed after the shot, but was quickly washed away by tidal flushing and wave action.

\section{Execution}

Figure $13 \mathrm{~d}$ shows the project site just after emplacement of the charge canisters. The posts visible in this photograph are 4-by-4-in. posts used for the offset batter line during emplacement. Once the charges were emplaced, a 1/4in. wire rope was connected to each post running down each charge row and across the ends. This wire rope was used to support and reinforce the detonating cord ring main. Each of the detonating cord downlines was connected into the ring main. An electrical firing line was then run from the firing bunker, located on the Outer Banks $3000 \mathrm{ft}$ north of surface ground zero (SGZ), to the SGZ area. Finally, the, ring main was armed using two instantaneous blasting caps. Patrol boàts cleared all navigational traffic from the surrounding area prior to the detonation. The 22 excavation charges and the 4 disposal charges in the dredged channel were detonated simultaneously.

\section{Detonation Phenomenology}

\section{Photographic Coverage}

Due to operational requirements, some of the technical investigations normally conducted during a large-scale explosive project were not possible at Drum Inlet. However, the detonation was thoroughly documented by scientific and technical photography. This section 
Table 2. Ground-level photographic coverage of the Drum Inlet detonation.

\begin{tabular}{|c|c|c|c|c|}
\hline Camera & $\begin{array}{l}\text { Beseler Topcon } \\
35-\mathrm{mm} \text { (early } \\
\text { time) }\end{array}$ & $\begin{array}{l}\text { Beseler Topcon } \\
35-\mathrm{mm} \text { (post- } \\
\text { shot) }\end{array}$ & $\begin{array}{l}\text { Canon } 16-\mathrm{mm} \\
\text { movie camera }\end{array}$ & $\begin{array}{l}\text { 100-ft Hycam } \\
16-\mathrm{mm} \text { high- } \\
\text { speed movie }\end{array}$ \\
\hline Frame rate & $\begin{array}{l}\text { Continuous burst, } \\
\text { motor drive } \\
\text { (about } 0.47 \mathrm{sec} / \\
\text { frame) }\end{array}$ & $\begin{array}{l}\text { Single photos of } \\
\text { crater, } 30- \\
60 \text { min postshot }\end{array}$ & 48 frames $/ \mathrm{sec}$ & $\begin{array}{l}588-592 \text { frames/ } \\
\text { sec }\end{array}$ \\
\hline Lens focal length & $\begin{array}{l}58 \mathrm{~mm} \text { (normal } \\
\text { lens) }\end{array}$ & 58 and $26 \mathrm{~mm}$ & 25 to $13 \mathrm{~mm}^{\mathrm{a}}$ & $\begin{array}{l}50 \mathrm{~mm}^{\mathrm{b}} \text { (equiva- } \\
\text { lent focal length } \\
59 \mathrm{~mm} \text { ) }\end{array}$ \\
\hline Film & Kodacolor $-\mathrm{X}$ & Kodacolor $-\mathrm{X}$ & Kodachrome II & $\begin{array}{l}\text { High-speed } \\
\text { Ektachrome } 7241\end{array}$ \\
\hline Exposure data & $\mathrm{f} / 6$ at $1 / 500 \mathrm{sec}$ & $1 / 500 \mathrm{sec}$ & Approx f/ 10 & $\begin{array}{l}\text { f } / 3.3 \text { at approx } \\
588 \text { frames } / \mathrm{sec}^{c}\end{array}$ \\
\hline $\begin{array}{l}\text { Timing mark } \\
\text { repetition rate }\end{array}$ & - & - & 一 & $\begin{array}{l}100 \text { marks /sec } \\
\text { (Redlake timing } \\
\text { light) }\end{array}$ \\
\hline Camera location & $\begin{array}{l}\text { Camera bunker, } \\
\text { perpendicular to } \\
\text { row }\end{array}$ & $\begin{array}{l}\text { Adjacent to } \\
\text { crater, and on } \\
\text { craft in dredge } \\
\text { cut }\end{array}$ & $\begin{array}{l}\text { Beside camera } \\
\text { bunker, per- } \\
\text { pendicular to } \\
\text { row }\end{array}$ & $\begin{array}{l}\text { Camera bunker, } \\
\text { perpendicular to } \\
\text { row }\end{array}$ \\
\hline Range (ft) & $\sim 1535$ & - & $\sim 1535$ & $\sim 1535$ \\
\hline $\begin{array}{l}\text { Angle between line } \\
\text { of sight and axis } \\
\text { of row (near } \\
\text { charges } 5 \text { and } 6 \text { ) }\end{array}$ & $74.1^{\circ}$ & - & $74.1^{\circ}$ & $74.1^{\circ}$ \\
\hline
\end{tabular}

${ }^{a}$ Canon zoom lens; focal length was adjusted from 25 to $13 \mathrm{~mm}$ at late time to follow cloud growth.

${ }_{\text {A }} 50-\mathrm{mm}$ (2-in.) C-mount movie camera lens was used; internal elements in the Hycam optical system modify the equivalent focal length to approx $59 \mathrm{~mm}$.

${ }^{c}$ Hycam film was overexposed one stop to show mound growth and early cloud growth more effectively; mounds were partly blacklighted from viewpoint of camera station.

summarizes the photographic coverage and basic phenomena observed. Detailed analysis of the technical program results is presented in Sec. 9.

Technical programs related to the explosive event were executed by EERL, with support of the Wilmington District and the Special Photographic Detachment "CONUS" from Fort Bragg, North Carolina. Three ground-level cameras were located at a photographic bunker, approximately $1500 \mathrm{ft}$ north of the SGZ area. These included a Canon $16-\mathrm{mm}$ movie camera operated at 48 frames/sec, a

\section{5-mm motor-driven Beseler Topcon} camera operated at 2.13 frames/sec ( $0.47 \mathrm{sec}$ between photographs), and a 16-mm Hycam high-speed movie camera. The Hycam frame rate, determined from $100-\mathrm{Hz}$ timing light marks on the edge of the film, was 588 frames/sec at detonation time, gradually increasing to about 592 frames/sec at later times. Postshot photography of the crater was also obtained using the $35-\mathrm{mm}$ Beseler Topcon. Table 2 lists photographic data for the ground-level cameras. Additional photography of the detonation was acquired 
by a still camera located on the mainland beach near Atlantic, North Carolina (2-1/2 miles distant), and by still and movie cameras in a helicopter flying over the Core Sound (west) end of the cut. The helicopter and crew were furnished by the 182nd Aviation Company, XVIII Airborne Corps, Fort Bragg. The aerial photography was performed by the Wilmington District and the CONUS photographic team from Fort Bragg, North Carolina, Preshot aerial views were obtained on 16 November 1971, and the same personnel subsequently carried out photography of the detonation. All cameras functioned properly, and the photographic programs met with complete success.

Postshot surveys of the ground-level camera bunker position were not acquired due to rough water and to problems with other survey work. However, data reduction of photography from the three groundlevel cameras showed that the bunker was located $1535 \pm 25 \mathrm{ft}$ from the nearer (north) charge row (measured to a position midway between charges 5 and 6 ); the angle between the cameras' line of sight and the row axis was $74.1^{\circ}$ at the same position. The bunker was located to the west (Core Sound side) of a true perpendicular from the row axis; perpendicular distance from the cameras to a westward extension of the near row axis was $1477 \mathrm{ft}$. The horizontal photographic scale along the row axis was established on the basis of the known distances between charge emplacement position posts. Vertical distances, vertical velocities, and velocities perpendicular to the line of sight have been corrected for the scale error caused by the $74.1^{\circ}$ inclination of the line of sight. Measured positions, sizes, and velocities refer to the near row and the near row axis position unless otherwise stated. Far-row detonation and mound growth phenomena were partially visible at early times in the movie photography, but were quickly obscured by near-row mound growth.

\section{Charge Detonation}

Detonation occurred at 1327 hours Eastern Standard Time, 23 December 1971, near mean sea level on an ebbing tide. The event was set off $33 \mathrm{~min}$ ahead of schedule due to the onset of bad weather and the possibility of losing charges in the ocean surf zone. Winds were from the northeast at 15 to 25 knots. The ambient temperature was $56^{\circ} \mathrm{F}$. Seas were rough, with heavy breakers at the ocean side of the reef. Visibility was good, and the photographic definition was very clear. After the event, winds carried the sand and spray cloud along the outer edge of the reef and over the Atlantic Ocean in a generally southwestward direction; this motion caused the cloud to travel away from the camera bunker location at a slight angle to the line of sight.

Selected still photographs of the detonation are shown in Figs. 14-16. Figure $14 a$ is a preshot view of the SGZ area from the camera bunker $(35-\mathrm{mm}$ camera; Atlantic Ocean at left). Figure $14 \mathrm{~b}$, the first postdetonation picture, was taken at approximately $0.08 \mathrm{sec}$ after initiation. Note the dark-colored sand spall mounds above the charges near the center of the row, and the light-colored water plume spall above the submerged charges at either end of the row (water spall outran the underlying sand spall 


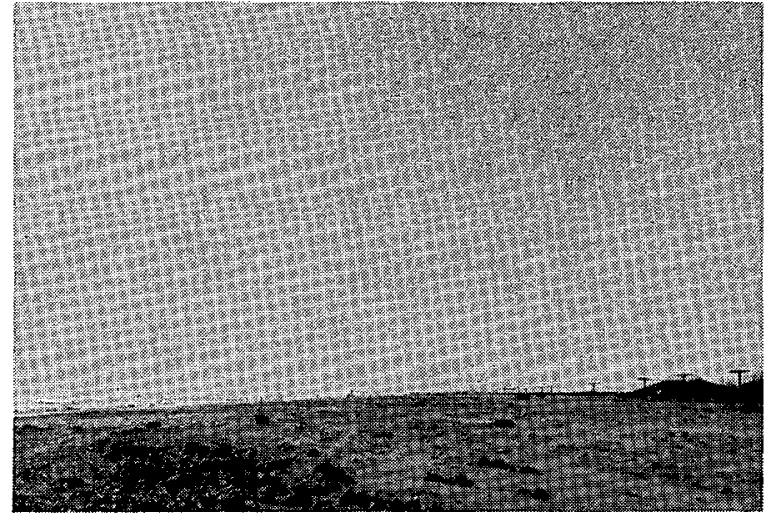

(a) Preshot photo

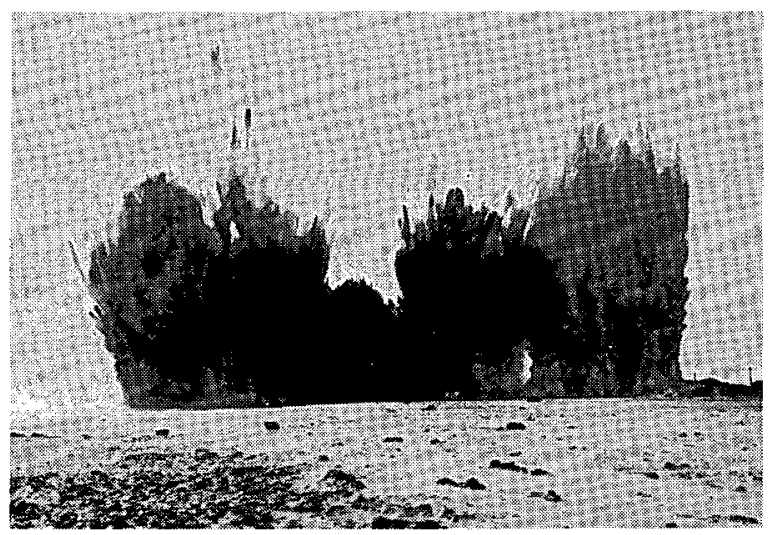

(c) At $+0.55 \mathrm{sec}$

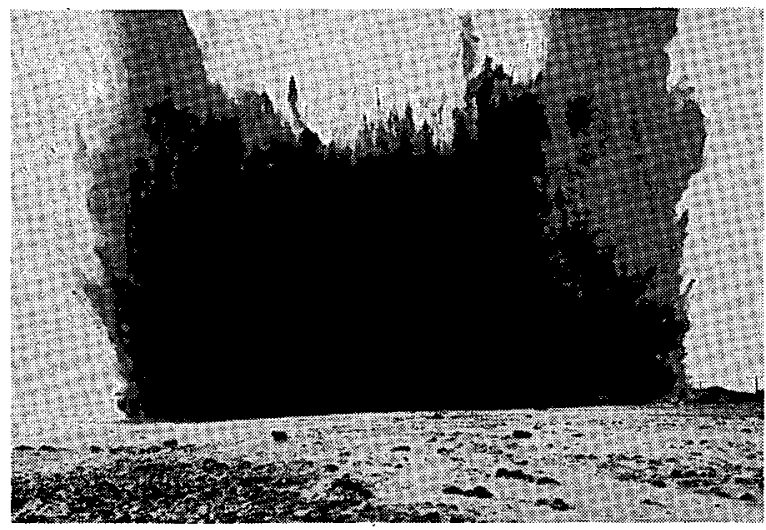

(e) $\mathrm{At}+1.49 \mathrm{sec}$

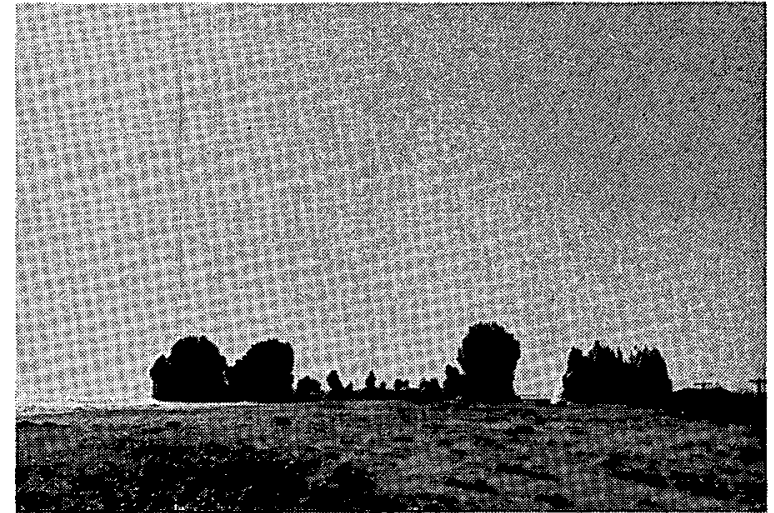

(b) $\mathrm{At}+0.08 \mathrm{sec}$

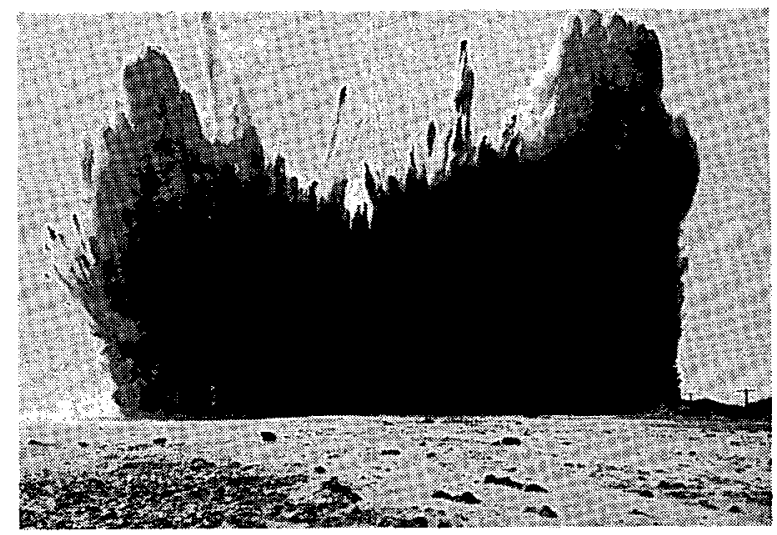

(d) At $+1.02 \mathrm{sec}$

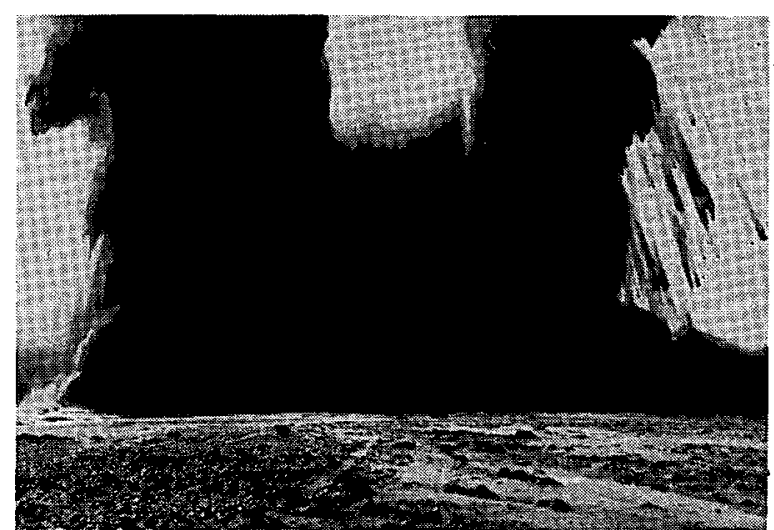

(f) Several seconds after the shot

Fig. 14. Ground-level sequence view of the detonation as seen from a range of about $1500 \mathrm{ft}$. The last photograph in the above sequence shows large falling ejecta and the growth of the low base-surge cloud. 


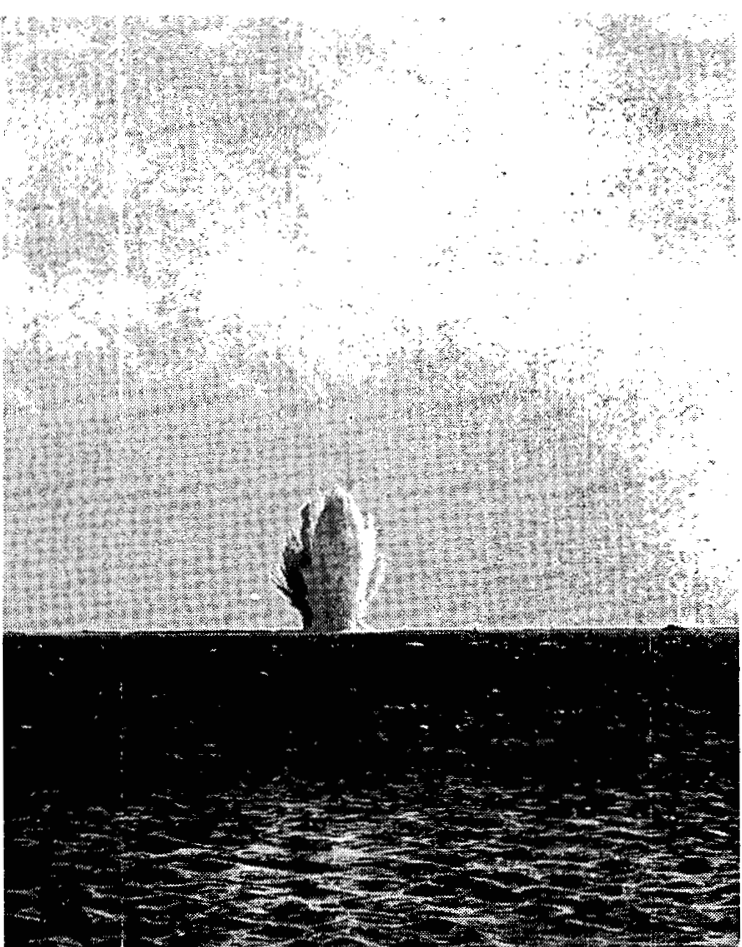

(a)
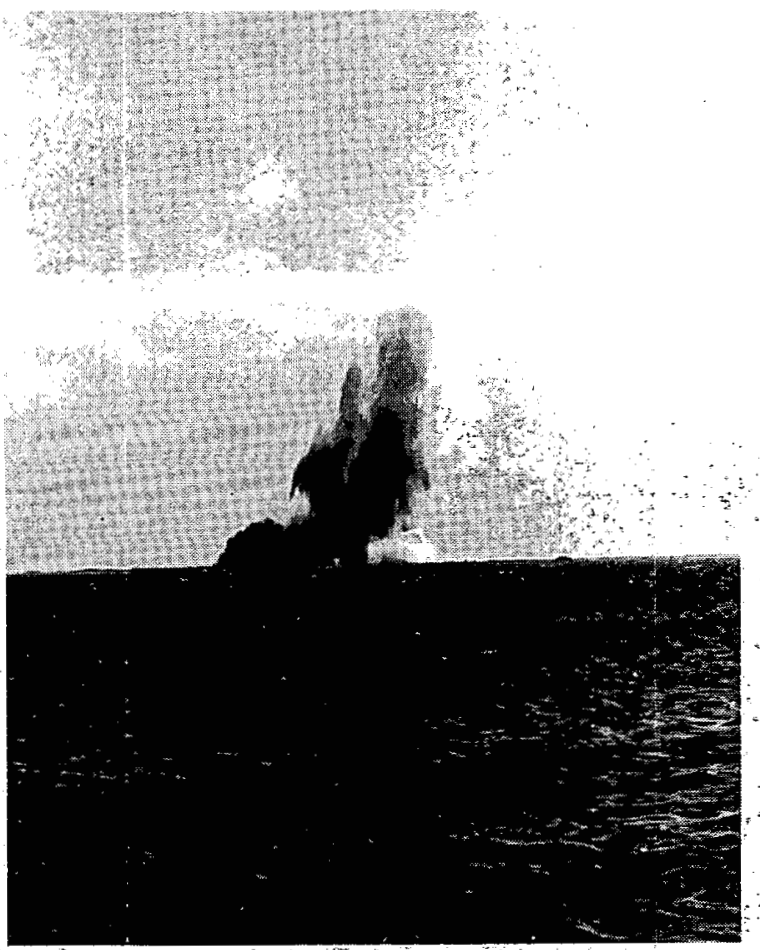

(c)

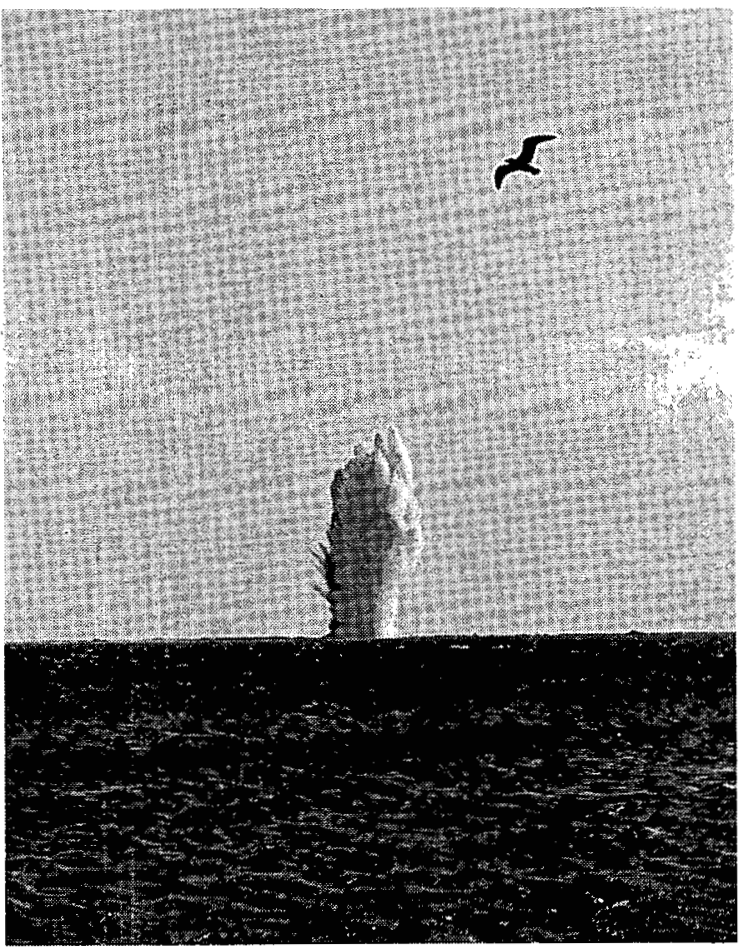

(b)

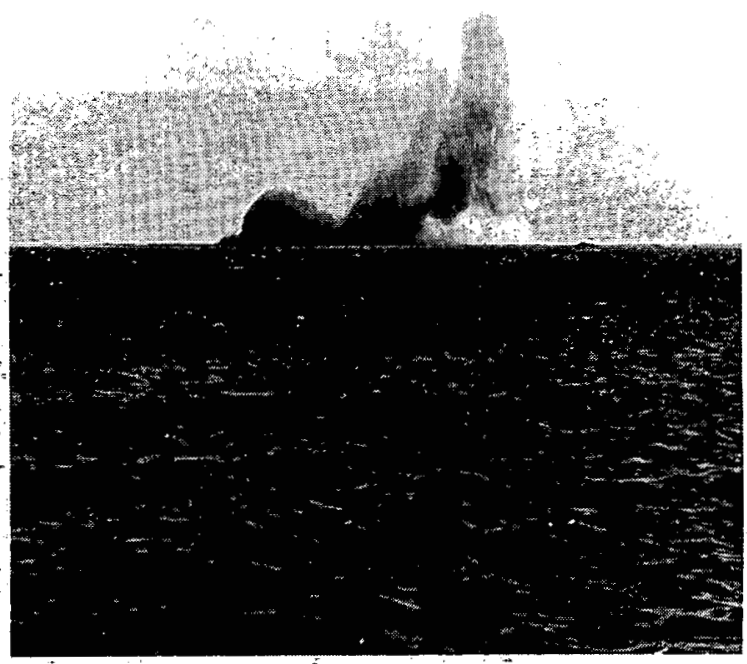

(d)

Fig. 15. Long-range sequence view of the detonation, photographed from the beach approximately 2.5 miles away. 


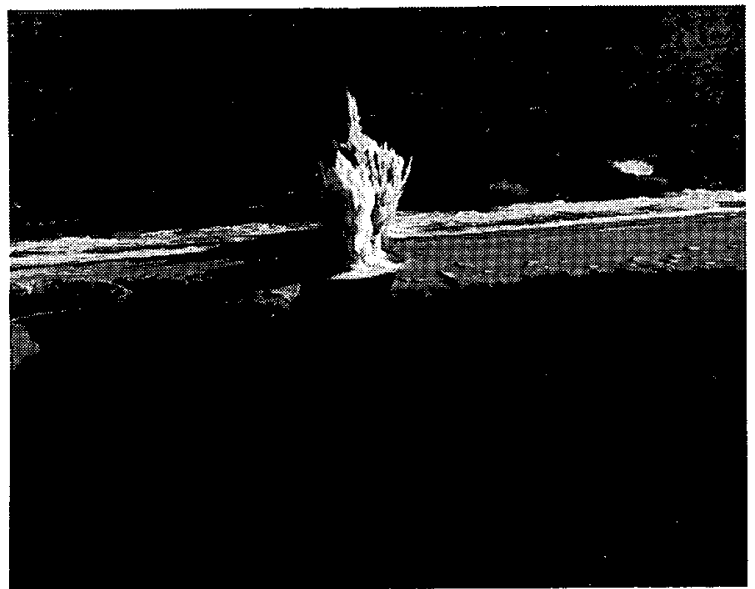

(a)

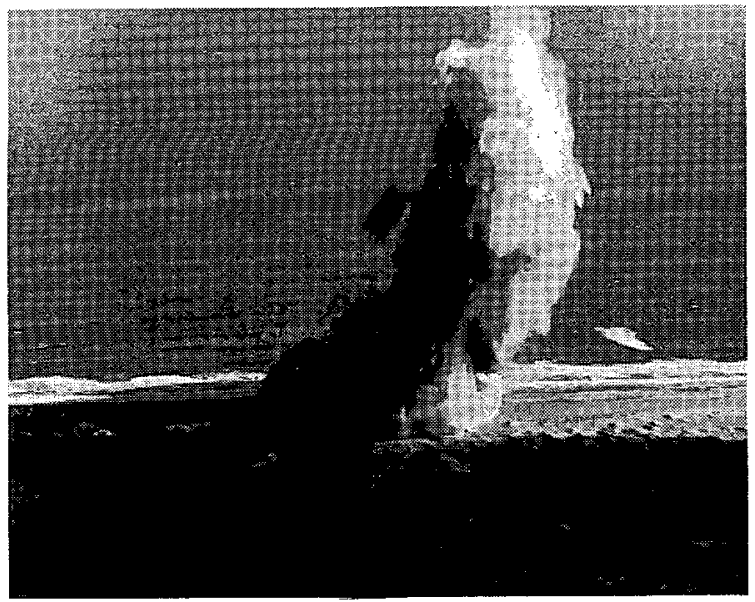

(c)

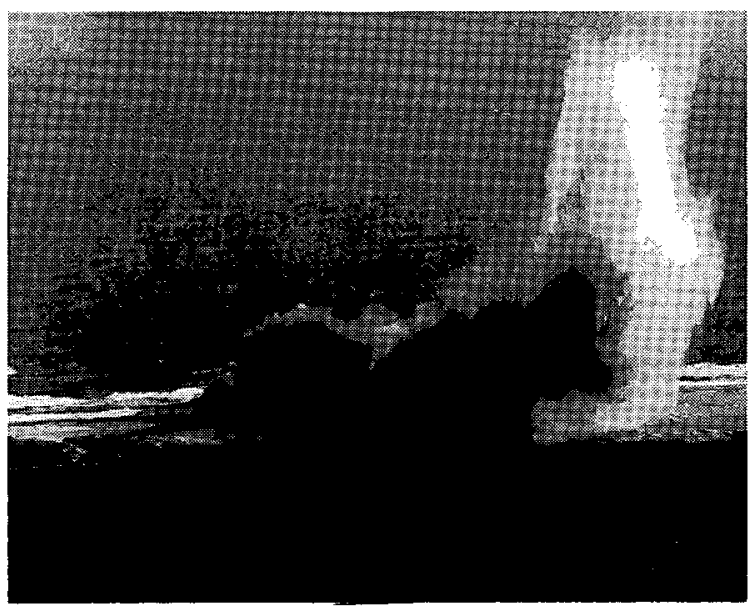

(e)

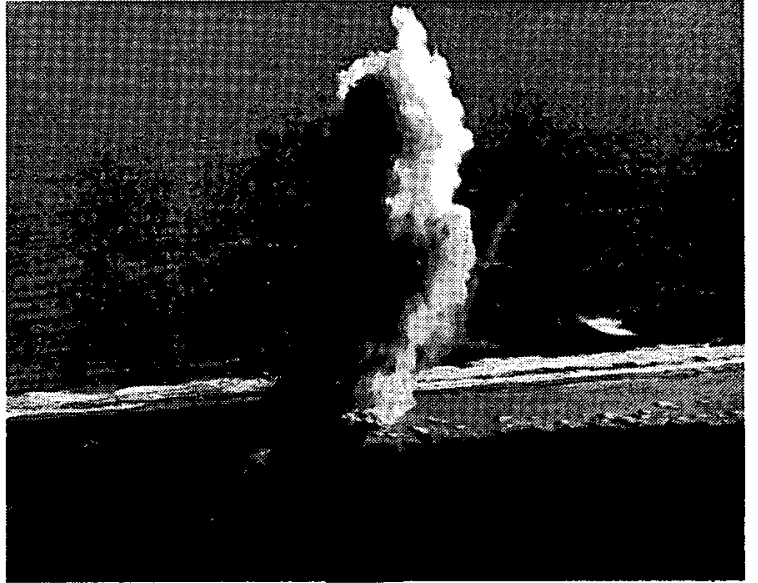

(b)

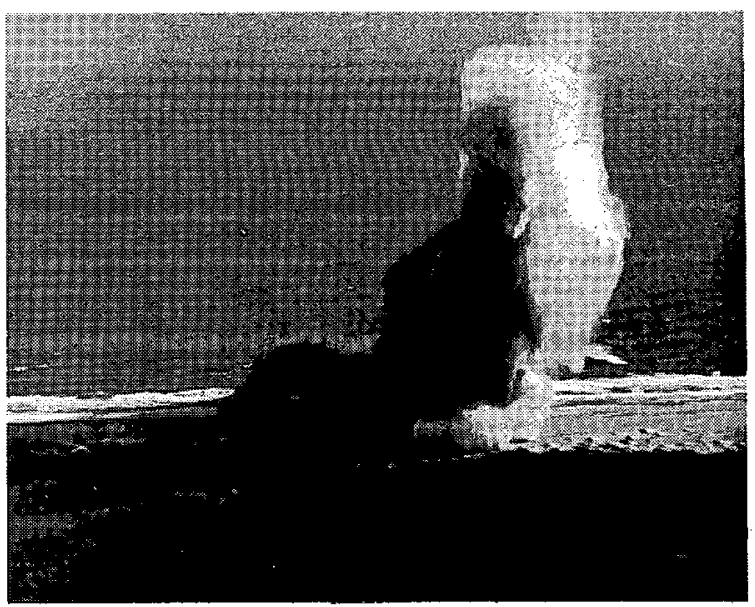

(d)

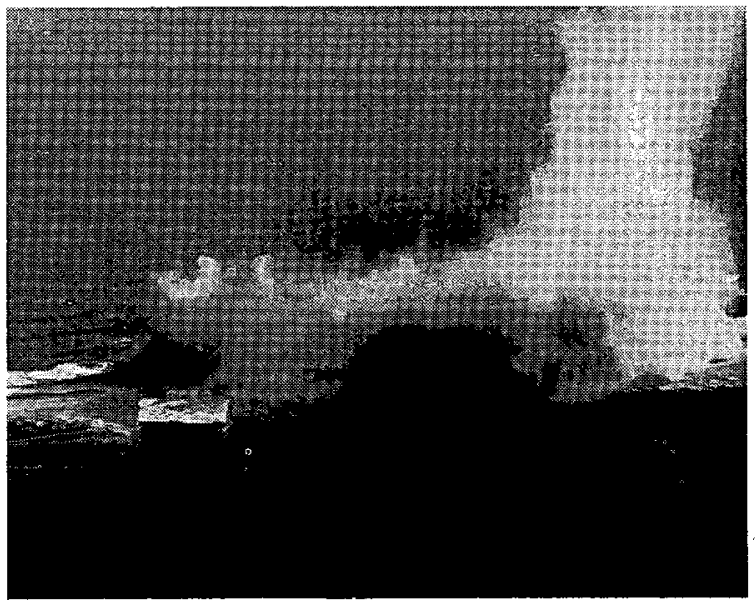

(f)

Fig. 16. Sequence view of the detonation and cloud taken from a helicopter flying on the Core Sound side of the Outer Banks. 
surface in these cases). Narrow stem ejection plumes are visible above the center charges, indicating that the stemming columns where the charges were emplaced spalled upward with high velocities at early time. Note also the white water spall domes launched by the four disposal charges in the dredge channel (off right end of row). These charges were located about $110-175 \mathrm{ft}$ beyond the last excavation charge pair $(1 \mathrm{a}-\mathrm{b})$, at the Core Sound end of the rows. Subsequent photographs were taken at $+0.55 \mathrm{sec}(14 \mathrm{c})$, $+1.02 \mathrm{sec}(14 \mathrm{~d}),+1.49 \mathrm{sec}(14 \mathrm{e})$, and late time (several seconds after initiation, 14f). High-velocity sand clump ejecta particles can be seen penetrating the spall domes above both excavation and disposal charges in photographs $14 \mathrm{c}-14 \mathrm{e}$. Figure $14 \mathrm{f}$ shows the horizontal development of the low base-surge cloud near ground level, as well as the descent and disintegration of large ejecta clumps. Note that the tall column of material or "main cloud" is much higher at the ends of the row (above the submerged and disposal charges) than at the center of the row.

Figure 15 presents long-range views of the detonation, photographed from the mainland beach at Atlantic, about 2.5 miles away. Again; the white spray cloud (at near end of row), dark sand : cloud, and late-time development of the base cloud are clearly visible.

Figure 16 shows aerial photographs taken from the helicopter. In Fig. 16a; note the dredge cut and the water spray clouds above the disposal charges at the Core Sound end of the rows (foreground). The shape of the base cloud during growth and stabilization is particularly apparent in Figs. 16c and 16d. Figure $16 \mathrm{f}$ depicts late-time downwind dispersal of the cloud material.

Analysis of the movie films also produced a number of useful results. The Hycam high-speed photography clearly resolved the detonation flash of the primacord traveling along the rows. Initiation was started at the Core Sound end (charges $1 \mathrm{a}-\mathrm{b}$ ) and proceeded sequentially to the ocean end (charges 11a-b). Charge pairs $1 a-b$ and $2 a-b$ were initiated at the time of first postdetonation Hycam frame; after this time, the mean propagation velocity of the visible flash between charges 2 and 8 (near row) was $24,100 \mathrm{ft} /$ sec, slightly faster than the usual velocity specified for primacord. Assuming a total length of $350 \mathrm{ft}$, only $14.5 \mathrm{msec}$ was required to initiate the entire charge sequence. This may be considered essentially a simultaneous detonation for charge rows as long as Drum Inlet. About 0.005 to $0.017 \mathrm{sec}$ after charge initiation, violent stem ejection was observed from most of the charges buried in sand at the center and Core Sound end of the rows. Water spall mound growth above the submerged charges became visible at +0.007 to $+0.015 \mathrm{sec}$, and was well advanced by $+0.026 \mathrm{sec}$. Growth of the sand spall mounds above charges at the center and Core Sound end of the rows became apparent at +0.031 to $+0.034 \mathrm{sec}$, and displacement was measurable by $+0.039 \mathrm{sec}$. Initial surface velocities above the submerged charges were much higher than those above the sand charges, but the overall spall mound growth was fairly smooth and complete along the entire row. Movie sequences from the Hycam and Canon cameras showed that all 11 charges in the near row detonated at or 
near full yield. Far-row mound growth appeared quite similar to the spall mounds above the corresponding nearrow charges, but the view was partly blocked by the near-row detonation. It is believed that all far-row charges detonated at or near full yield. High-velocity water spall from the submerged and disposal charges created very tall, lightcolored main cloud columns consisting largely of water spray. Lower velocity spall launch above the sand charges produced a much shorter, dark-colored cloud made up of dense sandy material. Thus, the main cloud displayed a dark sand section near the center of the row, flanked by two taller columns of water spray and sand.

Shortly after the detonation, an intense ground motion wave arrived at the camera bunker (range $\approx 1535 \mathrm{ft}$ ). Both movie cameras underwent violent oscillation that is visible in the film. The initial arrival occurred about $+0.271 \mathrm{sec}$ (Canon camera) to $+0.292 \mathrm{sec}$ (Hycam camera). The observed arrival times indicate mean sonic velocities of 5650 and $5250 \mathrm{ft} / \mathrm{sec}$, respectively. A mean velocity of $5450 \mathrm{ft} /$ sec is adopted, in agreement with the expected transmission velocity for saturated sand. The Canon camera, mounted on a tripod adjacent to the bunker, underwent 11 complete cycles of somewhat irregular vertical oscillation between +0.271 and $+1.46 \mathrm{sec}(9.3 \mathrm{~Hz}$ mean frequency). The first two cycles were relatively mild; the 11 th was followed by further irregular vertical movements of lower frequency and lesser intensity. Late-time oscillations continued until about $+2.13 \mathrm{sec}$. The Hycam, mounted in a heavy camera bunker, began strong horizontal oscillations with superimposed vertical oscillations at $+0.292 \mathrm{sec}$. Four cycles of oscillation occurred between 0.292 and $0.408 \mathrm{sec}$, followed by a quiescent period. Four additional cycles of primarily horizontal oscillation were observed from 0.451 to $0.586 \mathrm{sec}$, then another halt, followed by $3-1 / 2$ cycles of oscillation between 0.604 and $0.766 \mathrm{sec}$. (Frequencies were about 22 to $35 \mathrm{~Hz}$ ). Irregular low-frequency oscillation continued at later times. The superimposed vertical oscillations observed during the first four cycles of motion were most violent during the period from the end of the first cycle through the end of the third cycle (about 0.33 to $0.381 \mathrm{sec}$ ). The last very evident late-time vibration occurred at $1.55 \mathrm{sec}$, but faint horizontal movement was detectable until about $2.23 \mathrm{sec}$. The initial strong arrivals were almost certainly transmitted through the underlying saturated sand; succeeding arrivals may have been caused by reflections and surface wave transmission in the less dense overlying sand layer. The early ground motion arrivals were quite intense, as expected for a saturated transmission layer overlain by less dense material. It is estimated that peak velocities capable of causing minor architectural damage to residential structures occurred at ranges of 1500 to $3500 \mathrm{ft}$ from SGZ. No endangered structures were located near the project site in this case, but ground motion may be the controlling safety factor for future events in saturated sand. 


\section{Excavation Results}

Due to extremely rough sea conditions, detailed surveys of the Drum Inlet crater were not possible immediately after the event. However, on-site observation verified a mean width of about $80 \mathrm{ft}$ near water level. The crater had a somewhat bow-shaped appearance, being widest and rather shallow in the region of the optimum depth charges near the center of the cut, visibly narrower but still shallow at the ocean end, and of intermediate width but much deeper at the Core Sound end. The four disposal charges in the dredge cut exerted no apparent effect on the crater, although they did throw water about $200 \mathrm{ft}$ laterally. Some of the water ejected by these and other charges washed back into the crater, but did not cause major failure or slumping of the dry-land side lips. It was evident that certain portions of the explosive cut did not initially meet design depth specifications. Underexcavation was most severe at the eastern (ocean) end and along the center line of the cut. Crater depth contours were observed to be -6.0 to $-8.0 \mathrm{ft}$ MLW at the Core Sound end of the rows, and -0.6 to $-2.0 \mathrm{ft}$ near the ocean end. $\mathrm{A}$ nearly complete offshore lip projecting $2 \mathrm{ft}$ above water level was visible beyond the ocean beach. This lip appeared semicircular in shape, on a radius of roughily $40 \mathrm{ft}$ (about equal to the crater half-width). Small elongated mounds were also ob-: served precisely on the center axis of the cut (midway between the two row alignments) and near the center of the channel (vicinity of charges $6 a-b$ ). These mounds or islets initially protruded about $1.5 \mathrm{ft}$ above the water surface, and the exposed area was approximately $6 \mathrm{ft}$ wide by $12 \mathrm{ft}$ long at water level. Figure 17 shows aerial views of the offshore lip and the underexcavated central mound area, taken immediately after the detonation cloud had cleared. Some intercharge cusping is also visible along the side lips of the crater, particularly between the shallow, widely spaced charges near the ocean end of the row (Fig. 17b). The center mound and the lip cusping indicate that the inter-row separations and perhaps even the wider intercharge spacings used in the design were too great. The lip and mound peaks were washed away within a few minutes after the event. The mounds remained faintly visible as a rough water area near the center of the crater for about an hour.

In spite of the relatively shallow "flatbottomed" aspect of the Drum Inlet crater, the lips along the dry-land sides were extremely steep. These embankments presented side slopes of up to $45^{\circ}$ of greater, and extended about $12 \mathrm{ft}$ above the postshot,water level. This height corresponds to a total lip height (above preshot sand surface) of more than $6 \mathrm{ft}$. Predicted lip height, based on smallscale modeling detonations in saturated sand, was approximately $4 \mathrm{ft}$. Craters produced by modeling events are often irregular in shape; steep, high lips of the type seen àt Drum Inlet have also occurred for a few small-scale tests in saturated sand and in saturated sand with very shallow overlying water layers. They have never been observed for detonations with deeper overlying water layers $\left(D_{\mathrm{w}} / \mathrm{D}_{\mathrm{m}}>0.1\right)$. 

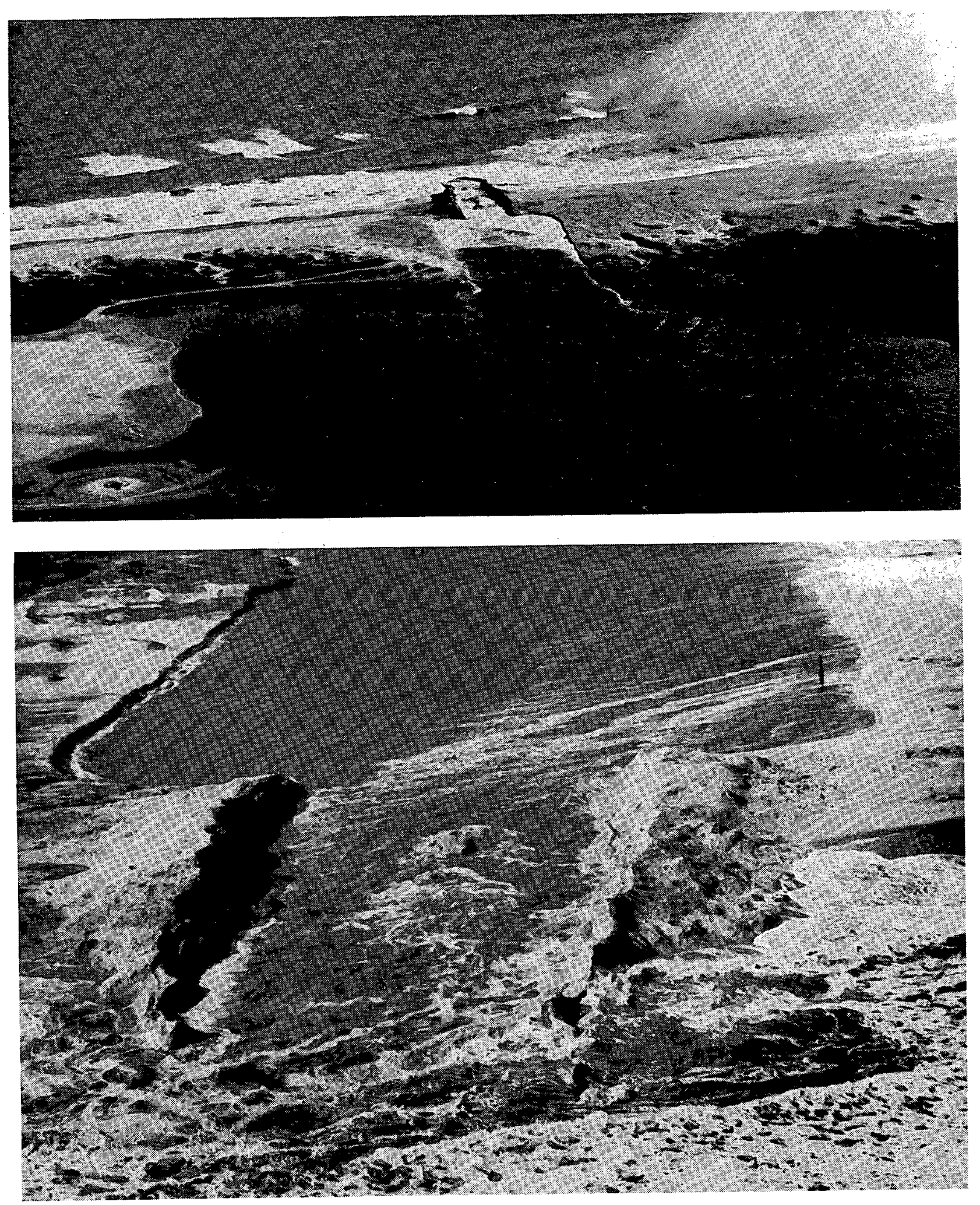

Fig. 17. Early-time postdetonation photographs of Drum Inlet channel showing offshore lip and islets near center of crater. Upper picture taken from sound side, lower picture from ocean side. 
Estimated postshot contours of the Drum Inlet crater are sketched in Fig. 18. Since survey data are not available, these contours are based on the descriptive information presented above and must be considered approximate. The underexcavation shown in the cross section profile midway between the two rows (along the center axis) is definitely real. Excavated contours along the axis of each charge row are much closer to design depth. The extreme shallowness of the crater near charges 8-10 (lengthwise profiles) indicates that the preshot sand surface contours may have been slightly inaccurate; however, there is no doubt that the crater was quite shallow and that the amount of material removed in the vicinity was smaller than expected. A discussion of cratering dynamics in saturated sand and suggested explanations for the underexcavated crater contours are presented in Sec. 8.

Since Drum Inlet was detonated near mean sea level on an ebbing tide, there was little hydraulic gradient or water flow across the inlet immediately after the event. The gradient and the water flow velocity steadily increased as the tide went out. Green dye markers placed in the dredge cut monitored and verified the sluggish tidal flow after the event and the rapidly increasing flow velocity at later times. The increasing sound-toocean flow helped to widen and deepen the channel and remove excess material by natural scouring. The overall configuration of the cut did not change dramatically during the first hour. Even the steep lips along the dry-land sides were fairly stable, and did not suffer significant erosion from washback and slumping or from water flow along the channel. By the end of the second hour, tidal flow from the sound into the ocean had increased substantially, and efficient scouring of the crater was under way. The lips were quickly undermined and began to slump. By morning of the following day, the steep side banks had completely disappeared, and the crater width had increased to $200 \mathrm{ft}$ (approximately equal to the width of the dredge channel). The first fishing trawler ventured to sea through the new inlet shortly after 1200 hours EST, 24 December 1971. The captain of the vessel reported a depth of $9.5 \mathrm{ft}$ throughout. 12,13

Tidal forces continued to excavate the channel for several days. On 27 December, a survey crew determined the width of the inlet gorge to be $700 \mathrm{ft}$, and the opening at the mouth was nearly $1000 \mathrm{ft}$. Measured depths at the 150-ft design width within the inlet varied from 8 to $11 \mathrm{ft}$. Between the Core Sound and ocean shores of the reef, the requirement for a 9-ft-deep by,150-ft-wide navigation channel was satisfactorily met without the need for supplemental dredging. The controlling depths across the ocean bar beyond the inlet were 6.5 to $10 \mathrm{ft}$. Surveys on 27 December and on 4 January 1972 also revealed the first problem: a sand shoal was beginning to form within the Core Sound navigation channel, about 1500 to $3400 \mathrm{ft}$ west of the center of the inlet. The configuration of the inlet appeared to remain stable, but the shoal was unstable and rapidly shifting. Dredge 


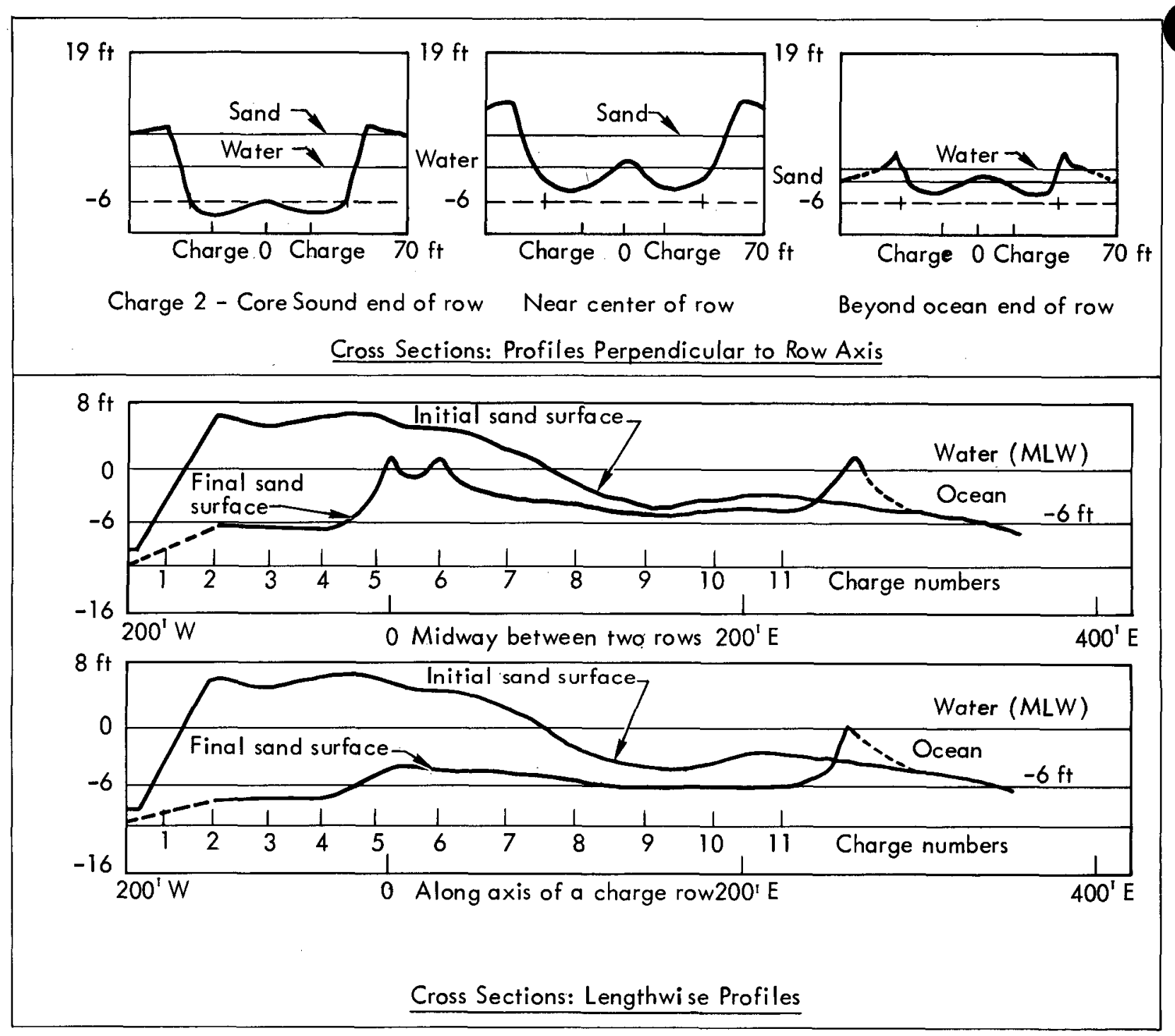

Fig. 18. Approximate postshot crater contours, based on visual estimates.

operations to remove the shoal were undertaken in mid-January of 1972.

Beneficial effects of the Drum Inlet project were quickly realized. The new inlet provided immediate access to the commercial fishing grounds in Raleigh Bay; interchange of ocean and Core Sound waters achieved the desired salinity balance to maintain environmental conditions within the Sound. Public and media re-

*Postshot and survey data courtesy of the Wilmington District, Corps of Engineers. sponse following the detonation were excellent, with favorable comments on local television and radio stations. However, the shoaling and stability problems that have often plagued small inlets in the past continued to occur at Drum Inlet. It was anticipated that further dredging operations would be necessary to keep the Core Sound access channel open. One year after project execution, the inlet itself was 800 to $900 \mathrm{ft}$ wide in the gorge and about $3500 \mathrm{ft}$ wide at the ocean mouth. The depth was $10 \mathrm{ft}$ or greater throughout, 
exceeding initial design requirements and expectations. The shoal areas in the Core Sound channel were significantly shallower than design depth at several locations, and shoaling extended about $5000 \mathrm{ft}$ inside the inlet.

Maintenance dredging of the Core Sound channel was performed in March 1973 and provided project dimensions of $7 \mathrm{ft}$ deep by $150 \mathrm{ft}$ wide from the Pamlico Sound-Beaufort Harbor channel to Drum Inlet. At its narrowest point in the gorge, Drum Inlet is currently $1100 \mathrm{ft}$ wide and has a controlling bottom depth of $-14.0 \mathrm{ft}$. MLW. Following the March 1973 maintenance dredging in Core Sound, the Coast Guard provided navigational aids marking the Drum Inlet channel for the first time since its reopening in December 1971 .

Selected preshot and postshot views of the Drum Inlet project area and channel are presented in Figs. 19 through 21. Figure 19a shows the contract dredge completing preshot excavation on the Core Sound side of the Outer Banks (prior to charge emplacement). Figures 19b and $19 \mathrm{c}$ are aerial postshot views of the dredge-cut and explosively excavated channel, taken about $30 \mathrm{~min}$ after the event. In Fig. 19b, the dredge spoil, area north of the channel on the Core Sound side of the reef is clearly visible. The large craft moored in the dredge channel was used to transport spectators to and from the Banks.

Figure 20 presents ground-level photographs of the channel, taken about an hour after the shot: The steep side banks are especially apparent in Fig. 20b, while Figs. 20a-20d show the area of turbulent water (eddy currents) near the center of

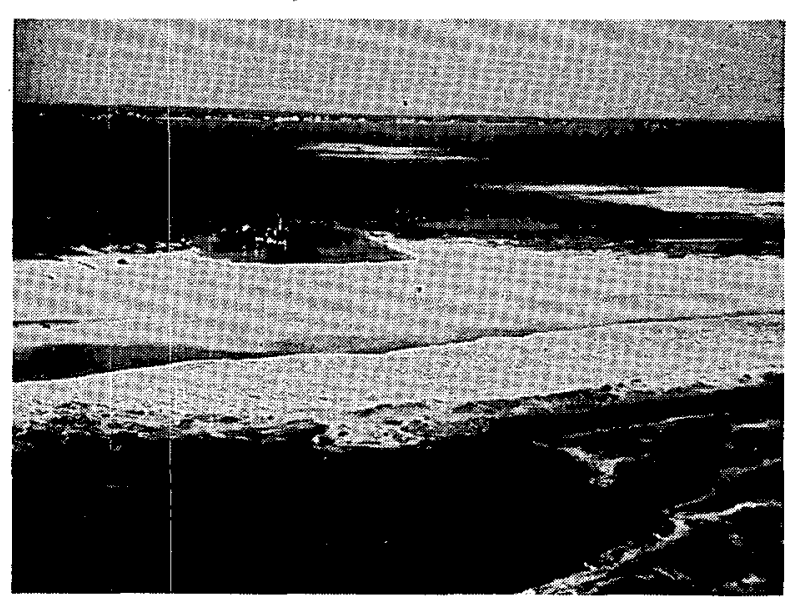

(a) Pipeline dredge working on Core Sound side of new Drum Inlet

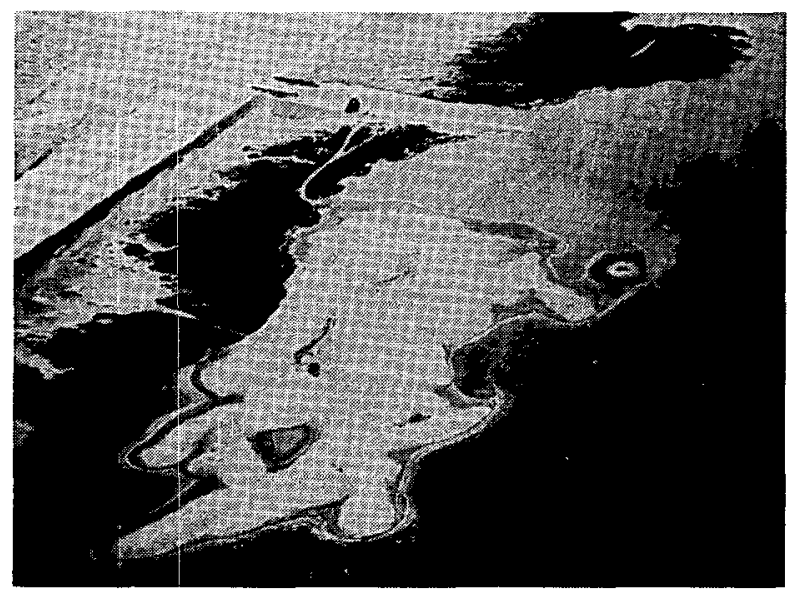

(b) Excavated inlet about $30 \mathrm{~min}$ after the shot, viewed from Core Sound side

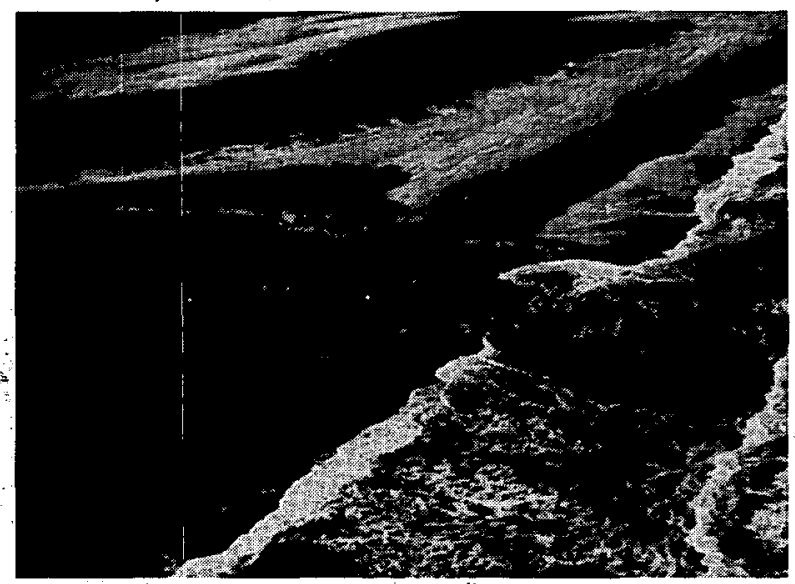

(c) Closer photo of excavated inlet $30 \mathrm{~min}$ after the shot, taken from ocean side

Fig. 19. Preshot and postshot views of the Outer Banks area and the excavated Drum Inlet channel. Note the dredge spoil area visible in the aerial postshot photographs of the channel. 


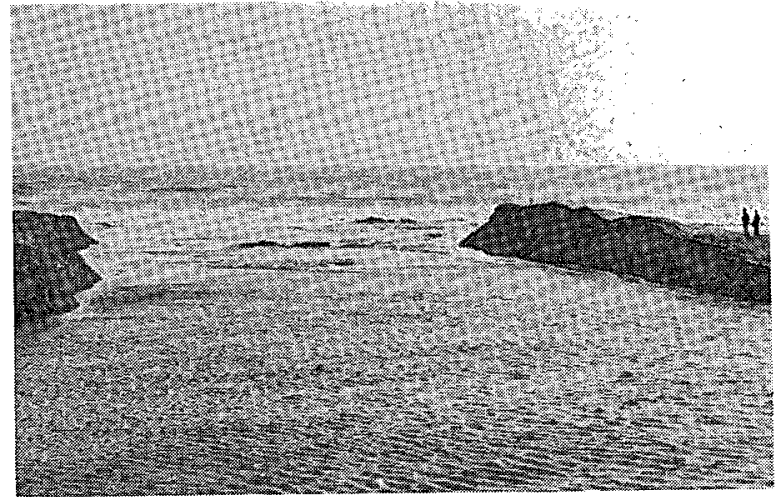

(a)

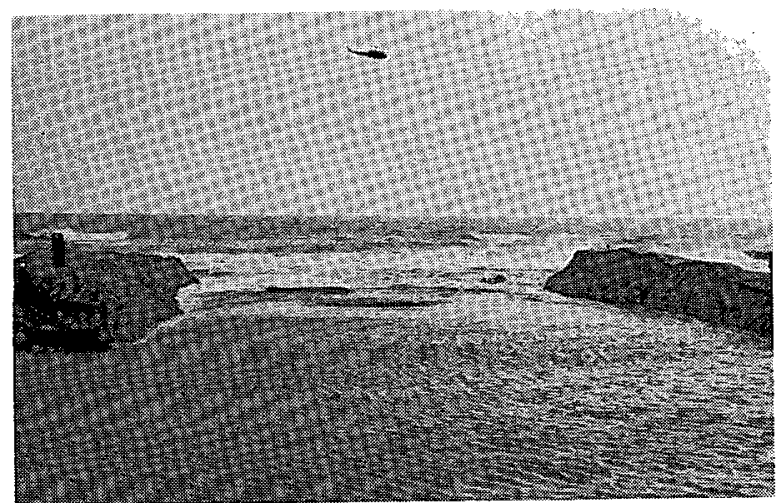

(c)

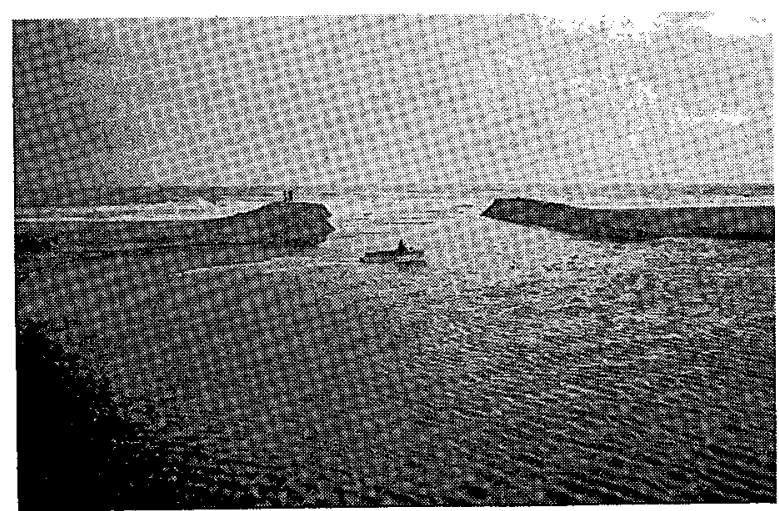

(e)

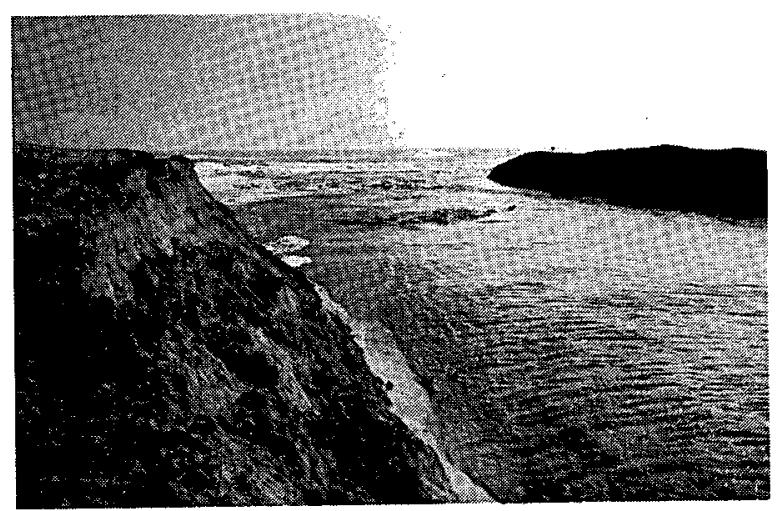

(b)

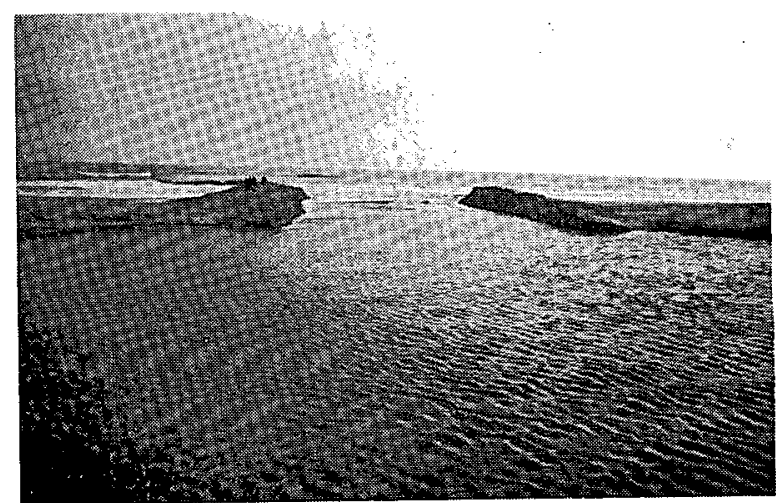

(d)

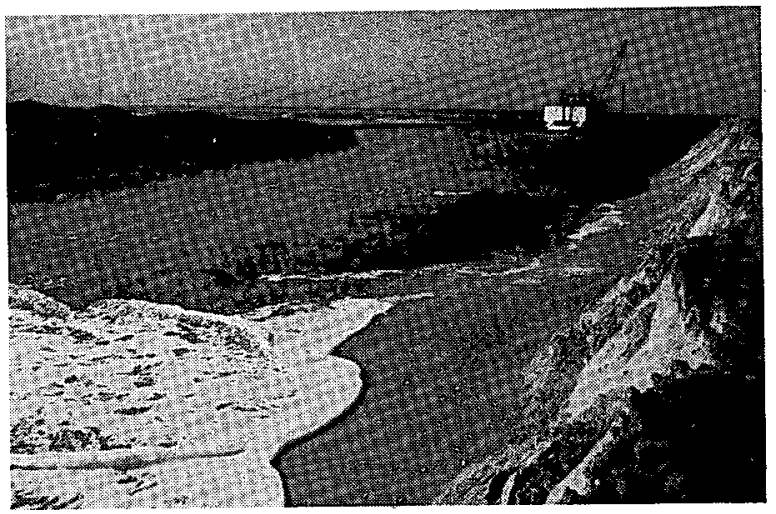

(f)

Fig. 20. Postshot view of the Drum Inlet channel, 23 December 1971. These photographs were taken about an hour after the detonation.

the crater caused by the remaining subsurface mound material. Depth of the center mound or bar was estimated to be 1 to $3 \mathrm{ft}$ below water level at this time.
The photographic helicopter is visible in the background of Fig. 20c. In Fig. 20e, note the small pleasure boat traversing the dredge channel (foreground) and the 


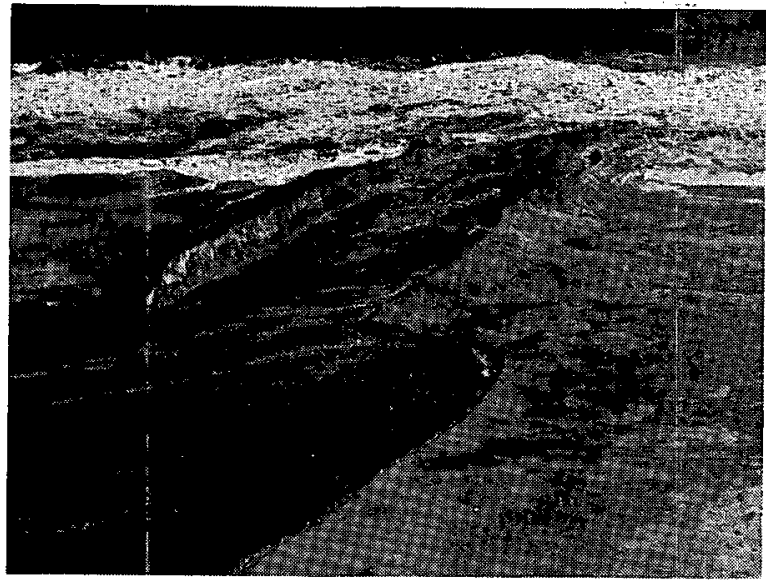

(a)

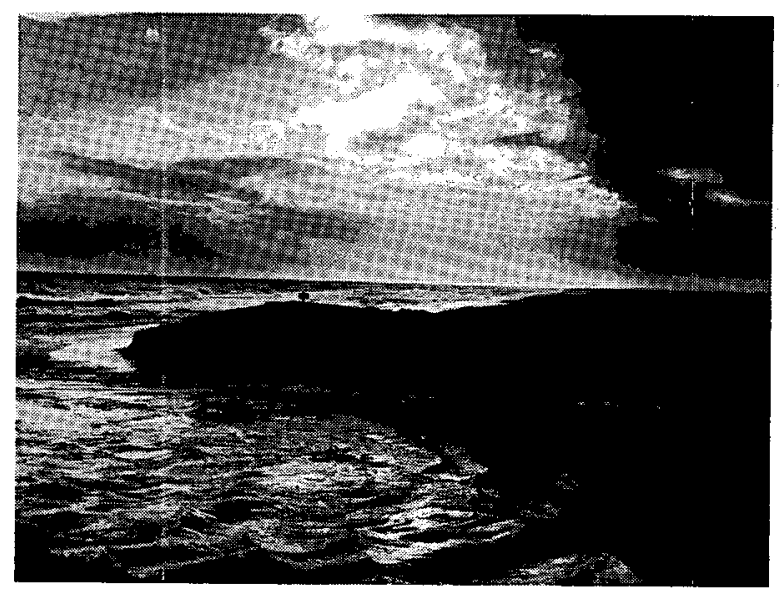

(c)

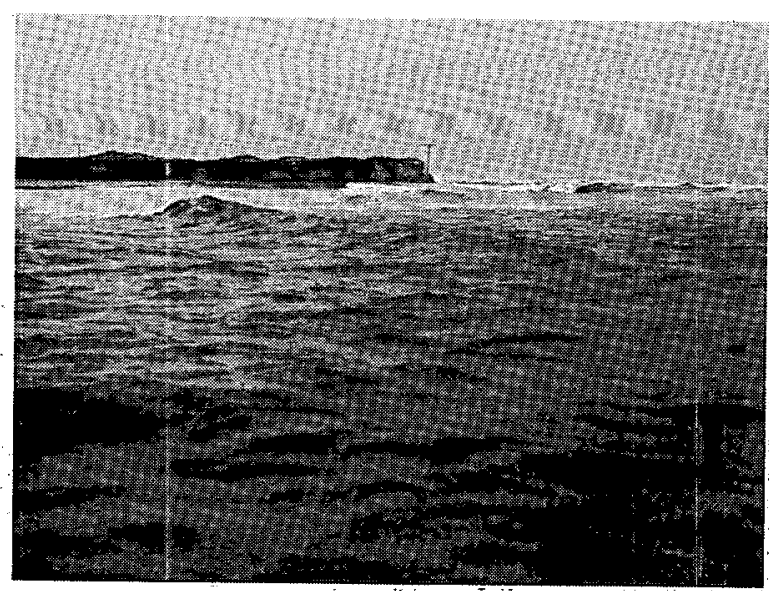

(e)

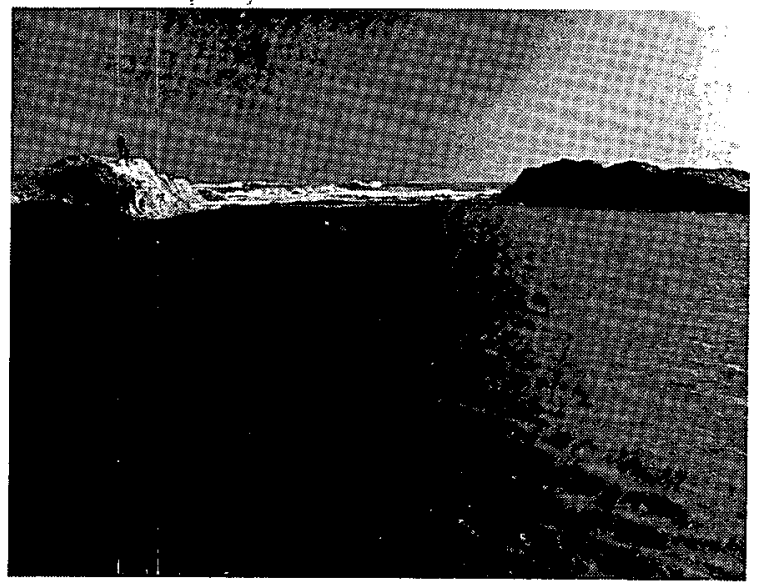

(b)

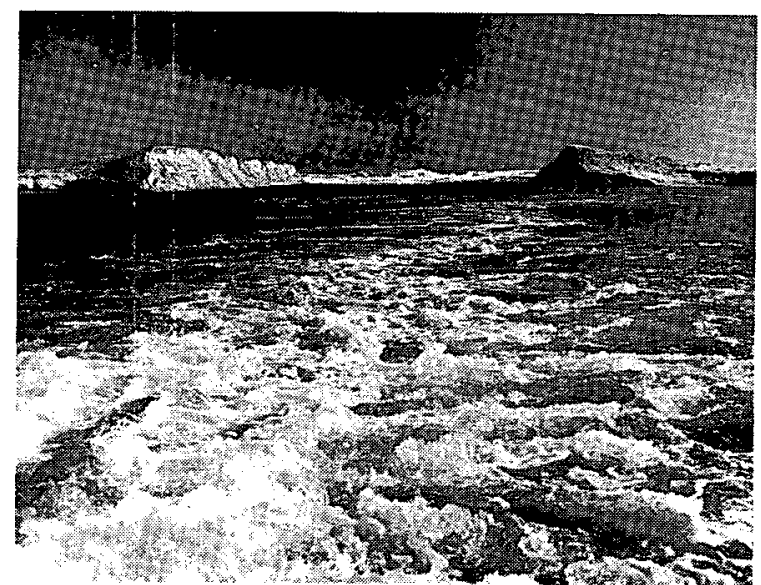

(d)

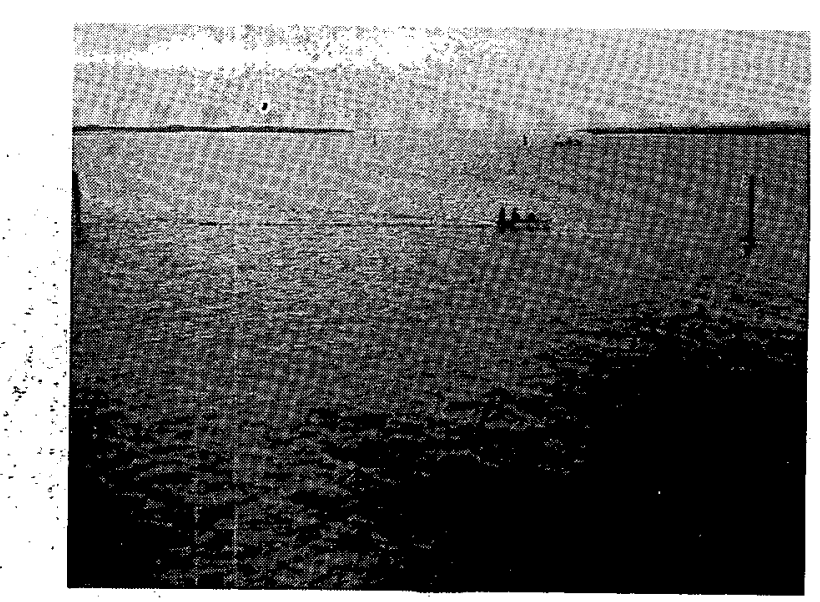

(f)

Fig. 21. Postshot views of the Drum Inlet channel immediately after the shot and 19 days later. The first four photographs show the channel immediately after the detonation, on 23 December 1971. The last two photographs, taken on 11 January 1972, show the channel after tidal forces widened it to a width of about $1000 \mathrm{ft}$. 
men standing on the lip of the crater. Figure $20 \mathrm{f}$ depicts the departure of the spectator craft (in the dredge channel), as viewed from the north lip of the crater.

Additional photographs of the Drum Inlet channel are given in Fig. 21. Pictures $21 \mathrm{a}-21 \mathrm{~d}$ were taken about $30 \mathrm{~min}$ to $2 \mathrm{hr}$ postshot; $21 \mathrm{e}$ and $21 \mathrm{f}$ show the inlet configuration 19 days later. Figure 21a is an aerial photograph taken shortly after the event; the connection to the dredge cut is visible in the foreground, and the steep, clearly defined side lips are quite evident. Note the heavy breakers on the ocean beach. It is thought that these breakers assisted in demolishing the narrow offshore lip very soon after the shot. Figures $21 \mathrm{~b}$ and $21 \mathrm{~d}$ are ground-level views of the channel as seen from the dredge cut. Figure 21c shows the south seaward end of the crater lip. Note that the connecting offshore lip had been completely washed away at the time of this photograph.

Figures $21 \mathrm{e}$ and $21 \mathrm{f}$ are ground-level photographs taken on 11 January 1972, after tidal forces had eroded the channel to a width of about 700-1000 ft. Figure $21 \mathrm{e}$ was photographed from the Outer Banks, looking across the new inlet. Figure $21 \mathrm{f}$ presents a view of the inlet as seen from the Core Sound navigation channel (posts in the foreground are channel markers). The inlet was clear for navigation at the time of these photographs, but shoaling effects were already apparent within Core Sound.

\section{Technical Program Results}

Technical studies conducted in conjunction with the Drum Inlet project fall into two classes: (1) long range investigations concerned with inlet formation and dynamics, and (2) investigations directly related to the explosive event. Long range studies, carried out by Wilmington District, CERC, the Waterways Experiment Station, and the National Park Service, encompass the following topics: (1) investigations of the effects of inlet closure on island formation and the succession of ecosystems at the old inlet location; (2) studies of the stabilization of dredge spoil areas with artificially planted salt marsh grass; (3) determination of the manner in which an artificial inlet achieves equilibrium with the prevailing natural processes; (4) identification of the natural processes which influ- ence the character and properties of the inlet; (5) determination of the hydraulic properties of the inlet, particularly the dependence of tidal current velocities upon tidal differential, cross-sectional size and shape, and channel roughness; (6) measurement of the effect of a small inlet-upon tidal characteristics of the enclosed sound; and (7) effectiveness and success of small inlet excavation. In order to accomplish these goals, a oneyear program was planned to monitor tides, current velocities, wave heights, and winds at the new inlet. Topographic and hydrographic surveys were also included. Results of these basic research programs, which should contribute to the understanding of inlet mechanics, will be reported by the individual participants. 
Technical programs conducted by EERL were limited to the immediate effects of the explosive event. Results of the following investigations are reported in this section: (1) cloud formation, (2) spall mound growth, (3) stem ejection and venting effects, (4) fish kill and underwater effects, (5) ejecta velocities, and (6) cratering dynamics. The scope of these studies was somewhat restricted by operational and economic considerations.

\section{Cloud Formation}

The Drum Inlet cloud exhibited the two-cloud structure which typifies buried cratering events. Initial spall launch produced a tall, thin, column-shaped main cloud extending along the entire axis of the cut. The ends of this cloud (above the submerged and disposal charges) were tall and contained a large amount of white water spray. The center of the cloud (above the sand charges) was shorter and consisted primarily of dark sand material. At times after $+3 \mathrm{sec}$, suspended particles began to fall and swirl outward, producing the flattened, pancake-shaped base cloud: Late-time. cloud forms may be seen in Figs.'14f : and $16 \mathrm{~d}$.

Drum Inlet cloud dimensions-were measured as a function of time using selected frames from the three groundlevel cameras; some supplementary data were derived from the aerial-photography. The cloud outgrew camera frame sizes at late times, but the zoom lens of the Canon movie camera was carefully adjusted through a known focal length interval $(25 \rightarrow 13 \mathrm{~mm})$ to follow the growth.
Photographically measured dimensions and displacements are subject to errors caused by the following factors: incorrectly established scale, geometric effects away from the camera's line of sight (optical axis), camera frame jitter, camera vibration, normal measurement or film orientation errors, cloud growth, and wind-induced cloud motion. If dimensions are calculated from lens focal length and camera position (rather than from a known scale or reference points on the film), additional errors may be introduced by uncertainty in lens focal length, uncertainty of the camera position, and shrinkage or changes in the photographic emulsion. Measured times and velocities are also affected by errors in the zero reference time and uncertainties in the camera frame rate. The most serious errors affecting measured cloud sizes are usually attributable to geometric line-of-sight effects, cloud growth, and cloud motion. All vertical dimensions and dimensions perpendicular to the line of sight have been corrected for scale errors introduced by the $74.1^{\circ}$ inclination between the row axis and the camera's line of sight; no other geometric corrections have been applied. Other corrections are generally less than $10-15 \%$ in this case because the measured cloud dimensions were smaller than the camera-to-cloud distance. Errors in the measured base cloud heights may be larger than $15 \%$ because the edge of the base cloud moved rapidly toward the camera during its early growth, then moved rapidly away during cloud dispersal. Errors arising from wind-induced cloud motion cannot be established solely on the basis of data from one camera 
station. Due to the high wind velocities and rapid cloud transport, these errors were dominant for the Drum Inlet observations, and other geometric or measurement errors may be considered negligible. Wind motion of the cloud away from the camera had little effect on the intermediate-time observations, but rendered the very-late-time measurements inaccurate.

Cloud dimensions measured for the Drum Inlet experiment include the base cloud radii, $R_{b c}$, off the ends of the row and perpendicular to the row axis, main cloud heights, $\mathrm{H}_{\mathrm{mc}}$, at the center of the row and at the ends of the row, base cloud heights, $\mathrm{H}_{\mathrm{bc}}$, at the edge of the base cloud closer to the ground-level cameras (north edge), and the height of an anomalous plume which expanded toward the camera bunker from the north edge of the base cloud. Aerial photography was used to derive the base cloud radius perpendicular to the row axis (not visible from camera bunker) and the height of the tall main cloud plumes (which outgrew the ground-level camera frames at early time). Measured dimensions were in good mutual agreement and were consistent with expectations. The measured base-cloud radii off the ends of the row were slightly larger for the $35-\mathrm{mm}$ photographs than for the $16-\mathrm{mm}$ Canon film; this small discrepancy is attributed to the higher quality of the 35-mm photographs, which clearly revealed the faint white water spray at the outer edges of the base cloud. Base cloud radii were also affected by lateral displacement at late times; the cloud was translated eastward (toward the ocean end of the cut) from the viewpoint of the ground-level cameras. This error was corrected by taking the average of the measured radii off the ocean end and off the Core Sound end of the cut at any given time. This average was considered to be the true base-cloud radius off the ends of the row. The base cloud radius was calculated as follows: First, the total length of the base cloud, $\mathrm{L}_{b c}$, along the row axis direction was measured. The length of the charge configuration was equal to the row length plus the distance to the last disposal charge, or $350 \mathrm{ft}+175 \mathrm{ft}$ $=525 \mathrm{ft}$. Thus, the mean base-cloud radius beyond the ends of the row was given by

$$
\mathrm{R}_{\mathrm{bc}} \approx \frac{\mathrm{L}_{\mathrm{bc}}-525}{2} .
$$

Likewise, perpendicular to the row axis, the total width of the base cloud was $\mathrm{W}_{\mathrm{bc}}$. The two row axes were separated by about $40 \mathrm{ft}$, so the mean radius perpendicular to each row axis was

$$
\mathrm{R}_{\mathrm{bc}} \approx \frac{\mathrm{W}_{\mathrm{bc}}-40}{2} \text {. }
$$

Base-cloud growth rates perpendicular to the row axis could not be determined due to the lack of a time scale for the aerial photography. Therefore, only the final or stabilized base-cloud radius perpendicular to the axis was measured.

The Drum Inlet cloud configuration at very late time $(+35 \mathrm{sec})$ is shown in Fig. 22. Note the extensive base cloud with its associated plume, and the two tall end segments of the main cloud. The central portion of the main cloud had partially dispersed and was no longer visible in the photographs at this time. The remaining main-cloud material was 


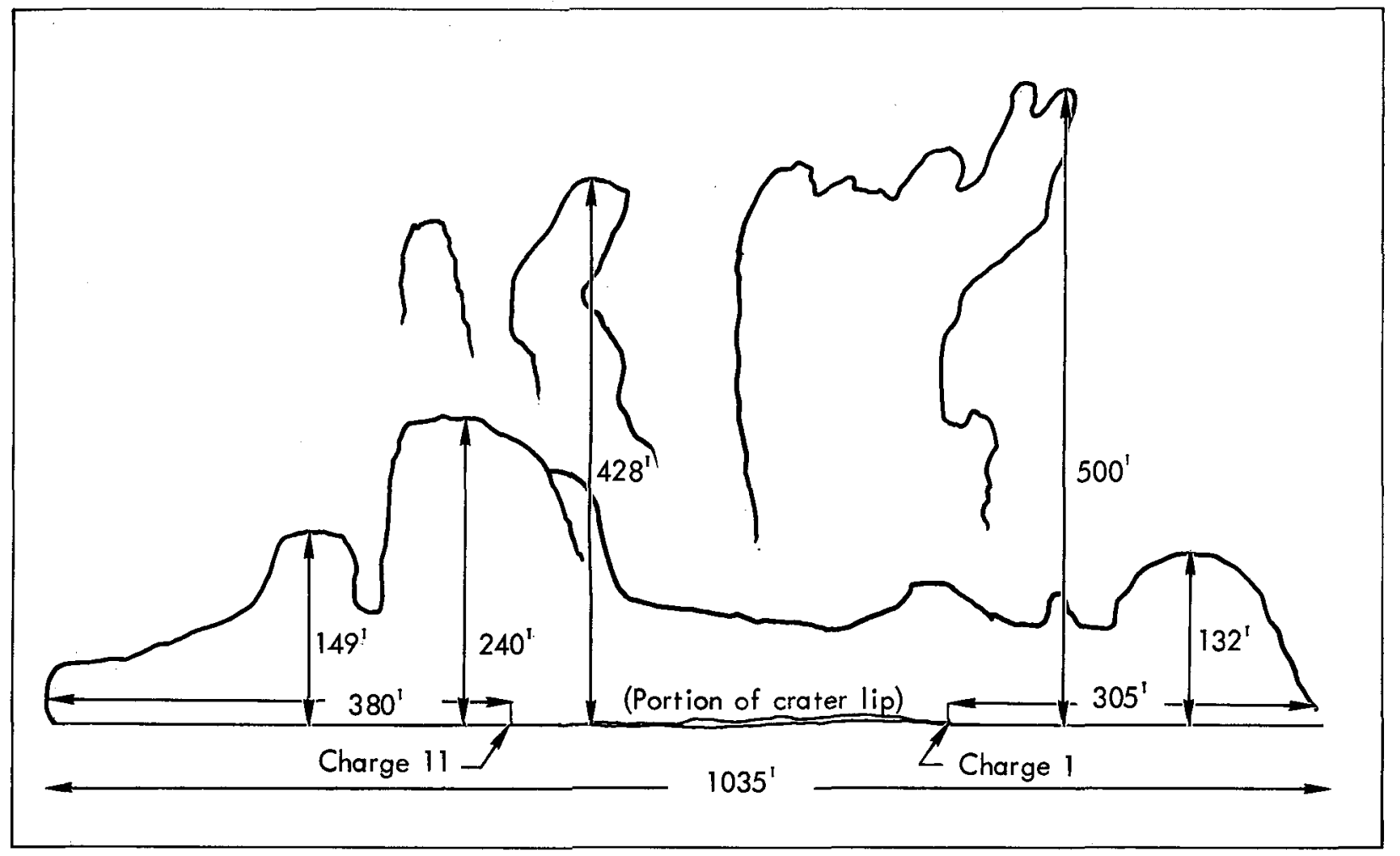

Fig. 22. Cloud dimensions at very late time, $+35.0 \mathrm{sec}$. (From picture taken with Canon 16-mm movie camera, wide angle lens, approximately $13-\mathrm{mm}$ focal length.)

very nebulous and consisted primarily of fine white water-spray. The base cloud radius (allowing for the row length and the disposal charges beyond charge 1) was determined to be

$$
R_{b c}=\frac{1035-525}{2}=255 \mathrm{ft} \text {. }
$$

The cloud heights were measured directly from the photograph (with the appropriate scale correction, as shown). The dimensions listed in Fig. 22 do not correspond exactly to the true stabilized dimensions; the cloud had suffered extensive wind motion which influenced these late-time measurements. In particular, the tall main-cloud plumes had moved far beyond SGZ (away from the camera location) and were rapidly descending and dispersing.
Thus, the listed main-cloud heights are less than the maximum heights.

Drum Inlet cloud dimensions have been measured over the entire phase of rapid cloud growth: The resultant growth rate curves are plotted in Fig. 23 (mean basecloud radius off the ends of the row), Fig. 24 (base cloud height and height of anomalous plume at north edge of base cloud), and Fig. 25 (main cloud height at the dense center portion, above the charges buried in sand). Figures 23 and 24 show measured early-time and latetime growth rate curves, as well as extrapolated late-time curves which have been roughly corrected for cloud motion relative to the cameras. The anomalous base cloud plume (Fig. 24) expanded rapidly toward the camera bunker at early to 


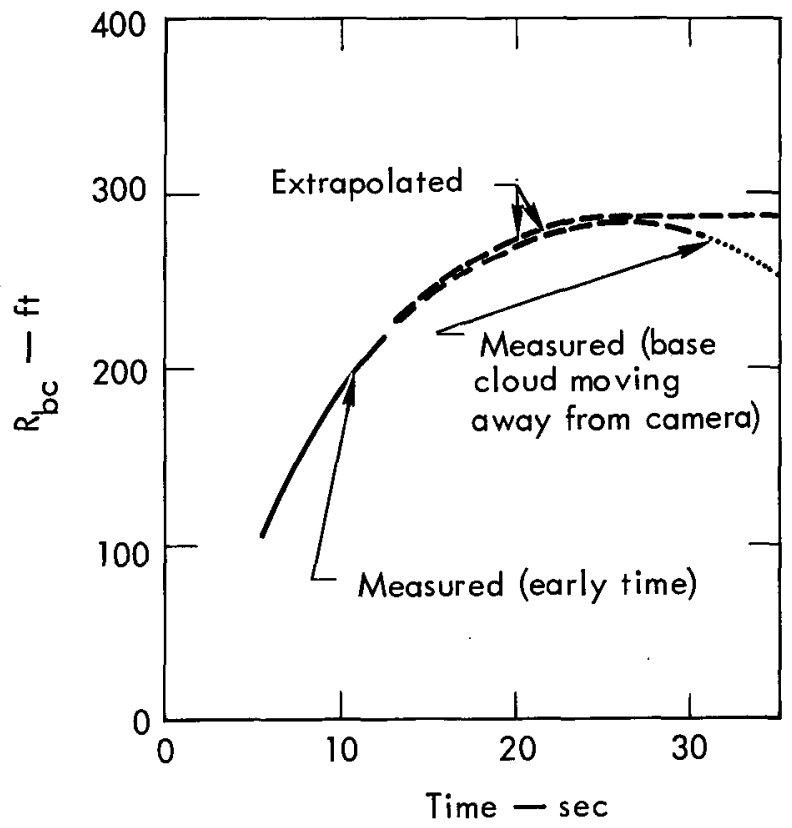

Fig. 23. Base cloud radius off ends of row as a function of time. (Radius measured beyond charge 11 at ocean end of row and beyond last disposal charge at Core Sound end of row; total base cloud length $\approx$ row length + dis tance to last disposal charge $+2 \mathrm{R}_{\mathrm{bc}} \approx 525 \mathrm{ft}+2 \mathrm{R}_{\mathrm{bc}}$.)

intermediate times, then began to recede at late times; thus, its measured heights are not extremely accurate. Note that the height of the central sandy portion of the main cloud (Fig. 25) decreased at late times; part of this apparent shrinkage was caused by cloud motion away from the camera, but part is believed to be real. This segment of the main cloud consisted primarily of coarse sand grains, with few fine particles. Thus, relatively rapid descent and depletion of the cloud is expected. The center portion of the main cloud dispersed and became photographically undetectable at times later than $15 \mathrm{sec}$.

The rapid growth phase was completed and the Drum Inlet clouds stabilized at
$3.4 \mathrm{sec}$ (center of main cloud) or 11-15 sec (base cloud). Approximate stabilized cloud dimensions are compiled in the last column of Table 3 . Typical dimensions for 1 -ton single-charge events at optimum depth of burial in other media are also listed for comparison. ${ }^{1,2,23}$ It is evident that the Drum Inlet cloud sizes are generally comparable to the 1-ton single-charge cloud dimensions in other media. The isolated base cloud plume reached a height of $200-250 \mathrm{ft}$ at a stabilization time of 11 to $12 \mathrm{sec}$ (not listed in table), but this feature was anomalous and should not be directly compared with other events. Drum Inlet main-cloud heights do differ slightly from those of other media: the height of the center sandy portion of the cloud $\left(\mathrm{H}_{\mathrm{mc}}=374 \mathrm{ft}\right)$ is smaller, while the maximum height of the spray cloud plumes at the ends of the row $\left(\mathrm{H}_{\mathrm{mc}} \approx 850 \mathrm{ft}\right)$ is larger. The plume heights are significantly greater than the observed heights for the 1 -ton Tugboat ${ }^{2}$ events in coral overlain by seawater (column 3); however, it should be noted that the submerged charges at the ends of the Drum Inlet rows were emplaced at shallower-than-optimum burial depth. The water spall velocities above these charges were also higher than the measured velocities for the Tugboat events (see below). In order to obtain a more accurate comparison, the spray plume height for a 1-ton TNT charge submerged in seawater was calculated. 24,25 A submersion depth of $19 \mathrm{ft}$ was assumed (the hydrostatic pressure at this depth is equivalent to the pressure beneath $8 \mathrm{ft}$ of sand $+3 \mathrm{ft}$ of seawater). Predicted plume height for the 1-ton TNT event in free water is $820 \mathrm{ft}$, comparable to 


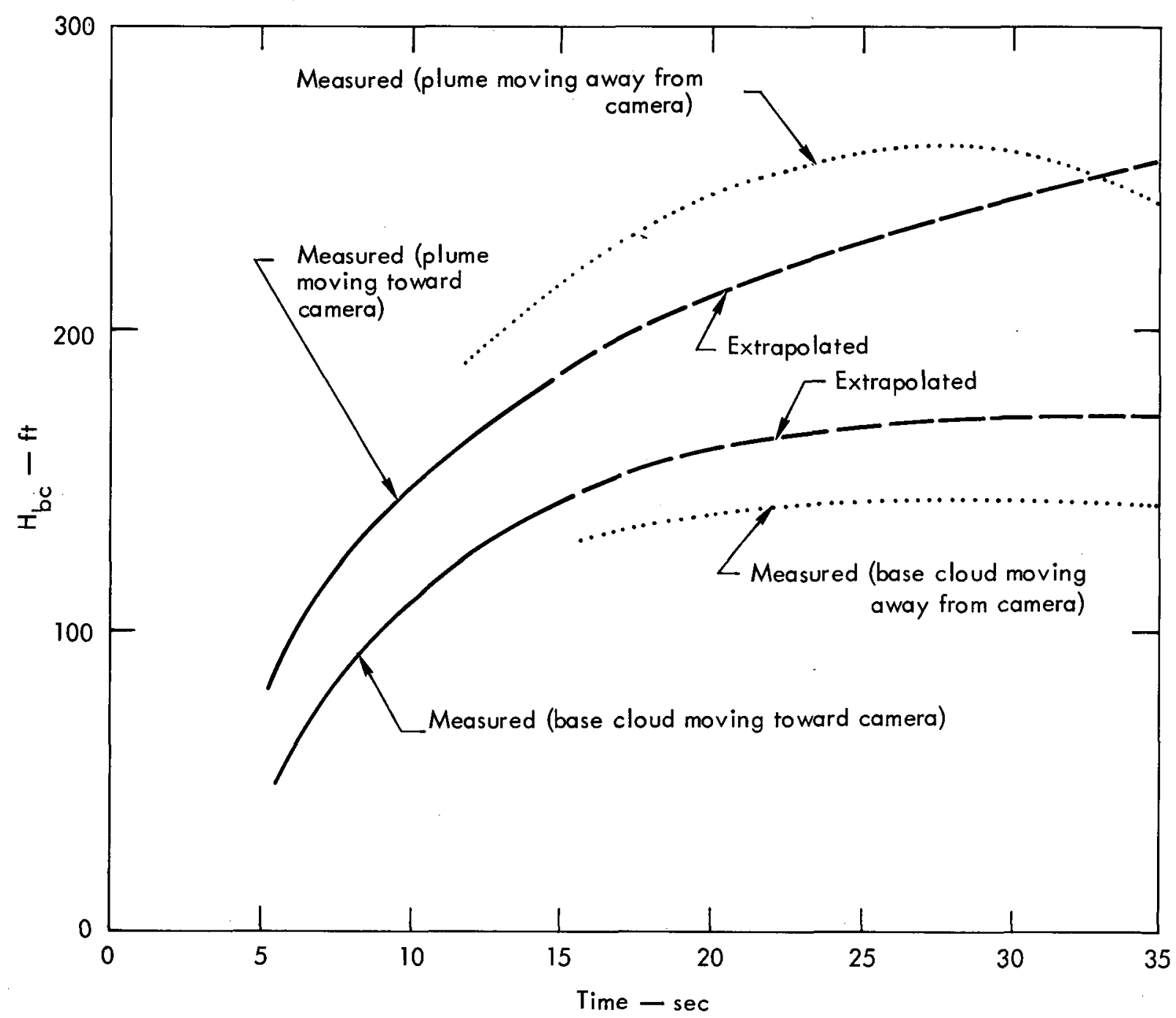

Fig. 24. Height of base cloud and base cloud plume as functions of time.

the measured Drum Inlet height. The : spray column diameters above individual charges 1 and 8 in the near row were also determined (last column of Table 3 ). These diameters were measured at rather early time (spray columns combined with the rest of the main cloud after $+0.15 \mathrm{sec}$ ). but they are quite similar to the Tugboat spray-column diameters: The shapes of spray columns produced by submerged: TNT charges vary dramatically with changes in depth of burst and bubble pulse dynamics $^{25}$; therefore, no direct comparison with underwater charges is attempted.
Perhaps the most interesting result of the Drum Inlet cloud investigation is the close similarity between the row-charge cloud dimensions and the dimensions for 1 -ton single-charge events in similar media. The stabilized base-cloud radii beyond the ends of the row and perpendicular to the row axis were nearly equal to base cloud radii for single-charge events at comparable depths of burial. Likewise, the base cloud height for the row charge event was equal to or slightly greater than single-charge base cloud heights. The task of predicting cloud 


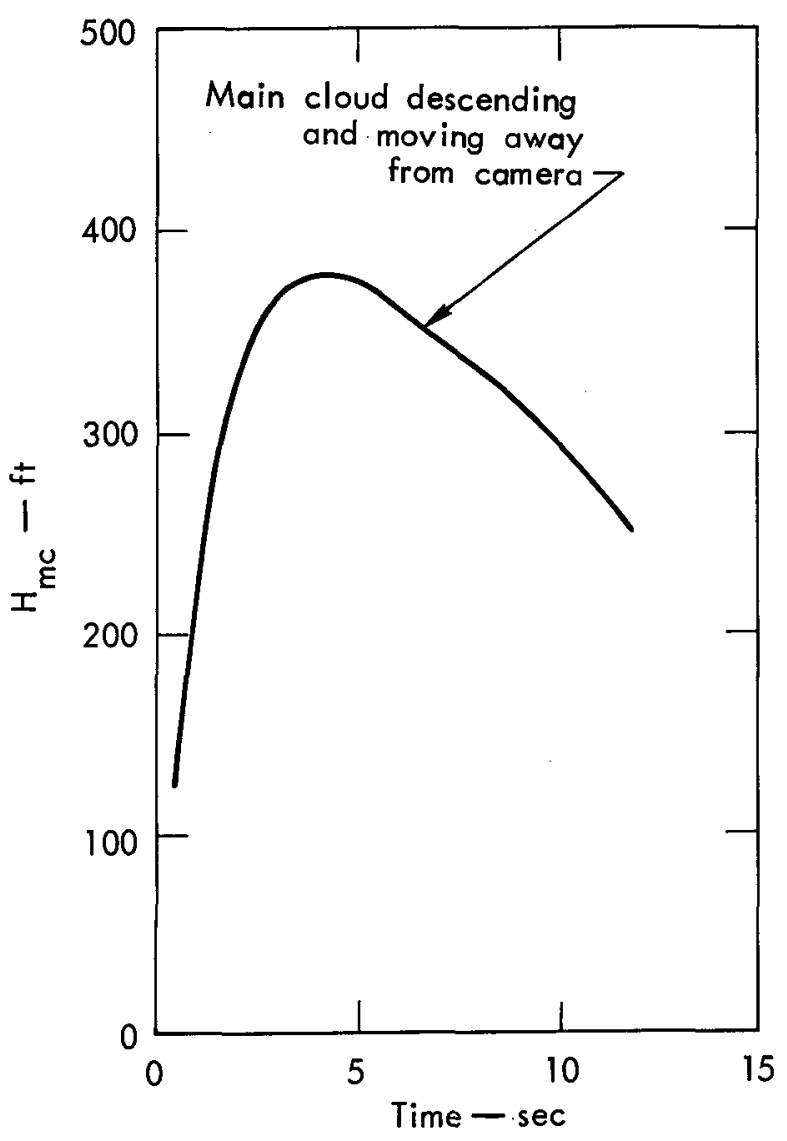

Fig. 25. Main cloud height as a function of time (sand cloud only, near center of row, charges 5 and 6 ).

sizes will be greatly simplified if analogous trends hold for large row-charge configurations in various other media.

The total extent of the Drum Inlet base cloud may be calculated by adding the stabilized radii to the dimensions of the charge rows. Thus, the total cloud length is given by

$$
\begin{aligned}
\mathrm{L}_{\mathrm{bc}}=2 \mathrm{R}_{\mathrm{bc}}+525 \approx & 2 \times 250 \\
& +525=1025 \mathrm{ft},
\end{aligned}
$$

and the width is

$$
\begin{aligned}
\mathrm{W}_{\mathrm{bc}}=2 \mathrm{R}_{\mathrm{bc}}+40 \approx 2 & \times 240 \\
& +40=520 \mathrm{ft} .
\end{aligned}
$$

These and other measured dimensions may be used in conjunction with best available empirical scaling relations to predict cloud sizes.

Mound Growth and Stem Ejection

Mound growth effects are important to verification of full-yield charge detonation, understanding of crater formation dynamics, and analysis of the airblast produced by a buried explosion. Accordingly, mean early-time velocities for charges at the Core Sound end and center of the near row were measured using the high-speed movie film. Water plume velocities and stem ejection phenomena were also observed. Due to the lack of surface motion targets and the relatively low time and space resolution of the photography, only the average ballistic velocities could be measured. The mean accuracy of the measurements is estimated to be about $\pm 25 \%$. Surface dis placement of the mounds was not visible prior to 0.02-0.04 sec. Nonetheless, there were no indications of separate early-time spall velocity and late-time gas-acceleration-induced velocity peaks. The measured ballistic velocities are believed to correspond approximately to true peak vertical spall velocities.

Mound and water plume growth above charges 1 through 8 is depicted in Fig. 26 $(0.039-0.150 \mathrm{sec})$. Vertical growth appears symmetrical and complete for all charges, but considerable mound cusping is evident between the sand charges $(3-7)$ and there was apparently little intercharge reinforcement of the velocity fields. Water spall launch velocities were very high, and water plumes outran the underlying sand spall above 
Table 3. Approximate stabilized cloud dimensions for Drum Inlet and for comparable 1-ton single-charge detonations near optimum depth of burial (15-20 ft).

\begin{tabular}{|c|c|c|c|c|}
\hline \multirow[b]{2}{*}{ Medium } & \multicolumn{4}{|c|}{ Dimensions ( $\mathrm{ft}$ ) } \\
\hline & $R_{b c}{ }^{a}$ & $\mathrm{H}_{\mathrm{bc}}$ & $\mathrm{H}_{\mathrm{mc}}$ & $\begin{array}{l}\text { Water-epray } \\
\text { column diam }\end{array}$ \\
\hline $\begin{array}{l}\text { Drum Inlet: sat- } \\
\text { urated sand, with } \\
\text { and without sea- } \\
\text { water overlay }\end{array}$ & $\begin{array}{l}200-250 \text {, off ends } \\
\text { of row }(11-15 \mathrm{sec} \\
\text { stabilization } \\
\text { time); } 240 \text {, perpen- } \\
\text { diculár to row } \\
\text { axis }\end{array}$ & $\begin{array}{l}140(11-15 \mathrm{sec} \\
\text { stabilization } \\
\text { time) }\end{array}$ & $\begin{array}{l}374 \text { (center of } \\
\text { sand cloud, near } \\
\text { charges } 5 \text { and } 6 \text {; } \\
3.4 \text { sec stabiliza- } \\
\text { tion time); } 500- \\
850 \text { (plumes of } \\
\text { white spray and } \\
\text { associated sand, } \\
\text { near ends of } \\
\text { rows)b }\end{array}$ & $\begin{array}{l}88 \text { (charge } 8), \text { and } \\
76(\text { charge } 1), c \\
\text { both at } 0.15 \mathrm{sec}\end{array}$ \\
\hline $\begin{array}{l}\text { Sandstone } \\
\text { (Ref. 23) }\end{array}$ & 230 & 63 & 492 & 一 \\
\hline $\begin{array}{l}\text { Saturated coral } \\
\text { overlain by sea- } \\
\text { water (Ref. } 2 \text { ) }\end{array}$ & 304 & 120 & $\begin{array}{l}\quad 543 \\
\text { (water spray and } \\
\text { coral) }\end{array}$ & $\begin{array}{l}70-116(0.4 \mathrm{sec} \text { or } \\
\text { later })\end{array}$ \\
\hline $\begin{array}{l}\text { Saturated clay } \\
\text { shale and weak } \\
\text { rock (Ref. 1) }\end{array}$ & 266 & $\begin{array}{l}70-180 \text { or } \\
\text { more }\end{array}$ & 600 & - \\
\hline
\end{tabular}

\footnotetext{
${ }^{a}$ Off ends of row: $R_{b c}$ measured beyond charge 11 off ocean end of row and beyond last disposal charge off Core Sound end of row. Total length of base cloud = row length + distance off end of row to last disposal charge $+2 R_{b c} \approx 525 \mathrm{ft}+2 R_{b c}$, where $R_{b c}=$ mean of measured base cloud radii off ocean and Core Sound ends of row.

Perpendicular to rows: $R_{b c}$ measured perpendicular to axis of each of the two rows, beside each row. Total width of base cloud = inter-row separation $+2 R_{b c} \approx 40 \mathrm{ft}+2 R_{b c}$, where $R_{b c}$ = mean of measured base cloud radii perpendicular to axis of each of the two rows.

${ }^{b}$ These heights refer to the spray plumes from the shallow charges at the ends of the rows. The maximum spray-plume height for a 1-ton TNT explosion in free water at a depth of $19 \mathrm{ft}$ (roughly equivalent to a hydrostatic head of $8 \mathrm{ft}$ of sand plus $3 \mathrm{ft}$ of water) is $820 \mathrm{ft}$ (Ref. 24 ).

${ }^{c}$ Water column diameters for these two charges were measured at relatively early time; the columns grew somewhat broader at late times, but measurements were not possible due to combination with adjacent-charge spray clouds.

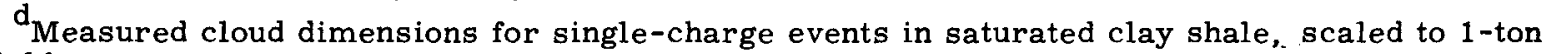
yield.

Base cloud is sometimes not well defined and distinct from the main cloud for clay shale; thus, the base cloud height may not be accurately determined.
}

submerged charges 1 and 8 (except for a few late-time, high-velocity ejecta).

Note that Fig. 26 also shows the primacord transit flash for five frames after first initiation $(0.0-0.0068 \mathrm{sec})$. Stem ejection plumes, omitted from the above figure, are sketched in Fig. 27 (0.026$0.187 \mathrm{sec})$. Both near-row and far-row plumes are shown for some of the charges. Note the widely variable appearance and growth rates of the various ejection plumes near the center of the row.

Mean velocities for the various features shown in Figs. 26 and 27 are listed in Tables 4 through 6 . Table 4 gives the sand-surface peak vertical spall velocities, $V_{0}$, at $S G Z$, for charges 3-7 (buried in sand only). Also given for charges 5-7 are the vertical velocities at various horizontal ranges on each side of SGZ. These velocities are expressed as a 


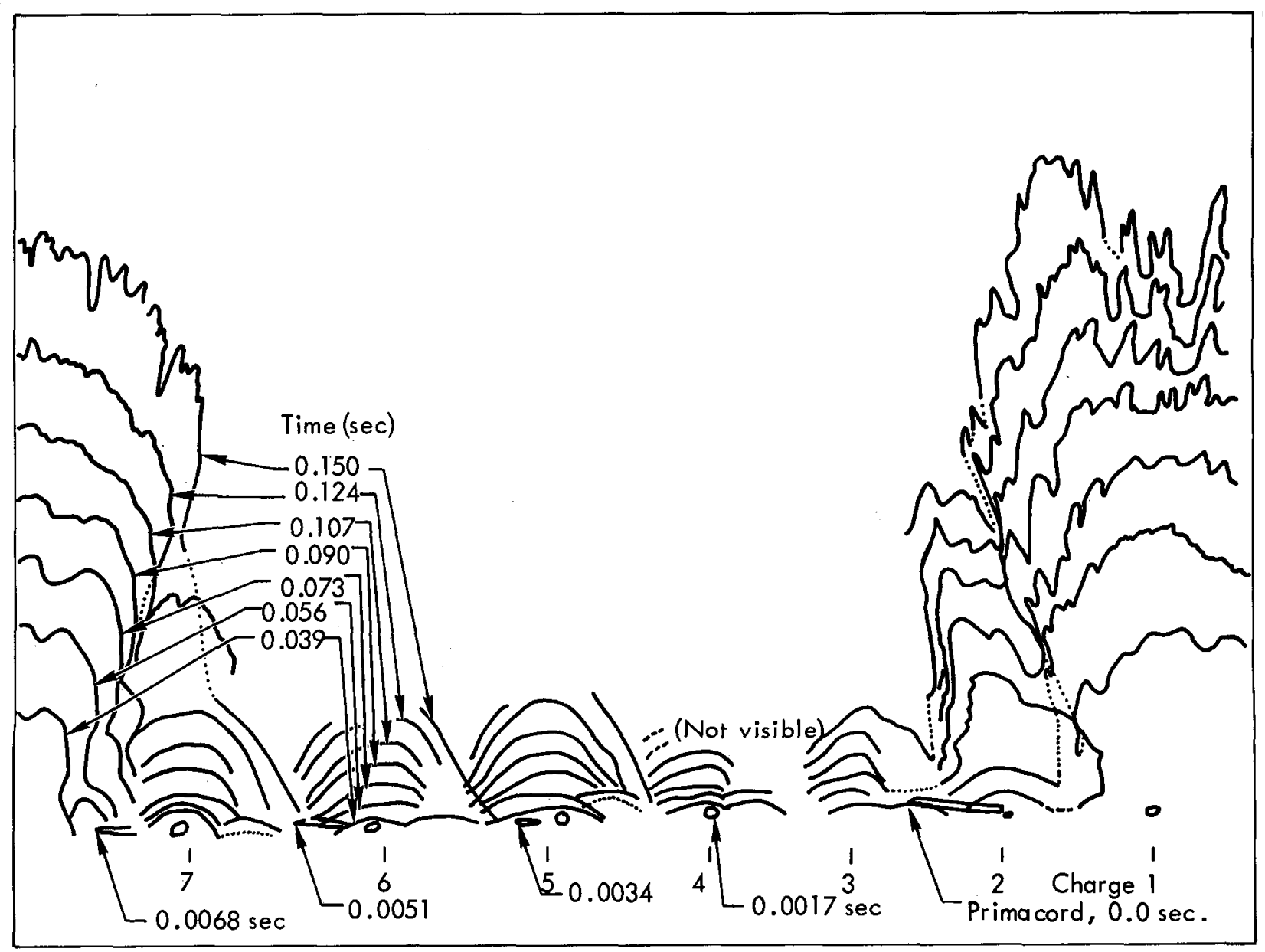

Fig. 26. Early-time mound and water-plume growth, charges 1 through 8 . (From photos made with Hycam 16-mm high-speed camera, 588 frames/sec.)

dimensionless ratio $\left(\mathrm{V} / \mathrm{V}_{0}\right)$, where $\mathrm{V}_{0}$ is the SGZ velocity measured for the charge. This conversion is used because peak vertical velocity profiles above singlecharge detonations usually follow a relationship of the form

$$
\left(\frac{\mathrm{V}}{\mathrm{V}_{0}}\right)=\left(\frac{\mathrm{DOB}}{\mathrm{S}}\right)^{\mathrm{n}}
$$

where

$$
\begin{aligned}
\mathrm{DOB} & =\text { depth of burial to the charge } \\
\text { center. } & \text {. }
\end{aligned}
$$

$\mathrm{S}=$ slant range from the charge to the ground surface location at which $\mathrm{V}$ is measured,

$\mathrm{n}=$ positive constant, $\mathrm{n} \approx 2$.
The horizontal range from SGZ is equal to $\left[\mathrm{S}^{2}-(\mathrm{DOB})^{2}\right]^{1 / 2}$.

The velocity ratios $\left(\mathrm{V} / \mathrm{V}_{0}\right)$ at long horizontal ranges (small DOB/S) were measured on the basis of the relative vertical displacement (i.e., mound shape) at late time $(\sim 0.150 \mathrm{sec})$; these values may be systematically too small by several percent because shock wave arrival and spall launch occur slightly later at longer ranges from SGZ. True time-dependent surface velocities far from SGZ could not be accurately determined due to inadequate resolution. All velocities listed in Table 4 are assumed to be in the vertical direction; mound growth appeared to be 


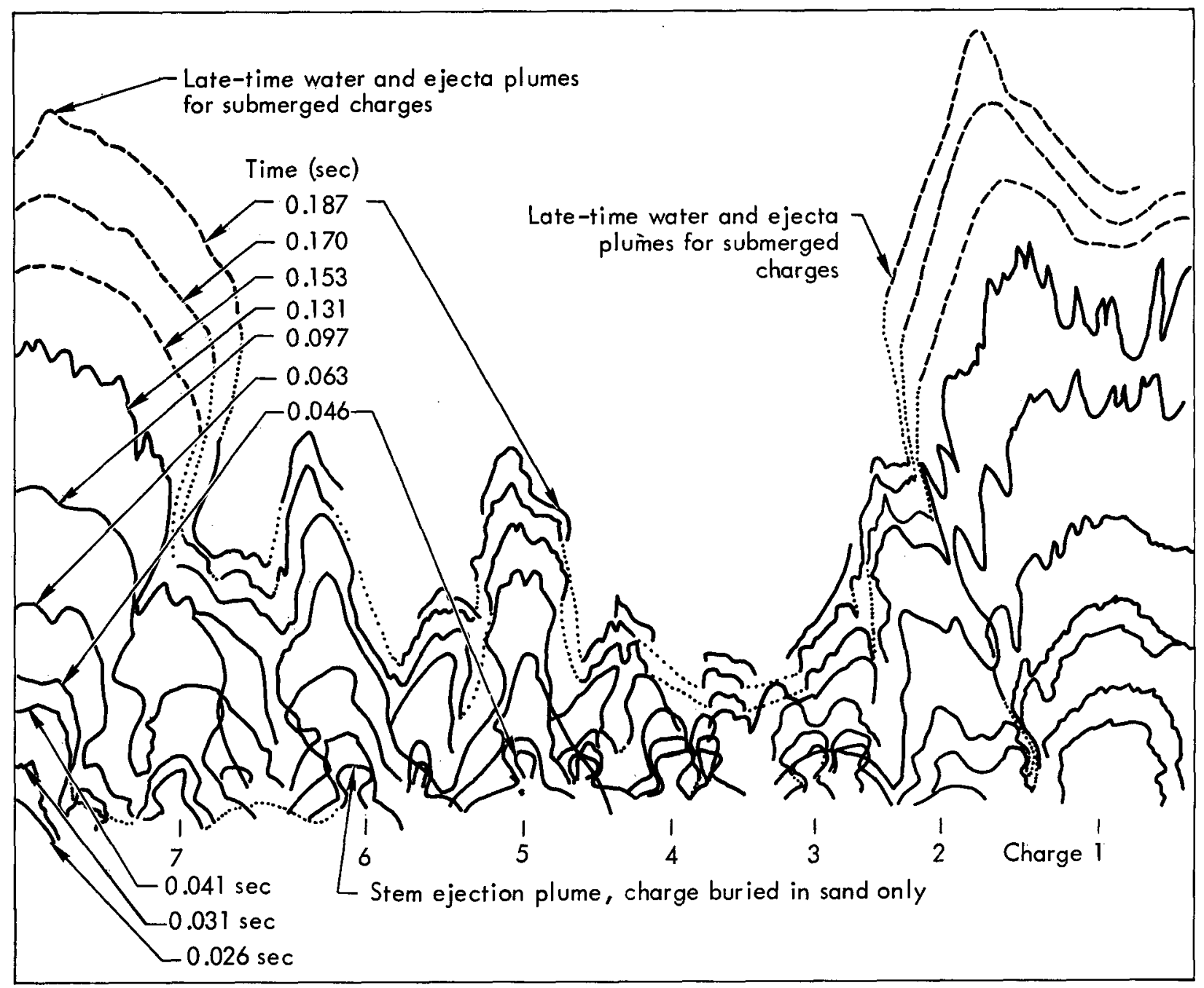

Fig. 27. Early-time stem ejection and plume development, charges 1 through 8 .

(From photos made with Hycam 16-mm high-speed camera, 588 frames/sec.)

almost completely vertical, as expected for a saturated medium. There wàs no indication of large horizontal spall velocity components, or of late-time gas venting with horizontal disruption of the mounds.

The only observable vent effects for the Drum Inlet charges were localized quite close to SGZ, and occurred at very early times. Most of the charges buried in sand $(2-7)$ violently ejected a narrow column of stem material near the emplacement site. These stem vent or stem ejection plumes began to develop about
0.005 to $0.009 \mathrm{sec}$ after individual charge initiation (much earlier than any normal. gas-vent phenomena associated with 1-ton charges at optimum burial depth), and violent acceleration of the material continued until about t0.017 sec. The vent plumes than ceased to accelerate rapidly and underwent steady ballistic growth at nearly constant velocities. The intensity and direction of stem vent were quite irregular along the row. Charge 2 (near row) did not produce a violent vent, although weak material ejection was visible at $+0.015 \mathrm{sec}$. Charge 2 (far row), 
Table 4. Measured sand-surface peak vertical spall velocities and spall velocity profiles for the Drum Inlet detonation, charges 3 through 7 . (The other charges were overlain by seawater, and water plumes rendered the sand mound growth invisible. Velocities for charge 3 are approximate.) All measurements obtained from $16-\mathrm{mm}$ Hycam film, taken at $588 \mathrm{frames} / \mathrm{sec}$. Velocities measured vertically, from preshot ground surface plane.

\begin{tabular}{|c|c|c|c|c|c|c|c|}
\hline $\begin{array}{c}\text { Charge } \\
\text { No. }\end{array}$ & $\begin{array}{c}\mathrm{DOB} \\
(\mathrm{ft})\end{array}$ & $\begin{array}{c}\text { Horizontal } \\
\text { range from } \\
\text { charge } \\
\text { SGZ (ft) }\end{array}$ & $\left(\frac{\mathrm{DOB}}{\mathrm{S}}\right)$ & $\left(\frac{\mathrm{DOB}}{\mathrm{S}}\right)^{2}$ & $\begin{array}{l}\text { Veloc- } \\
\text { ity } \\
\text { ratio, a } \\
\frac{V}{V_{0}}\end{array}$ & $\begin{array}{c}\mathrm{V}_{0} \text { at } \\
\mathrm{SGZ} \\
(\mathrm{ft} / \mathrm{sec})\end{array}$ & $\begin{array}{c}\text { Time } \\
\text { interval over } \\
\text { which } \mathrm{V}_{0} \text { was } \\
\text { measured } \\
\text { (sec) }\end{array}$ \\
\hline 3 & 15.5 & $0(\mathrm{SGZ})$ & 1.0 & 1.0 & 1.0 & 215 & $0.039-0.124$ \\
\hline $4^{b}$ & 16.5 & $0(\mathrm{SGZ})$ & 1.0 & 1.0 & 1.0 & 144 & $0.039-0.107$ \\
\hline \multirow[t]{8}{*}{5} & 16.5 & 20 & 0.637 & 0.406 & $(0.254)$ & - & \\
\hline & & 15 & 0.740 & 0.548 & 0.481 & - & \\
\hline & & 10 & 0.855 & 0.731 & 0.759 & - & \\
\hline & & 5 & 0.958 & 0.917 & 0.962 & - & \\
\hline & & $0(\mathrm{SGZ})$ & 1.0 & 1.0 & 1.0 & 239 & $0.039-0.124$ \\
\hline & & 5 & 0.958 & 0.917 & 0.937 & - & \\
\hline & & 10 & 0.855 & 0.731 & 0.734 & 一 & \\
\hline & & 15 & 0.740 & 0.548 & 0.468 & - & \\
\hline \multirow[t]{8}{*}{6} & 15.5 & 20 & 0.613 & 0.375 & $(0.199)$ & - & \\
\hline & & 15 & 0.719 & 0.516 & $(0.448)$ & 一 & \\
\hline & & 10 & 0.841 & 0.707 & 0.720 & 一 & \\
\hline & & 5 & 0.952 & 0.907 & 0.976 & 一 & \\
\hline & & $0(\mathrm{SGZ})$ & 1.0 & 1.0 & 1.0 & 225 & $0.039-0.124$ \\
\hline & & 5 & 0.952 & 0.907 & 0.942 & 一 & \\
\hline & & 10 & 0.841 & 0.707 & 0.824 & 一 & \\
\hline & & 14 & 0.742 & 0.551 & 0.582 & - & \\
\hline \multirow[t]{7}{*}{7} & 13.0 & 20 & 0.545 & 0.297 & $(0.144)$ & 一 & \\
\hline & & 15 & 0.655 & 0.429 & 0.303 & - & \\
\hline & & 10 & 0.793 & 0.628 & 0.735 & - & \\
\hline & & 5 & 0.934 & 0.872 & 0.938 & 一 & \\
\hline & & $0(\mathrm{SGZ})$ & 1.0 & 1.0 & 1.0 & 229 & $0.039-0.124$ \\
\hline & & 5 & 0.934 & 0.872 & 0.963 & 一 & \\
\hline & & 10 & 0.793 & 0.628 & $(0.774)$ & - & \\
\hline
\end{tabular}

\footnotetext{
${ }^{a}$ Most velocity ratios were determined for a time of $0.124 \mathrm{sec}$ after zero time; those in parentheses were determined for a time of about $0.150 \mathrm{sec}$, on the basis of comparisons with adjacent displacements closer to SGZ.

${ }^{\mathrm{b}}$ Mound growth was obscured at late times and appeared somewhat retarded and incomplete for this charge.
} 
Table 5. Sand plume (stem vent) ballistic ejection velocities for the Drum Inlet detonation, charges 3 through 6. All measurements obtained from 16-mm Hycam film, taken at 588 frames $/ \mathrm{sec}$. The maximum plume ejection velocities did not occur precisely in the vertical direction $\left(90^{\circ}\right)$; displacements and velocities were measured in the direction of fastest growth (peak velocity) perpendicular to the line of sight. This direction is listed in the table for each charge plume.

\begin{tabular}{ccccc}
\hline Charge & $\begin{array}{c}\text { Approx di- } \\
\text { rection from } \\
\text { horizontal } \\
\text { of peak } \\
\text { velocity } \\
\text { vector }(\mathrm{deg})\end{array}$ & $\begin{array}{c}\text { Time interval } \\
\text { for velocity } \\
\text { measurement } \\
\text { (sec after } \\
\text { zero time) }\end{array}$ & $\begin{array}{c}\text { Corresponding } \\
\text { displacement } \\
\text { interval (ft) }\end{array}$ & $\begin{array}{c}\text { Mean plume } \\
\text { velocity } \\
\text { (ft/sec) }\end{array}$ \\
\hline 6 & 85 & $0.046-0.187$ & $13-82$ & 489 \\
5 & 88 & $0.063-0.187$ & $17.5-77$ & 480 \\
4 & 77 & $0.046-0.170$ & $14-42$ & 226 \\
3 & 74 & $0.046-0.131$ & $13-29$ & 188 \\
\hline
\end{tabular}

Table 6. Measured radial water-plume velocities for the Drum Inlet detonation, charges 1 and 8. All measurements obtained from 16-mm Hycam film, taken at 588 frames $/ \mathrm{sec}$. Velocities were measured radially from the charge SGZ location. No corrections were applied for geometric line-of-sight effects away from the center of the plume; such corrections are not appreciable in this case due to the relatively small sizes of the plumes.

\begin{tabular}{|c|c|c|c|}
\hline $\begin{array}{c}\text { Charge } \\
\text { No. }\end{array}$ & $\begin{array}{c}\text { Direction from } \\
\text { horizontal } \\
\text { along which } \\
\text { velocity is } \\
\text { measured } \\
\text { (deg) }\end{array}$ & $\begin{array}{l}\text { Peak early- } \\
\text { time radial } \\
\text { plume velocity } \\
\text { (ft/sec) and } \\
\text { corresponding } \\
\text { time (sec) }\end{array}$ & $\begin{array}{l}\text { Mean radial } \\
\text { plume velocity } \\
\text { (ft/sec) and cor- } \\
\text { responding time } \\
\text { interval (sec) }\end{array}$ \\
\hline \multirow{6}{*}{$\begin{array}{l}\text { Charge } 1 \\
\text { (beneath } \\
7 \mathrm{ft} \mathrm{sand} \\
+4 \mathrm{ft} \\
\text { water) }\end{array}$} & $\begin{array}{l}90 \text { (vertically } \\
\text { above SGZ) }\end{array}$ & $1176(0.048)$ & $741(0.039-0.124)$ \\
\hline & 80 & $1000(0.048)$ & $777(0.039-0.124)$ \\
\hline & 80 & $1118(0.048)$ & $894(0.039-0.124)$ \\
\hline & 70 & $941(0.048)$ & $883(0.039-0.073)$ \\
\hline & 70 & $1059(0.048)$ & $718(0.039-0.124)$ \\
\hline & $60^{\mathrm{a}}$ & $765(0.048)$ & $549(0.039-0.090)^{a}$ \\
\hline \multirow{4}{*}{$\begin{array}{l}\text { Charge } 8 \\
\text { (beneath } \\
9 \mathrm{ft} \text { sand } \\
+2 \mathrm{ft} \\
\text { water) }\end{array}$} & $\begin{array}{l}90 \text { (vertically } \\
\text { above SGZ) }\end{array}$ & $941(0.048)$ & $802(0.039-0.150)$ \\
\hline & 80 & $941(0.048)$ & $775(0.039-0.150)$ \\
\hline & 70 & $882(0.048)$ & $604(0.039-0.150)$ \\
\hline & 60 & $706(0.048)$ & $459(0.039-0.150)$ \\
\hline
\end{tabular}

${ }^{a}$ Plume surface expansion was not radial at the $60^{\circ}$ direction in this case; therefore, the late-time plume surface displacements and velocities could not be accurately determined. 
under identical emplacement conditions, gave rise to an intense ejection plume which was apparent by $+0.008 \mathrm{sec}$.

Stem ejection is thought to have been caused by a combination of factors including the emplacement method and the large length-to-diameter ratio of the charges $(L / D$ ratio $=4.0)$. The water jetting technique left an incompletely mixed and inhomogeneous column of saturated material above each charge emplacement. This material was apparently ejected by the initial spall wave and by a "shotgun" pressure effect of the long charge cylinders. Stem ejection was not observed for any submerged charges but may have been obscured by water plume growth. "Late-time" velocities measured at the tip of each ejection plume are listed in Table 5 (charges 3-6, near row only; the plume for charge 7 was not clearly defined after $0.097 \mathrm{sec})$. These are essentially ballistic velocities measured at times after $+0.046 \mathrm{sec}$, and may be smaller than the true maximum velocities. Film resolution did not permit measurement of highly accelerated early-time motion. For each charge, the direction of fastest plume growth is given (vertical direction $=90^{\circ}$, followed by the time interval over which the velocity was determined, displacement of plume tip from SGZ (perpendicular to the line of sight), and calculated plume velocity. The ejection velocities vary between 188 and $489 \mathrm{ft} / \mathrm{sec}$, and are up to 2.2 times greater than the SGZ spall velocities for the individual charges; true maximum ejection velocities were probably even higher. Some of the effective cratering energy of the charges was dispersed during stem vent; in particular, energy loss to the lower layers of the saturated spall material may have been appreciable. It remains problematical whether stem ejection significantly decreased crater sizes and material ejection in this case (see below).

Mound growth near the ocean and Core Sound ends of the row was obscured by the high-velocity water spall. Waterspray plume growth appeared almost radial at early times, and formed vertical water columns about $80 \mathrm{ft}$ in diameter at later times. Plume surface velocities for charges 1 and 8 (near row) were measured along various directions radially away from the initial SGZ locations. Results are presented in Table 6 . The charge number is given, followed by the radial direction along which velocity was measured $\left(90^{\circ}=\right.$ vertical direction), the approximate peak early-time radial plume velocity $(t \approx 0.048 \mathrm{sec})$, and the mean radial plume velocity over a longer time interval. The mean velocities are always less than the early-time peak velocities, but are more accurately determined.

The peak vertical sand and water spall velocities at SGZ, as listed in Tables 4 and 6 , are plotted as functions of scaled depth of burial in Fig. 28. Also plotted for comparison are the measured and/or fitted spall velocities in saturated clay shale, ${ }^{26-28}$ saturated submerged coral (water surface), ${ }^{29}$ saturated coral (estimate), ${ }^{29}$ saturated concrete (1-1b C -4 charges), ${ }^{9}$ and moist sand (1-1b C-4 charges)." 6 The "moist sand" fits derive from measured surface velocities less than $170 \mathrm{ft} / \mathrm{sec}$ (events near or below optimum depth), and are thought to be inaccurate at high velocities. All scaled 


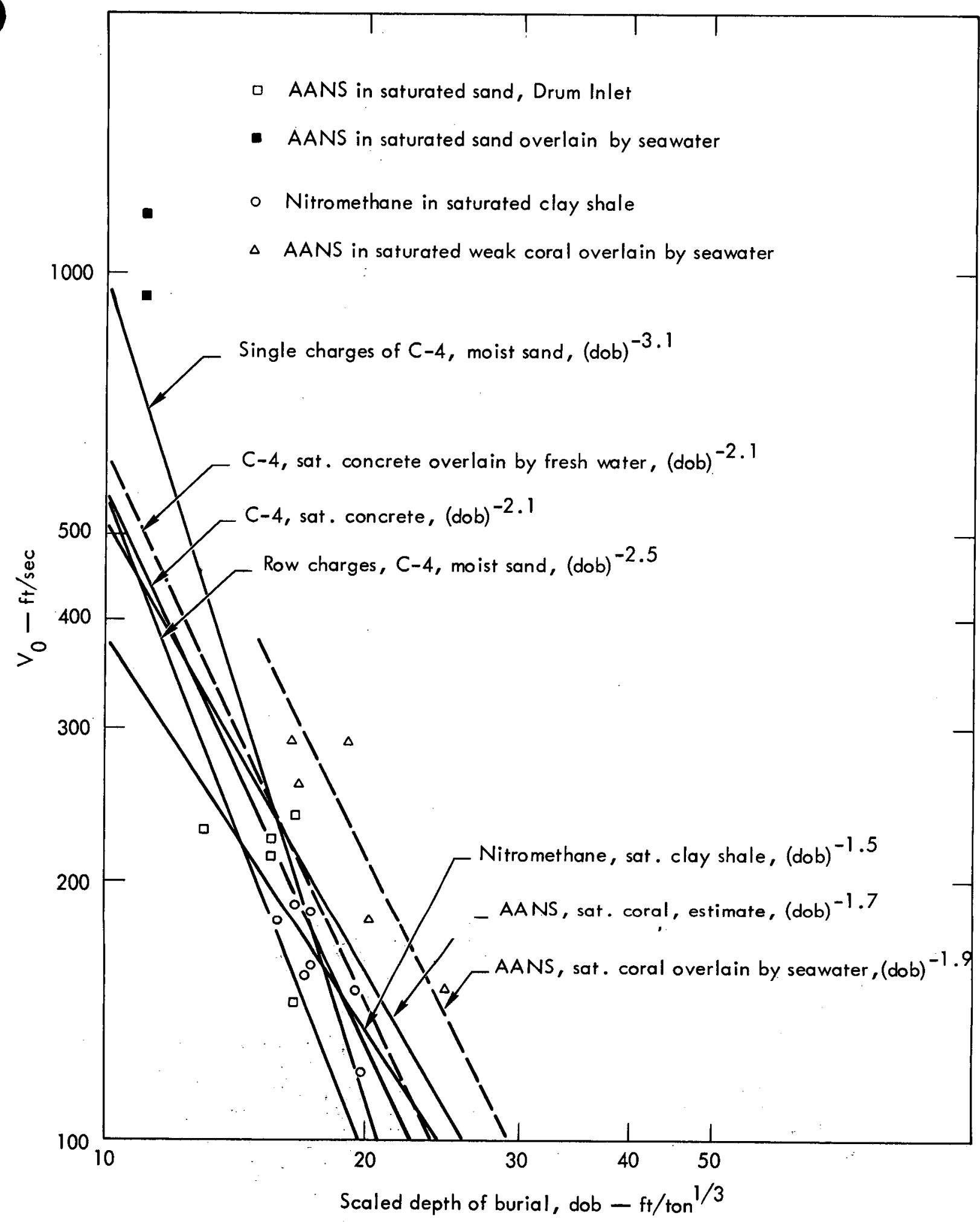

Fig. 28. SGZ peak vertical spall velocity, $V_{0}$, as a function of scaled depth of burial, $\mathrm{dob}$, for events in saturated media, moist sand, and saturated media overlain by water. 
burial depths are calculated on the basis of total charge depth (medium + water). Note that the Drum Inlet sand-surface spall velocities are comparable to the other saturated-medium surface velocities shown. Also, the water surface velocities (submerged events) are generally much higher than the surface velocities for cratering media with an overlying water layer.

The Drum Inlet sand spall velocity measurements were not sufficiently extensive and were not spread over a broad enough range in dob (scaled depth of burial) to permit an accurate fit. Therefore, an estimated spall velocity line has been drawn through the mean of the four higher velocity measurements, with a slope almost parallel to the fit for saturated concrete ${ }^{9}$ (concrete used in the modeling tests was made with fine sand similar to the Drum Inlet material and had about the same final density). The resultant fitted line, shown in Fig. 29 (together with comparison data for moist sand and concrete), is as follows:

$\mathrm{V}_{0} \approx 5.12 \times 10^{4}(\mathrm{dob})^{-2}\left(\mathrm{dob}\right.$ in $\left.\mathrm{ft} / \operatorname{ton}^{1 / 3}\right)$

Note that the fit is based on data for saturated sand overlain by a variably thick layer of less dense (incompletely saturated) sand. Peak spall velocities of completely saturated material layers are expected to be higher than the fit would indicate.

The Drum Inlet velocity profiles or velocity ratios $\left(\mathrm{V} / \mathrm{V}_{0}\right)$ for charges 5,6 , and 7 are plotted as a function of $(\mathrm{DOB} / \mathrm{S})^{2}$ in Fig. 30. The quantity (DOB/S $)^{2}$ has been used, instead of (DOB/S), so as to expand the horizontal scale of the $\log -\log$

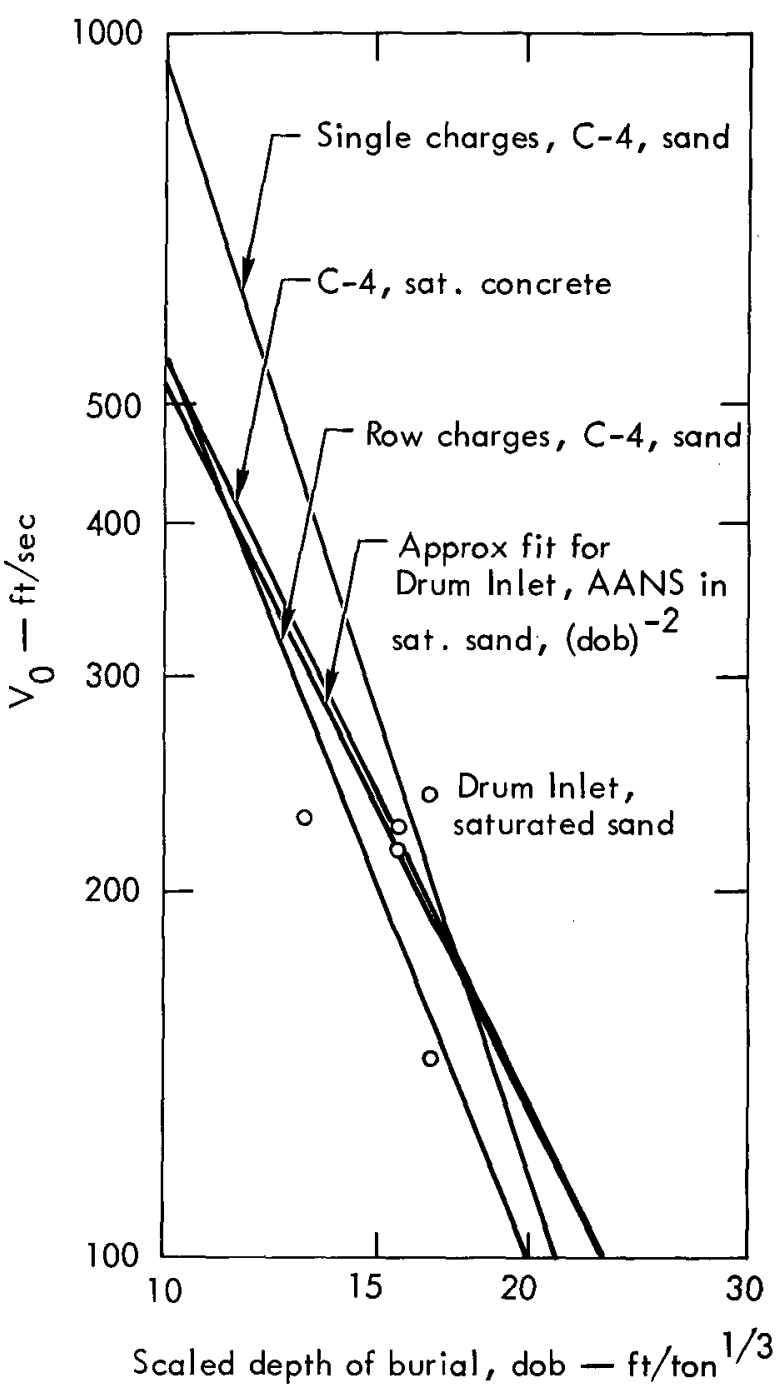

Fig. 29. SGZ peak vertical spall velocity as a function of scaled depth of burial, for sand and concrete.

graph. Also shown are the straight lines

$$
\frac{\mathrm{V}}{\mathrm{V}_{0}}=\left(\frac{\mathrm{DOB}}{\mathrm{S}}\right)^{\mathrm{n}} \text { for } \mathrm{n}=2,3 \text {, and } 6 \text {, }
$$

and a two-segment fit:

$$
\begin{aligned}
& \frac{\mathrm{V}}{\mathrm{V}_{0}}=1.174\left(\frac{\mathrm{DOB}}{\mathrm{S}}\right)^{3} \text { at } \frac{\mathrm{DOB}}{\mathrm{S}} \leq 0.948, \\
& \mathrm{~V}=\mathrm{V}_{0} \text { at } \frac{\mathrm{DOB}}{\mathrm{S}}>0.948 .
\end{aligned}
$$




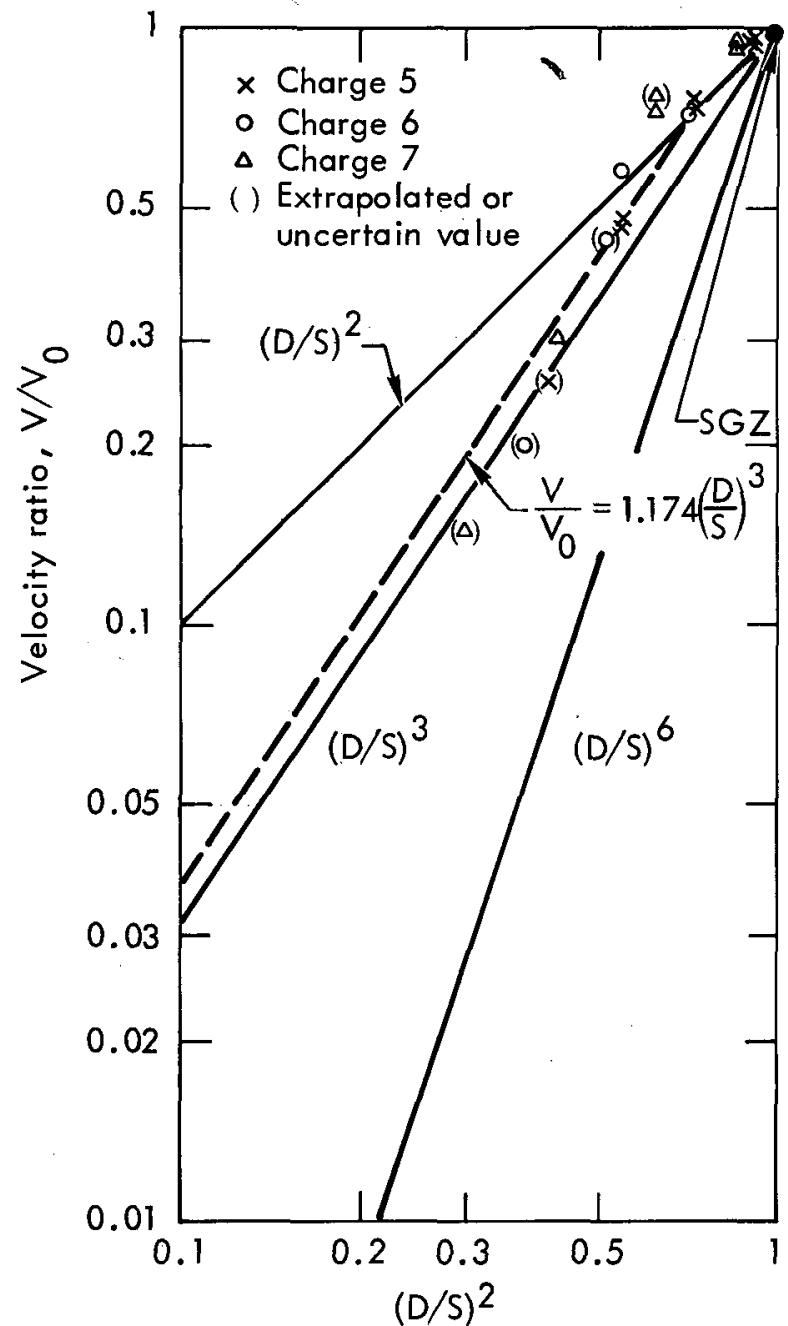

Fig. 30. Velocity ratio $\left(V / V_{0}\right)$ as a function of dimensionless slant range from shot point squared, $(\mathrm{D} / \mathrm{S})^{2}$, for charges 5, 6, and 7. (Here $\mathrm{D}$ is used as an abbreviation for DOB, depth of burial.)

The latter fit agrees well with the bestestablished velocity measurements (charge 5). Data for the other two charges indicate still higher velocity ratios very close to $\mathrm{SGZ}$ (at DOB/S $>0.79$ ). Note that the long-range $\mathrm{V} / \mathrm{V}_{0}$ values (in parentheses) are all slightly low relative to the straight-line fits; this effect is expected due to the small measurement errors mentioned previously. A velocity attenuation of $(\mathrm{DOB} / \mathrm{S})^{3}$ appears quite satisfactory at longer ranges, in view of the inherent uncertainty of the observations.

The anomalously high velocity ratios close to SGZ and "flat-topped" velocity mound shape shown in Fig. 30 have been observed for other events in saturated media. ${ }^{26}$ The cause is not known. It is possible that the large length-to-diameter ratio of the vertically emplaced charge cylinders may have accentuated the effect in this case. Such extended charges produce a stress field which is not spherically symmetric but instead is distorted lengthwise along the axis of the charge. The close-range pressure along the axial direction is higher than the pressure at the same scaled range from the center of a spherical charge, and the spall launch velocity is thus expected to be somewhat high close to SGZ (near the top of the vertically oriented canister).

The Drum Inlet spall velocity and velocity profile data may be used to estimate free-field shock transmission parameters for AANS explosive in saturated sand. ${ }^{29}$ According to acoustic transmission and reflection laws, the free-field peak particle velocity $\mathrm{V}_{\mathrm{f}}$ at scaled range $R_{S}$ from the center of the charge is given by

$$
\mathrm{V}_{\mathrm{f}}=\frac{1}{2} \mathrm{~V}_{0} \text {, }
$$

where $V_{0}$ is the free-surface vertical spall velocity directly above a charge at dob $=R_{S}$. If the velocity at SGZ, $V_{0}$, is known as a function of dob, the function $V_{f}\left(R_{S}\right)$ may be determined. Assume that

$$
\mathrm{V}_{0}=\mathrm{k}(\mathrm{dob})^{-\mathrm{m}}
$$

where $\mathrm{k}$ and $\mathrm{m}$ are constants for a given 
medium and explosive; then

$$
\mathrm{V}_{\mathrm{f}}=\frac{\mathrm{k}}{2}(\mathrm{dob})^{-\mathrm{m}}=\frac{\mathrm{k}}{2}\left(\mathrm{R}_{\mathrm{s}}\right)^{-\mathrm{m}}
$$

By a similar method, the free-field velocity may be calculated from a single known $V_{0}$ value (at 1 dob) and the velocity profile. Expressing all lengths in terms of scaled range, the surface velocity profile is described by an equation of the form

$$
\left(\frac{\mathrm{V}}{\mathrm{V}_{0}}\right)=\left(\frac{\mathrm{dob}}{\mathrm{R}_{\mathrm{S}}}\right)^{\mathrm{n}}
$$

where dob and $R_{S}$ are scaled depth of burial to the charge center and scaled slant range from the charge, respectively. The free-field particle velocity at any scaled range $R_{S}$ is then ${ }^{29}$

$$
\mathrm{V}_{\mathrm{f}} \approx \frac{1}{2} \mathrm{~V}_{0}\left(\frac{\mathrm{dob}}{\mathrm{R}_{\mathrm{S}}}\right)^{\mathrm{n}-1}
$$

Ignoring the small inconsistencies close to SGZ and the problems caused by the extended charge cylinder configuration, Drum Inlet velocity profiles approximately follow a $\left(\mathrm{dob} / \mathrm{R}_{\mathrm{s}}\right)^{3}$ law. Thus, both of the above techniques produce similar estimates of $V_{f}$ :

$\mathrm{V}_{\mathrm{f}} \approx 2.56 \times 10^{4} \mathrm{R}_{\mathrm{s}}^{-2} \quad\left(\mathrm{R}_{\mathrm{S}}\right.$ in $\mathrm{ft} /$ ton $\left.^{1 / 3}\right)$

or

$$
\begin{aligned}
& \mathrm{V}_{\mathrm{f}} \approx 2.56 \times 10^{6} \mathrm{R}_{\mathrm{S}}^{-2} \quad \begin{array}{l}
\left(\mathrm{R}_{\mathrm{S}}\right. \text { converted to } \\
\left.\mathrm{ft} / \mathrm{kt}^{1 / 3}\right) .
\end{array}
\end{aligned}
$$

Free-field velocity functions determined from spall velocity data apply only at close ranges (in the cratering region). Further from the charge, shock transmission becomes more nearly elastic.
Within the elastic regime, attenuation rates approach the acoustic value of $\mathrm{R}_{\mathrm{S}}^{-1.0}$. Based on reasonable assumptions about the transmission parameters in sand and on comparison with data for other media, the long-range velocity function may be estimated as

$$
\begin{aligned}
\mathrm{V}_{\mathrm{f}} \approx & 1.77 \times 10^{4} \mathrm{R}_{\mathrm{s}}^{-1.2} \\
& \left(\mathrm{R}_{\mathrm{S}}>500 \mathrm{ft} / \mathrm{kt}^{1 / 3}, \text { long range }\right) .
\end{aligned}
$$

The free-field peak particle velocity functions are plotted against scaled range in Fig. 31. Approximate transmission parameters for saturated sand are also listed. The data presented in this figure may be used to investigate shock trans mission and spall interactions for the

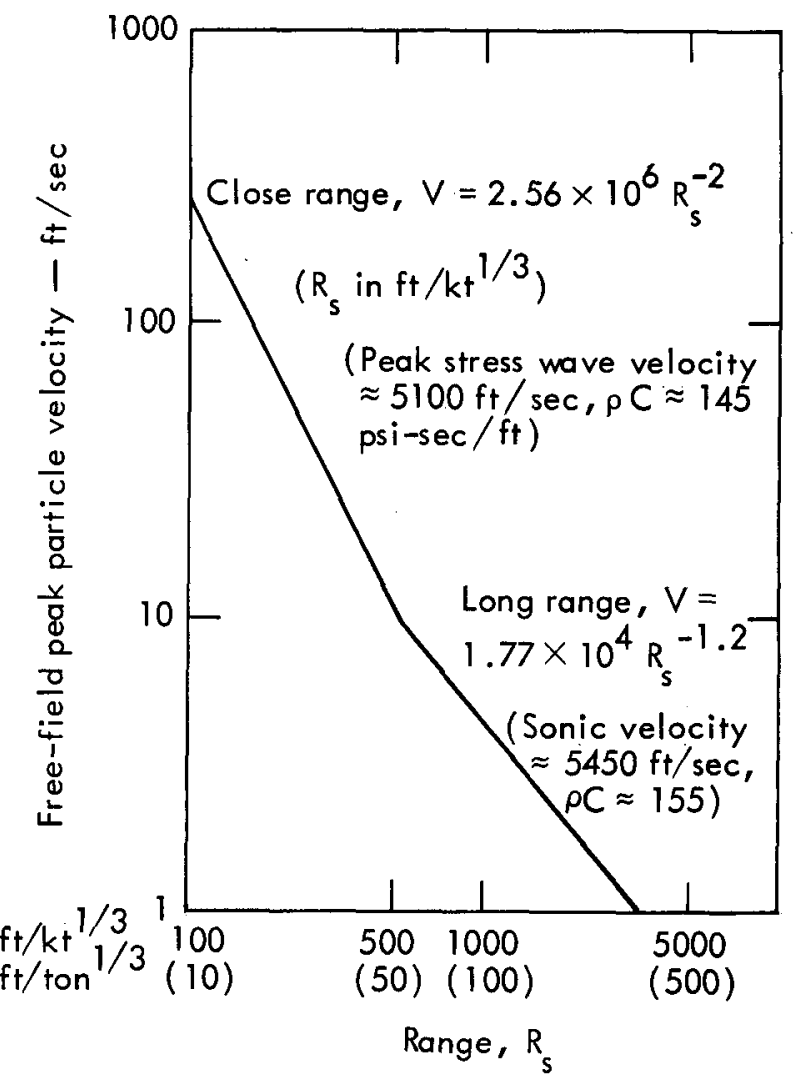

Fig. 31. Estimated free-field particle velocities as a function of range, for AANS explosive in saturated sand. 
Drum Inlet experiment. A simplified safety prediction computer code known as MULTIMEDIA is used for this purpose..$^{29}$ MULTIMEDIA is not a complete cratering dynamics code, but is a quasi-nonlinear. acoustic transmission analysis which calculates three-layer peak pressure transmission and reflection parameters for saturated media overlain by water. The code determines pressures within the layers, peak spall velocities at the interfaces, spall velocity profiles, etc. It also enables prediction of airblast overpressures in a third layer of air. MULTIMEDIA calculations for the Tugboat highexplosive experiments in submerged coral predicted that the underlying coralsurface interface would have a high spall launch velocity and would probably penetrate the water spray dome at early times, in agreement with observation. Airblast predictions were likewise consistent with experimental results. By contrast, calculations for the submerged concrete modeling experiments showed that the water surface should spall rapidly away from the underlying concrete, again in agreement with photographic observations of the experiment. Similar calculations. have been performed for Drum Inlet; the following input parameters were adopted to describe the water layer (seawater at $10^{\circ} \mathrm{C}$, Ref. 29):

Sonic velocity, $\mathrm{C}_{\mathrm{w}}=4890 \mathrm{ft} / \mathrm{sec}$.

Acoustic impedance, $\rho_{\mathrm{w}} \mathrm{C}_{\mathrm{w}}$

$$
=67.68 \mathrm{psi}-\mathrm{sec} / \mathrm{ft} .
$$

For typical charge emplacement configurations, results indicated that the water dome should outrun the sand spall, as was observed in the high-speed films. However, the predicted surface velocities were somewhat lower than experimentally measured values. Selected results, for submerged charges 1 and 8 , are presented in Table 7. Measured velocities are high by as much as $36 \%$ relative to the saturated sand predictions, and by $16 \%$ relative to the predictions for saturated concrete of similar density. At least five factors may contribute to the discrepancy: (1) Due to the large length-to-diameter ratio of the charges, explosive material was located very close to the sand-water interface, and shock contours were probably asymmetrical. This effect was particularly important for the shallowly buried submerged charges; at $D O B=7 \mathrm{ft}$, the top of the charge was only about. $3 \mathrm{ft}$ from the interface. Pressures were therefore anomalously high at very close ranges along the vertical axis, invalidating the spherical geometry used in the calculations and increasing the peak vertical spall velocities near SGZ. (2) The sand medium above the submerged charges was thoroughly saturated; there was no overlying layer of less dense material. Thus, the efficiency of compressional shock transmission should be high, and the attenuation rate should be less rapid than $R_{S}^{-2}$. In addition, energy losses due to partial shock reflection at saturated-nonsaturated transitions within the sand layer should be absent for the submerged charges. Thus, pressures and spall velocities are expected to be higher than predictions based on the input data of Fig. 31 . MULTIMEDIA predictions are less accurate for the very high (nonacoustic) pressure levels and high particle velocities at 
Table 7. Predicted and observed peak water spall velocities above charges 1 and 8 .

\begin{tabular}{|c|c|c|c|c|c|c|}
\hline $\begin{array}{c}\text { Charge } \\
\text { No. }\end{array}$ & Location & $\begin{array}{l}\text { Depth (ft } \\
\text { of sand } \\
+\mathrm{ft} \text { of } \\
\text { water) }\end{array}$ & $\begin{array}{c}\text { Observed } \\
\text { peak spall } \\
\text { velocity } \\
\text { near SGZ } \\
(\mathrm{ft} / \mathrm{sec})\end{array}$ & $\begin{array}{c}\text { Observed } \\
\text { mean spall } \\
\text { velocity } \\
\text { over a } \\
\text { longer time } \\
\text { interval } \\
\text { near SGZ } \\
(\mathrm{ft} / \mathrm{sec})\end{array}$ & $\begin{array}{l}\text { MULTIMEDIA } \\
\text { prediction for } \\
\text { Drum Inlet, } \\
\text { saturated } \\
\text { sand (ft/sec) }\end{array}$ & $\begin{array}{l}\text { MULTIMEDIA } \\
\text { prediction for } \\
\text { saturated con- } \\
\text { crete of sim- } \\
\text { ilar density } \\
\text { (earlier re- } \\
\text { sults) (ft } / \mathrm{sec}^{-}\end{array}$ \\
\hline 1 & $\begin{array}{l}\text { Core } \\
\text { Sound } \\
\text { end of } \\
\text { row }\end{array}$ & $7+4$ & 1176 & $741-894$ & 869 & 1067 \\
\hline 8 & $\begin{array}{l}\text { Near } \\
\text { ocean } \\
\text { end of } \\
\text { row }\end{array}$ & $9+2$ & 941 & $775-802$ & 693 & 811 \\
\hline
\end{tabular}

${ }^{a}$ Observed velocities were measured at or near the vertical direction $\left(\theta=80\right.$ to $\left.90^{\circ}\right)$.

extremely close ranges. The submerged charges were at shallow burial depths (much less than optimum), so some inaccuracy is expected. (4) Erosion and material transfer at the ocear. end of the row may have modified the sand surface contours, thus changing the charge burial depths in sand and the shock transmission geometry. (5) High-pressure vent and stem ejection effects (similar to those observed for "dry-land" charges near the center of the row) may have increased pressures and spall velocities close to SGZ.

It is evident that the above-listed effects may appreciably modify shock transmission and spall velocities, depending on the local conditions. The first two factors are considered most important. Predictions for saturated sand are still subject to uncertainties which can be reduced as better input data become available. One conclusion, however, is not in doubt: water surface spall for shallow water layers outruns the deeper saturated sand material. Thus, the measured peak water surface velocities do not give direct information about cratering dynamics of the underlying layers.

\section{Fish Kill and Underwater Pressures}

Underwater shock is another important safety factor for submerged excavation events. This factor caused some controversy prior to the Pre-Gondola ${ }^{1}$ project (located adjacent to the Fort Peck reservoir) and the Tugboat ${ }^{2}$ submerged detonations. However, results of these tests demonstrated that environmental damage due to water shock was minimal. Caged fish kill experiments conducted during Project Tugboat showed that fish kill did not occur beyond $300 \mathrm{ft}$ even for the largest events (40 tons).

Underwater pressure measurements and caged fish kill experiments were not possible at Drum Inlet. However, a thorough examination of the crater vicinity was carried out immediately after the shot. Six dead fish were found on dry land at the edge of the dredge cut channel 
within a few hundred feet of the charge rows. Extensive trawling adjacent to the detonation site minutes later netted a number of fish, all apparently unharmed. The dead fish are thought to have been killed by the intense shock waves from the underwater disposal charges in the shallow dredge cut.

\section{Ejecta}

High-velocity ejecta particles penetrated the Drum Inlet sand and water spall domes at times later than $+50 \mathrm{msec}$. The trajectories of these particles reveal useful information about material ejection dynamics; therefore, the positions and velocities of 52 typical examples have been determined. Figure 32, derived from 48-frame/sec movie film, shows the observed paths of 38 ejecta, each labeled with a particle number and with the calculated velocities ( $\mathrm{ft} / \mathrm{sec}$ ) over one to five segments along the path. Similar measurements were made for 14 particles using the. Hycam film. Measured velocities are summarized in Table 8 , which presents data for particles 1-38 (from Fig. 32, Canon camera, 48 frames/ sec; times between +0.0625 . and t0.854 sec) and particles 39-52 (Hycam camera, 588 frames/sec; times between +0.153 and $+0.639 \mathrm{sec})$. Data are tabulated in the following format: the first column lists the apparent charge of origin for each particle (charges 11 to 1 , or dredge cut disposal charges); the second gives the particle number (1-52); next, the altitude above the ground surface at two or more points along each particle trajectory is given; the fourth column lists the measured angular direction of motion after each trajectory point (vertical direction $=90^{\circ}$; no direction is given aftèr the last point for each particle, because the measured trajectory ends at that point); column 5 gives the time at which each altitude point in column 3 was measured (zero time was arbitrarily chosen as the time of first visible initiation in each film); the last column presents the calculated mean velocities between successive points along the trajectory. All altitudes, displacements, and velocities were determined directly from the photography (i.e., perpendicular to the camera's line of sight), with the appropriate scale correction for the $74.1^{\circ}$ inclination between the line of sight and the near-row axis (nearrow length of $350 \mathrm{ft}$ was used to establish the scale). Velocity components in the line of sight are obviously not visible and are not included in the measurements. Note that all velocities listed in the table are total vector velocities perpendicular to the line of sight, calculated from the total visible displacements between successive points (vertical velocity component $=$ total velocity $\times \sin \theta$, where $\theta$ $=$ trajectory angle). Also, note that the ejecta may originate from either the near or far row, and may be displaced along the line of sight during their trajectories. No corrections have been applied for motion along the line of sight and changes in camera-to-particle distance. Such corrections are not possible unless motion in the line of sight is independently known (as from photography at another camera location).

The measured velocities and direction angles for many of the individual particles in Table 8 show erratic internal variations. These variations may be partly 


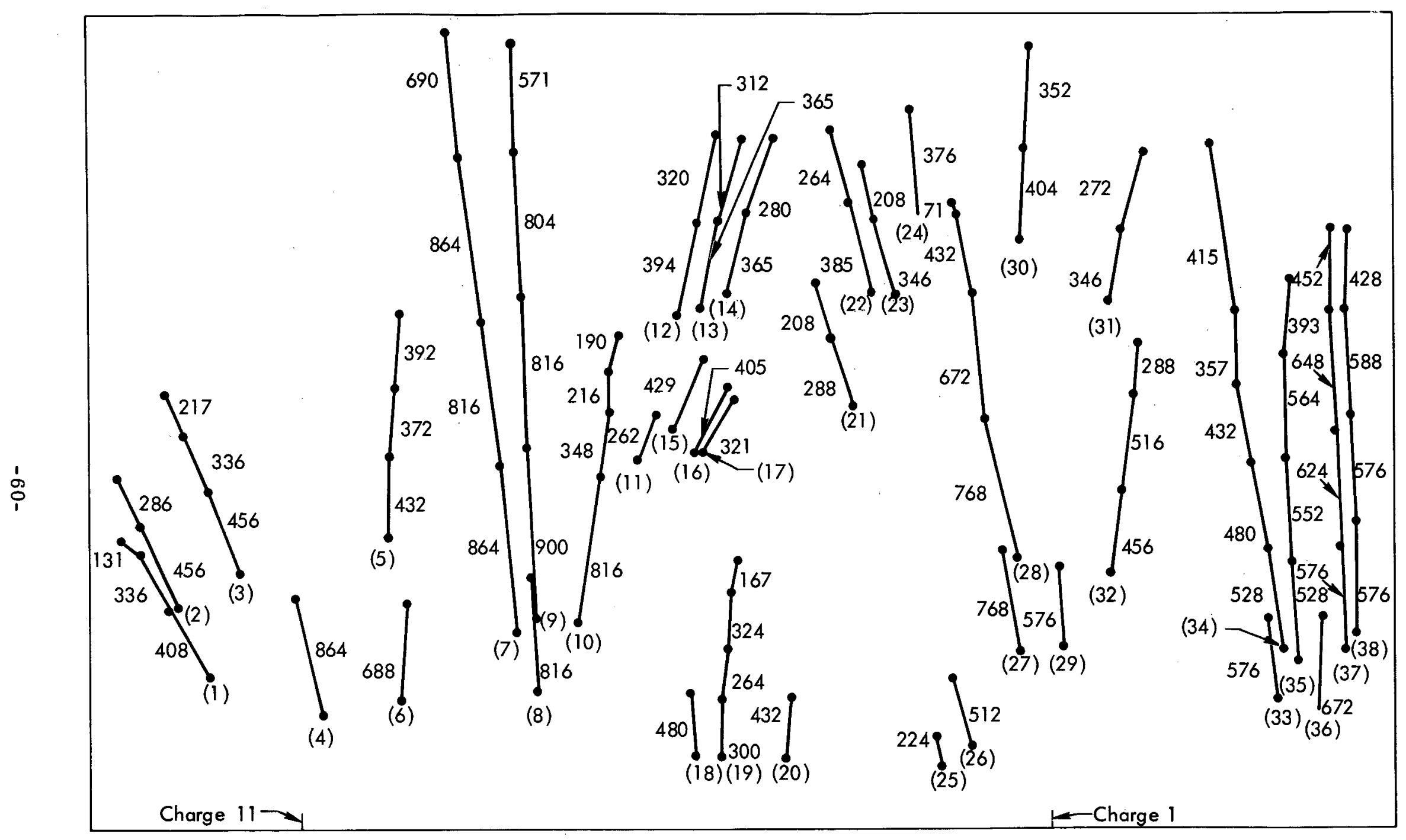

Fig. 32. Sample trajectories of high-velocity ejecta labeled with the ejecta particle number (see text) and the approximate velocities (in $\mathrm{ft} / \mathrm{sec}$ ). (From photos taken with Canon 16-mm movie camera, 25-mm focal length, $48 \mathrm{frames} /$ sec.) 
Table 8. Measured late-time ejecta velocities perpendicular to the camera-bunker line of sight for the Drum Inlet detonation.

Ejecta particles 1 through 38: 16-mm Canon movie camera film, taken at 48 frames $/ \mathrm{sec}$.

Ejecta particles 39 through 52: 16-mm Redlake 100-ft Hycam

film, taken at 588 frames $/ \mathrm{sec}$.

There is some duplication between particles measured on the Canon film and particles measured on the Hycam film, although the measurements were made over different time intervals.

\begin{tabular}{|c|c|c|c|c|c|}
\hline $\begin{array}{c}\text { Charge } \\
\text { No. }\end{array}$ & $\begin{array}{c}\text { Ejecta } \\
\text { particle } \\
\text { No. }\end{array}$ & $\begin{array}{c}\text { Approx } \\
\text { altitude of } \\
\text { particle } \\
\text { above ground } \\
\text { (ft) }\end{array}$ & $\begin{array}{c}\text { Approx angle } \\
\text { of trajectory } \\
\text { to horizontal, } \\
\text { perpendicular } \\
\text { to line of sight } \\
\text { (deg) }\end{array}$ & $\begin{array}{l}\text { Approx } \\
\text { time after } \\
\text { zero time } \\
\quad(\mathrm{sec})\end{array}$ & $\begin{array}{c}\text { Mean particle } \\
\text { velocity } \\
\text { perpendicular } \\
\text { to line of sight } \\
(\mathrm{ft} / \mathrm{sec})\end{array}$ \\
\hline \multirow[t]{4}{*}{11} & \multirow[t]{4}{*}{1} & 65 & 60 & 0.1875 & \multirow{2}{*}{408} \\
\hline & & 94 & 60 & .2708 & \\
\hline & & 120 & 38 & .354 & \multirow{2}{*}{$\begin{array}{l}336 \\
131\end{array}$} \\
\hline & & 126 & - & .438 & \\
\hline \multirow[t]{3}{*}{11} & \multirow[t]{3}{*}{2} & 96 & 65 & .2708 & \multirow{3}{*}{$\begin{array}{l}456 \\
286\end{array}$} \\
\hline & & 132 & 64 & .354 & \\
\hline & & 154 & - & .438 & \\
\hline \multirow[t]{4}{*}{11} & \multirow[t]{4}{*}{3} & 113 & 70 & .1875 & \multirow{2}{*}{456} \\
\hline & & 148 & 66 & .2708 & \\
\hline & & 176 & 64 & .354 & \multirow{2}{*}{$\begin{array}{l}336 \\
217\end{array}$} \\
\hline & & 192 & - & .438 & \\
\hline \multirow[t]{2}{*}{$10-11$} & \multirow[t]{2}{*}{4} & 48 & 75 & .0625 & \multirow{2}{*}{864} \\
\hline & & 100 & - & .125 & \\
\hline \multirow[t]{4}{*}{10} & \multirow[t]{4}{*}{5} & 127 & 87 & .1875 & \multirow{2}{*}{$\begin{array}{l}432 \\
372\end{array}$} \\
\hline & & 164 & 86 & .2708 & \\
\hline & & 194 & 86 & .354 & \multirow{2}{*}{392} \\
\hline & & 228 & - & .438 & \\
\hline \multirow[t]{2}{*}{10} & \multirow[t]{2}{*}{6} & 54 & 86 & .0625 & \multirow{2}{*}{688} \\
\hline & & 98 & 一 & .125 & \\
\hline \multirow[t]{5}{*}{8} & \multirow[t]{5}{*}{7} & 85 & 84 & .1042 & 864 \\
\hline & & 158 & 83 & .1875 & \multirow{2}{*}{816} \\
\hline & & 225 & 82 & .2708 & \\
\hline & & 298 & 84 & .354 & \multirow{2}{*}{690} \\
\hline & & 356 & - & .438 & \\
\hline \multirow[t]{2}{*}{8} & 8 & 58 & 86 & .0625 & \multirow{2}{*}{816} \\
\hline & & 110 & - & 0.125 & \\
\hline
\end{tabular}


Table 8 (continued)

\begin{tabular}{|c|c|c|c|c|c|}
\hline $\begin{array}{c}\text { Charge } \\
\text { No. }\end{array}$ & $\begin{array}{c}\text { Ejecta } \\
\text { particle } \\
\text { No. }\end{array}$ & $\begin{array}{c}\text { Approx } \\
\text { altitude of } \\
\text { particle } \\
\text { above ground } \\
(\mathrm{ft})\end{array}$ & $\begin{array}{c}\text { Approx angle } \\
\text { of trajectory } \\
\text { to horizontal, } \\
\text { perpendicular } \\
\text { to line of sight } \\
\text { (deg) }\end{array}$ & $\begin{array}{l}\text { Approx } \\
\text { time after } \\
\text { zero time } \\
\quad \text { (sec) }\end{array}$ & $\begin{array}{c}\text { Mean particle } \\
\text { velocity } \\
\text { perpendicular } \\
\text { to line of sight } \\
(\mathrm{ft} / \mathrm{sec})\end{array}$ \\
\hline \multirow[t]{5}{*}{8} & \multirow[t]{5}{*}{9} & 92 & 89 & 0.1042 & 900 \\
\hline & & 168 & 89 & .1875 & \multirow{2}{*}{$\begin{array}{l}816 \\
804\end{array}$} \\
\hline & & 236 & 86 & .2708 & \\
\hline & & 302 & 89 & .354 & \multirow{2}{*}{571} \\
\hline & & 352 & - & .438 & \\
\hline \multirow[t]{5}{*}{8} & \multirow[t]{5}{*}{10} & 88 & 81 & .1042 & \multirow{2}{*}{816} \\
\hline & & 156 & 82 & .1875 & \\
\hline & & 185 & $87^{a}$ & .2708 & 348 \\
\hline & & 202 & 73 & .354 & \multirow{2}{*}{$\begin{array}{l}216 \\
190\end{array}$} \\
\hline & & 218 & - & .438 & \\
\hline \multirow[t]{2}{*}{8} & \multirow[t]{2}{*}{11} & 162 & 69 & .354 & \multirow{2}{*}{$262^{b}$} \\
\hline & & 184 & - & .438 & \\
\hline \multirow[t]{3}{*}{8} & \multirow[t]{3}{*}{12} & 228 & 78 & .625 & \multirow{3}{*}{$\begin{array}{l}394 \\
320\end{array}$} \\
\hline & & 268 & 78 & .729 & \\
\hline & & 308 & - & .854 & \\
\hline \multirow[t]{3}{*}{$7-8$} & \multirow[t]{3}{*}{13} & 230 & 79 & .625 & \multirow{3}{*}{$\begin{array}{l}365 \\
312\end{array}$} \\
\hline & & 269 & 74 & .729 & \\
\hline & & 307 & - & .854 & \\
\hline \multirow[t]{3}{*}{$7-8$} & \multirow[t]{3}{*}{14} & 236 & 76 & .625 & \multirow{3}{*}{$\begin{array}{l}365 \\
280\end{array}$} \\
\hline & & 274 & 70 & .729 & \\
\hline & & 308 & - & .854 & \\
\hline \multirow[t]{2}{*}{8} & \multirow[t]{2}{*}{15} & 175 & 68 & .354 & \multirow{2}{*}{429} \\
\hline & & 209 & - & .438 & \\
\hline \multirow[t]{2}{*}{8} & \multirow[t]{2}{*}{16} & 165 & 62 & .354 & \multirow{2}{*}{405} \\
\hline & & 196 & - & .438 & \\
\hline \multirow[t]{2}{*}{8} & \multirow[t]{2}{*}{17} & 166 & 60 & .354 & \multirow{2}{*}{321} \\
\hline & & 190 & - & .438 & \\
\hline 6 & 18 & 28 & 84 & .0625 & 480 \\
\hline & & 58 & - & 0.125 & 400 \\
\hline
\end{tabular}


Table 8 (continued)

\begin{tabular}{|c|c|c|c|c|c|}
\hline $\begin{array}{c}\text { Charge } \\
\text { No. }\end{array}$ & $\begin{array}{c}\text { Ejecta } \\
\text { particle } \\
\text { No. }\end{array}$ & $\begin{array}{c}\text { Approx } \\
\text { altitude of } \\
\text { particle } \\
\text { above ground } \\
\text { (ft) }\end{array}$ & $\begin{array}{c}\text { Approx angle } \\
\text { of trajectory } \\
\text { to horizontal, } \\
\text { perpendicular } \\
\text { to line of sight } \\
\text { (deg) }\end{array}$ & $\begin{array}{l}\text { Approx } \\
\text { time after } \\
\text { zero time } \\
\quad \text { (sec) }\end{array}$ & $\begin{array}{c}\text { Mean particle } \\
\text { velocity } \\
\text { perpendicular } \\
\text { o line of sight } \\
\text { (ft } / \mathrm{sec})\end{array}$ \\
\hline \multirow[t]{5}{*}{6} & \multirow[t]{5}{*}{19} & 28 & 89 & 0.1042 & \multirow{2}{*}{300} \\
\hline & & 54 & 82 & .1875 & \\
\hline & & 76 & 89 & .2708 & 264 \\
\hline & & 104 & 76 & .354 & \multirow{2}{*}{167} \\
\hline & & 118 & - & .438 & \\
\hline \multirow[t]{2}{*}{5} & \multirow[t]{2}{*}{20} & 28 & 86 & .0625 & \multirow{2}{*}{432} \\
\hline & & 55 & - & .125 & \\
\hline \multirow[t]{3}{*}{2} & \multirow[t]{3}{*}{21} & 188 & 73 & .625 & \multirow{3}{*}{$\begin{array}{l}288 \\
208\end{array}$} \\
\hline & & 216 & 73 & .729 & \\
\hline & & 242 & - & .854 & \\
\hline \multirow[t]{3}{*}{2} & \multirow[t]{3}{*}{22} & 238 & 77 & .625 & \multirow{3}{*}{$\begin{array}{l}385 \\
264\end{array}$} \\
\hline & & 278 & 74 & .729 & \\
\hline & & 310 & - & .854 & \\
\hline \multirow[t]{3}{*}{$1-2$} & \multirow[t]{3}{*}{23} & 235 & 75 & .625 & \multirow{3}{*}{$\begin{array}{l}346 \\
208\end{array}$} \\
\hline & & 270 & 76 & .729 & \\
\hline & & 295 & - & .854 & \\
\hline \multirow[t]{2}{*}{2} & \multirow[t]{2}{*}{24} & 272 & 85 & .729 & \multirow{2}{*}{376} \\
\hline & & 320 & - & .854 & \\
\hline \multirow[t]{2}{*}{$2-3$} & \multirow[t]{2}{*}{25} & 23 & 78 & .0625 & \multirow{2}{*}{224} \\
\hline & & 37 & - & .125 & \\
\hline \multirow[t]{2}{*}{2} & \multirow[t]{2}{*}{26} & 32 & 75 & .0625 & \multirow{2}{*}{512} \\
\hline & & 63 & - & .125 & \\
\hline \multirow[t]{2}{*}{1} & \multirow[t]{2}{*}{27} & 72 & 80 & .0625 & \multirow{2}{*}{768} \\
\hline & & 120 & - & .125 & \\
\hline \multirow[t]{5}{*}{1} & \multirow[t]{5}{*}{28} & 116 & 78 & .1042 & \\
\hline & & 179 & 84 & .1875 & 768 \\
\hline & & 236 & 80 & .2708 & 672 \\
\hline & & 272 & 76 & .354 & $43{ }^{6} b$ \\
\hline & & 278 & - & 0.438 & \\
\hline
\end{tabular}


Table 8 (continued)

\begin{tabular}{|c|c|c|c|c|c|}
\hline $\begin{array}{c}\text { Charge } \\
\text { No. }\end{array}$ & $\begin{array}{c}\text { Ejecta } \\
\text { particle } \\
\text { No. }\end{array}$ & $\begin{array}{l}\text { Approx } \\
\text { altitude of } \\
\text { particle } \\
\text { above ground } \\
\text { (ft) }\end{array}$ & $\begin{array}{l}\text { Approx angle } \\
\text { of trajectory } \\
\text { to horizontal, } \\
\text { perpendicular } \\
\text { to line of sight } \\
\text { (deg) }\end{array}$ & $\begin{array}{l}\text { Approx } \\
\text { time after } \\
\text { zero time } \\
\quad(\text { sec) }\end{array}$ & $\begin{array}{c}\text { Mean particle } \\
\text { velocity } \\
\text { perpendicular } \\
\text { to line of sight } \\
\text { (ft/sec) }\end{array}$ \\
\hline \multirow[t]{2}{*}{1} & \multirow[t]{2}{*}{29} & 76 & 86 & 0.0625 & \multirow{2}{*}{576} \\
\hline & & 112 & - & .125 & \\
\hline \multirow[t]{3}{*}{$1-2$} & \multirow[t]{3}{*}{30} & 259 & 88 & .625 & \multirow{3}{*}{$\begin{array}{l}404 \\
352\end{array}$} \\
\hline & & 302 & 86 & .729 & \\
\hline & & 348 & - & .854 & \\
\hline \multirow[t]{3}{*}{$1-2$} & \multirow[t]{3}{*}{31} & 230 & 79 & .625 & \multirow{3}{*}{$\begin{array}{l}346 \\
272\end{array}$} \\
\hline & & 266 & 75 & .729 & \\
\hline & & 300 & - & .854 & \\
\hline \multirow[t]{4}{*}{1} & \multirow[t]{4}{*}{32} & 109 & 81 & .1042 & \multirow{4}{*}{$\begin{array}{l}456 \\
516 \\
288\end{array}$} \\
\hline & & 146 & 83 & .1875 & \\
\hline & & 190 & 87 & .2708 & \\
\hline & & 214 & - & .354 & \\
\hline \multirow[t]{2}{*}{ Disposal } & \multirow[t]{2}{*}{33} & 52 & 82 & .0625 & \multirow{2}{*}{576} \\
\hline & & 89 & - & .125 & \\
\hline \multirow[t]{6}{*}{ Disposal } & \multirow[t]{6}{*}{34} & 76 & 82 & .1042 & \multirow{2}{*}{$\begin{array}{l}528 \\
480\end{array}$} \\
\hline & & 119 & 78 & .1875 & \\
\hline & & 159 & 82 & .2708 & \multirow{4}{*}{$\begin{array}{l}432 \\
357 \\
415\end{array}$} \\
\hline & & 196 & 89 & .354 & \\
\hline & & 226 & 82 & .438 & \\
\hline & & 304 & - & .625 & \\
\hline \multirow[t]{5}{*}{ Disposal } & \multirow[t]{5}{*}{35} & 70 & 85 & .1042 & \multirow{2}{*}{528} \\
\hline & & 114 & 90 & .1875 & \\
\hline & & 160 & $88^{a}$ & .2708 & $\begin{array}{l}552 \\
564\end{array}$ \\
\hline & & 207 & 86 & .354 & \multirow{2}{*}{393} \\
\hline & & 240 & - & .438 & \\
\hline \multirow[t]{2}{*}{ Disposal } & \multirow[t]{2}{*}{36} & 46 & 88 & .0625 & \multirow{2}{*}{672} \\
\hline & & 88 & - & .125 & \\
\hline \multirow[t]{2}{*}{ Disposal } & \multirow[t]{2}{*}{37} & 73 & 88 & .1042 & \multirow{2}{*}{$\begin{array}{l}576 \\
624\end{array}$} \\
\hline & & 120 & 88 & 0.1875 & \\
\hline
\end{tabular}


Table 8 (continued)

\begin{tabular}{|c|c|c|c|c|c|}
\hline $\begin{array}{c}\text { Charge } \\
\text { No. }\end{array}$ & $\begin{array}{c}\text { Ejecta } \\
\text { particle } \\
\text { No. }\end{array}$ & $\begin{array}{l}\text { Approx } \\
\text { altitude of } \\
\text { particle } \\
\text { above ground } \\
\therefore \quad \text { (ft) }\end{array}$ & $\begin{array}{c}\text { Approx angle } \\
\text { of trajectory } \\
\text { to horizontal, } \\
\text { perpendicular } \\
\text { to line of sight } \\
\text { (deg) }\end{array}$ & $\begin{array}{l}\text { Approx } \\
\text { time after } \\
\text { zero time } \\
\quad \text { (sec) }\end{array}$ & $\begin{array}{c}\text { Mean particle } \\
\text { velocity } \\
\text { perpendicular } \\
\text { to line of sight } \\
\text { (ft/sec) }\end{array}$ \\
\hline \multirow{3}{*}{$\begin{array}{c}\text { Disposal } \\
\text { (contd) }\end{array}$} & \multirow{3}{*}{$\begin{array}{c}37 \\
\text { (contd) }\end{array}$} & 172 & 87 & 0.2708 & \multirow{3}{*}{$\begin{array}{l}648 \\
452\end{array}$} \\
\hline & & 226 & 90 & .354 & \\
\hline & & 264 & - & .438 & \\
\hline \multirow[t]{5}{*}{ Disposal } & \multirow[t]{5}{*}{38} & 82 & 90 & .1042 & \multirow{2}{*}{576} \\
\hline & & 130 & 88 & .1875 & \\
\hline & & 178 & 88 & .2708 & 576 \\
\hline & & 227 & $88^{a}$ & .354 & \multirow{2}{*}{$\begin{array}{l}588 \\
428\end{array}$} \\
\hline & & 264 & - & .438 & \\
\hline \multirow{2}{*}{${ }^{8}$ (Star } & 39 & 115.5 & 76 & .1531 & \multirow{2}{*}{765} \\
\hline \multirow{2}{*}{\multicolumn{2}{|c|}{ Hycam data) }} & 128 & 76 & .1701 & \\
\hline & & 141 & - & .1871 & 765 \\
\hline \multirow[t]{3}{*}{8} & \multirow[t]{3}{*}{40} & 118 & 74 & .1531 & 912 \\
\hline & & 133 & 69 & .1701 & \multirow{2}{*}{706} \\
\hline & & 144.5 & - & .1871 & \\
\hline \multirow[t]{3}{*}{$7-8$} & \multirow[t]{3}{*}{41} & 96 & 76 & .1531 & \multirow{3}{*}{$\begin{array}{l}647 \\
529\end{array}$} \\
\hline & & 106.5 & 63 & .1701 & \\
\hline & & 115 & - & .1871 & \\
\hline \multirow[t]{3}{*}{6} & \multirow[t]{3}{*}{42} & 152 & 85 & .197 & \multirow{3}{*}{$\begin{array}{l}268 \\
221\end{array}$} \\
\hline & & 163 & 85 & .238 & \\
\hline & & 178.5 & - & .308 & \\
\hline \multirow[t]{3}{*}{6} & \multirow[t]{3}{*}{43} & 149 & 85 & .197 & \multirow{3}{*}{$\begin{array}{l}280 \\
236\end{array}$} \\
\hline & & 160.5 & 80 & .238 & \\
\hline & & 177 & - & .308 & \\
\hline \multirow[t]{3}{*}{5} & \multirow[t]{3}{*}{44} & 123.5 & 88 & .527 & \multirow{3}{*}{$\begin{array}{l}185 \\
205\end{array}$} \\
\hline & & 137.5 & $85^{a}$ & .600 & \\
\hline & & 145.5 & - & .639 & \\
\hline \multirow[t]{3}{*}{5} & \multirow[t]{3}{*}{45} & 124 & 88 & .527 & \\
\hline & & 137 & 89 & .600 & 178 \\
\hline & & 145 & - & 0.639 & 178 \\
\hline
\end{tabular}


Table 8 (continued)

\begin{tabular}{|c|c|c|c|c|c|}
\hline $\begin{array}{c}\text { Charge } \\
\text { No. }\end{array}$ & $\begin{array}{c}\text { Ejecta } \\
\text { particle } \\
\text { No. }\end{array}$ & $\begin{array}{c}\text { Approx } \\
\text { altitude of } \\
\text { particle } \\
\text { above ground } \\
\text { (ft) }\end{array}$ & $\begin{array}{c}\text { Approx angle } \\
\text { of trajectory } \\
\text { to horizontal, } \\
\text { perpendicular } \\
\text { to line of sight } \\
\text { (deg) }\end{array}$ & $\begin{array}{l}\text { Approx } \\
\text { time after } \\
\text { zero time } \\
\text { (sec) }\end{array}$ & $\begin{array}{l}\text { Mean particle } \\
\text { velocity } \\
\text { perpendicular } \\
\text { to line of sight } \\
(\mathrm{ft} / \mathrm{sec})\end{array}$ \\
\hline \multirow[t]{3}{*}{5} & \multirow[t]{3}{*}{46} & 119 & 87 & 0.527 & \multirow{3}{*}{$\begin{array}{l}164 \\
179\end{array}$} \\
\hline & & 131 & 85 & .600 & \\
\hline & & 138 & - & .639 & \\
\hline \multirow[t]{3}{*}{5} & \multirow[t]{3}{*}{47} & 117 & 79 & .527 & \multirow{3}{*}{$\begin{array}{l}171 \\
154\end{array}$} \\
\hline & & 129 & 85 & .600 & \\
\hline & & 135 & - & .639 & \\
\hline \multirow[t]{3}{*}{$1-2$} & \multirow[t]{3}{*}{48} & 74.5 & 76 & .1531 & \multirow{3}{*}{$\begin{array}{l}500 \\
412\end{array}$} \\
\hline & & 83 & 70 & .1701 & \\
\hline & & 90 & - & .1871 & \\
\hline \multirow[t]{3}{*}{$1-2$} & \multirow[t]{3}{*}{49} & 90 & 64 & .1531 & \multirow{3}{*}{$\begin{array}{l}588 \\
500\end{array}$} \\
\hline & & 99 & 77 & .1701 & \\
\hline & & 107.5 & - & .1871 & \\
\hline \multirow[t]{2}{*}{1} & \multirow[t]{2}{*}{50} & 143.5 & 80 & .1701 & \multirow{2}{*}{882} \\
\hline & & 158 & - & .1871 & \\
\hline \multirow[t]{2}{*}{1} & \multirow[t]{2}{*}{51} & 145 & 79 & .1701 & \multirow{2}{*}{882} \\
\hline & & 160 & - & .1871 & \\
\hline \multirow[t]{3}{*}{$1-2$} & 52 & 109.5 & 78 & .1531 & \multirow{3}{*}{$\begin{array}{l}559 \\
353\end{array}$} \\
\hline & & 119 & 82 & .1701 & \\
\hline & & 125 & - & 0.1871 & \\
\hline
\end{tabular}

\footnotetext{
${ }^{a}$ Apparent reversal in direction of the horizontal component of the velocity vector, caused by breakup of the ejecta particles and by normal inaccuracies in the measurements.

${ }^{b}$ Velocity measured near turnover (peak) of particle trajectory.

attributed to photographic measurement errors, camera frame jitter, etc. However, the nature of the cratering medium also exerts an important effect. Charges were emplaced in fine sand and shell, with some regions of compacted sand deeper than $-9 \mathrm{ft}$ MLW. No rock or massive material was present. The ejecta

are thus believed to consist of dense agglomerated chunks of sandy matter, which originated deep within the spall (perhaps in the compacted sand layer) and penetrated the surface at rather late times. Photographic observations lend support to this view: Most particles left brown or white-hued trails of sand and/or 
water spray indicative of air friction erosion along the rising trajectories; a few split in half or virtually disintegrated. Disintegration processes became more pronounced near and beyond the peaks of the trajectories. All ejecta deposited dark trails of sand along their descending arcs, and many had degenerated into long, dense sand plumes before impact occurred. These erosion and disintegration effects cause eroded sand material to fall nearer SGZ (along the ground projection of the trajectories) and also change the ballistics of the parent particles. Some of the larger chunks showed evidence of rapid deceleration and abrupt descent during breakup. The path of such a particle is difficult to calculate because of rapidly changing mass and air friction; however, the overall effect is to cause material deposition and ejecta impact at closer ranges. Air resistance evidently has considerable influence on the dynamics of low-cohesion sand ejecta.

The sand trails and disintegration effects also reduced photographic meas urement accuracy by obscuring each particle's center of gravity. For this reason, it was not possible to trace the late-time descending trajectories. Only the more clearly defined ejecta were measured on the films, but the positional error of a given measurement may still be relatively large.

Although there are some uncertainties in the ejecta dynamics data, the major trends are quite clear. The apparent particle launch density did not vary dramatically along the row. Most of the high-velocity missiles originated near the shallowly buried submerged charges and the underwater disposal charges. Veloc- ities were generally lower and the number of particles was somewhat smaller at the center of the row (charges 4-6, deeply buried in sand). The high-velocity particles, observed above the disposal charges (Fig. 32) are explained by the fact that these charges sank to a shallow depth in the saturated sand, thus producing a small number of very energetic ejecta from their immediate surroundings.

One phenomenon revealed by the ejecta analysis gives an important clue about cratering processes. The early portions of most high-velocity particle trajectories are almost vertical in direction; the horizontal velocity components are quite small. This result contrasts with observations of dry-medium events, which show greater horizontal dispersion of ejecta material. Horizontal ejecta ranges * may be calculated from the data in Table 8 (these calculations are necessarily approximate, due to the disintegration effects mentioned earlier). With an assumed air resistance factor of 0.10 (constant), ballistic ranges vary from 0 to more than $1000 \mathrm{ft}$. Typical ranges are on the order, of $200 \mathrm{ft}$. The $35-\mathrm{mm}$ photographs also showed that most ejecta beyond the ends of the row impacted within $200 \mathrm{ft}$ of the last charge (No. 11 at the ocean end of the row, or the disposal charges at the Core Sound end). Measured velocities and measured horizontal

The range in this case is defined as the horizontal transit distance from the apparent ground surface point of origin to the point of impact; the distance is calculated using the measured vertical and horizontal velocity components and the particle altitude at the time of measurement. 
ranges include only the motion perpendicular to the camera's line of sight; therefore, the true ejecta ranges will be somewhat greater (due to the additional horizontal velocity component or range along the line of sight). However, it is apparent that many of the particles fell at close ranges, within or near the crater. Air resistance and disintegration may accentuate this trend. The observed or calculated ranges apply to the fastest particles which penetrate the mound surface; the bulk of the deeper low-velocity saturated spall material (beneath the spall dome) will impact at still closer ranges. It thus appears probable that adequate horizontal velocity dispersion was not obtained, and that a large quantity of sand fell almost vertically back into the crater. This mechanism could partly account for the shallow crater depths and underexcavation experienced at Drum Inlet.

The predominantly vertical velocity vectors observed during this event correspond with theoretical expectations for saturated media. Such materials do not efficiently support shear or transverse waves; the horizontal components of the direct compression wave and the reflected spall (tension) wave tend to cancel. Hence, the spall velocity is primarily vertical. The effect is reinforced for row or multiple-row events because the horizontal spall launch vectors between charges or rows of charges also tend to cancel. The situation is worst for a cohesionless granular material such as saturated sand, because of ejecta disintegration, air resistance (which rapidly decelerates sand grains and small clumps of material), and liquefaction or wash- back effects within submerged areas of the crater (see below).

Ejecta from saturated sand events do not constitute a major environmental hazard. The short horizontal ejection ranges and the diffuse nature of the particles greatly reduce the probability of damage. Evidences of impact were discovered at ranges up to $250 \mathrm{ft}$ perpendicular to the north row. However, the sizable impact craters or indentations normally associated with massive projectiles were not found. Surface deposition clumps were small and irregular in shape, as expected for disintegrating or noncohesive missiles of low terminal velocity.

\section{Cratering Dynamics}

The side portions of the cut exhibited steep lips and fully excavated contours typical of "dry-land" craters in sand. Design dimensions were very nearly achieved at the sides of the cut (total crater width), and along the row axes at the center and Core Sound end of the rows. The central parts of the channel displayed the broad, flattened bottom contours characteristic of underwater craters in saturated cohesionless material. Underexcavation occurred along the centerline (midway between the two rows), and at the ocean end of the cut (shallow, submerged charges). Formation and stabilization processes were thus a mixture of dry-land and underwater mechanisms. From a design viewpoint, the enhancement technique correctly predicted crater widths and intercharge spacings for the charges near optimum depth, at the center and Core Sound end of the rows. The interrow separation and the configuration 
near the ocean end of the cut were less successful. Underexcavation near the ocean end is rather difficult to explain, since previous experience indicated that crater depths and radii should not decrease dramatically at sand burial depths of 7 to $9 \mathrm{ft} / \operatorname{ton}^{1 / 3}$ (Refs. 9, 16, etc.). Note, however, that the tops of the charge cylinders were only 3 to $5 \mathrm{ft}$ below the interface at the ocean end of the row. In addition, the row-charge enhancement design method has not been thoroughly tested for very shallow row charges. The small-scale modeling tests also failed to predict this problem. Reasons for the breakdown of model simulation are not fully understood, but are probably related to complex dynamics of material ejection, fallback, and washback, which do not scale correctly to larger yields. Crater depths, in particular, may be overpredicted, and the contours may be distorted. Caution must be exercised in scaling the results for spherical model charges in saturated sand to larger yields. Variation in rowcharge design and changes in the charge geometry further complicate the problem. Predictions are apparently most erroneous for shallowly buried submerged charges.

Cratering processes in the portions of the Drum Inlet cut below water level were dominated by heavy fallback, combined with liquefaction and washback effects. Material was not efficiently removed from the crater vicinity, and fallback deposition was particularly dense along the centerline of the cut. Several possible causes for this phenomenon have been suggested: (1) Spall launch is primarily directed toward the vertical in saturated media, and material is not efficiently ejected from the crater. This effect is most apparent between the two opposing rows, where the small horizontal velocity vectors tend to cancel. Thus, the lower layers of spall are deposited within the cut. Fallback is expected to be heaviest along the centerline, as observed. Ejecta disintegration and air resistance tend to restrict horizontal dispersion of material for cohesionless media such as sand. Air drag and deceleration effects on small particles may become most significant for "large" yield scales (i.e., Drum Inlet). (3) Slumping, liquefaction, and washback flow decrease crater depths and volumes, and produce flat contours in the submerged areas. These mechanisms were active between the crater walls, along the flat bottom areas, and at the ends of the cut. Washback effects were not apparent near the Core Sound end because efficient horizontal ejection occurred at the end of the row due to the steep diagonal face of the dredge cut, and because fallback material flowed away into the deeper water of the dredge channel. Thus, material was efficiently removed and the design parameters were achieved. However, the elimination of four charge pairs at the ocean end caused a complete lip which sealed the ocean exit. Wet sand was not able to escape; slumping and flow within the crater walls produced a flattened, underexcavated cut. These results demonstrate the importance of underwater depth contours in determining the final location of fallback material. These factors must be considered during the initial excavation design. Liquefaction and flow mechanisms could become even more crucial 
for future, completely submerged events in sand. If the crater is surrounded by water at depths $\left(\mathrm{D}_{\mathrm{w}} / \mathrm{D}_{\mathrm{m}}\right)$ greater than 0.1 to 0.2 , the steep-sided lips will probably be overtopped and severe washback of liquefied sand will occur. Thus, one would expect a very flat crater of increased radius, extending beyond the lip radius observed at Drum Inlet. Wide intercharge spacing could be used. However, the scaled crater depths would be even shallower than at Drum Inlet. (4) The large length-to-diameter ratio of the charges and the emplacement method used at Drum Inlet caused visible stem ejection. The exact degree of energy loss is not known. Significant venting of this type may decrease the crater formation energy available to eject the deeper material, causing underexcavation and cusps or mounds within the crater.

(5) Photographic analysis revealed considerable mound growth cusping and a lack of spall velocity reinforcement between the charges. Previous row-charge modeling experiments in sand have shown that almost flat velocity profiles along the row are necessary to prevent cusping in the crater. Excessively wide spacing produces incomplete velocity reinforcement, and craters with mounds between successive charges are formed. ${ }^{7}$ The Drum Inlet design was apparently less than ideal in this respect. Inadequate velocity reinforcement may have been partly responsible for the center mound between rows, and for the slight intercharge cusping visible along the side lips of the crater. Interestingly, the most noticeable intercharge cusping occurred for the shallow, submerged charges at the ocean end (widest charge spacing, and also the area of general underexcavation). The causes of incomplete mound growth reinforcement are not clear, but may be related to the large $L / D$ ratio of the charges. In this configuration, comparatively less energy may be imparted to the deep material, particularly at long horizontal ranges from the charge. Thus, velocity reinforcement, material ejection, and row-charge enhancement factors between charges are reduced. The effects are expected to be most severe for shallow charges near the cratering material interface (like those at the ocean end of the rows). Many of the currently used design and enhancement parameters were derived for spherical charges near optimum depth of burial, and caution is warranted in applying these data to extended cylindrical charges at shallow depths. Drum Inlet results indicate that the use of charges with an $L / D$ ratio much greater than 4 is not advisable in saturated cohesionless media. (6) Cratering processes for the submerged (ocean end) charges were undoubtedly influenced by complicated spall interactions involving shock wave reflection, transmission, and refraction at the sand-water interface, water surface reflection, and subsequent re-reflections. Unfortunately, Drum Inlet results do not provide detailed information about these processes, due to the lack of survey data and due to the additional complicating factors of variable charge depths, spacing, and separation, use of shallowly buried cylindrical charges, variable geometry of the preshot sand surface, closure of the ocean mouth of the inlet, and washback flow effects near the ocean end of the rows. Earlier investigations of single-charge 
submerged modeling events have been conducted on a semiempirical basis, without attempting to take into account the full details of multiple-layer interactions. 9 The influence of an overlying water layer may be completely analyzed only through the use of two-dimensional Lagrangian dynamic crater-simulation computer codes (such as the SOCTENSOR codes used by Lawrence Livermore Laboratory and EERL). Simulation of underwater cratering has not yet been attempted. Sample calculations of this type would be exceedingly useful in future design work. However, even hydrodynamic codes cannot currently simulate complex row-charge configurations, or late-time liquefaction and washback effects in submerged cohesionless media. (7) It has been suggested that the layer of incompletely saturated sand above the saturated emplacement material may have influenced cratering dynamics near the center of the rows (optimum depth "dry-land" charges). An overlying layer of less dense material is expected to increase shock attenuation near the ground surface and introduce subsurface partialreflection effects. Again, the complex dynamic effects of the less dense material and the impedance mismatch can be simulated by cratering codes (if the properties and equation of state of each

\footnotetext{
*One attempt has been made to empirically simulate acoustic mismatch with very-small-yield modeling charges. 30 The experiments utilized $0.8-$ and 1.7-gram lead azide hemispheres and spheres emplaced at total depths of 3 to 4 in. in a layer of saturated cemented sand overlain by less dense sand. Results were inconclusive, but indicated that the apparent crater radii and depths decreased relative to the dimensions expected for identical charges in sand
}

material layer are known). No calculations have been performed, but the interface effects are probably less important in this case than for submerged charges.

The Drum inlet cratering results have important implications for the design of future events in cohesionless media. To summarize, inter-row separations were significantly too wide for "dry-land" cratering charges near the center of the rows; both inter-row separation and intercharge spacings were evidently too wide for the shallow submerged charges, and underexcavation occurred near the ocean end of the cut. These difficulties may be attributed to either of two design factors: defective input data (singlecharge crater dimensions), or breakdown of the enhancement laws used to derive the double-row configuration and spacings. Both factors are almost certainly involved in this case. Various approaches may be applied to improve the design method: (1) Emplace charges at somewhat greater scaled depths of burial (near true optimum depth) whenever possible. Avoid the use of shallowly buried long cylindrical charges in saturated and submerged sand; the dynamic mechanisms involved are incompletely understood, but this configuration apparently does not produce efficient material ejection. Optimum burial depth and crater dimensions

alone, and were comparable to the dimensions for the higher strength cemented sand alone. However, the true crater radii (or material displacement zones) were significantly increased relative to the true radii in either sand or cemented sand alone. True radii appeared to be extremely sensitive to the presence and depth of the overlying less dense layer. The applicability of these results to large-scale cratering is somewhat doubtful at this time. 
in saturated sand could be more accurately determined by means of a few 1-ton single-charge experiments; spall velocity data indicated an optimum depth rather deeper than the $16 \mathrm{ft} /$ ton $^{1 / 3} \mathrm{em}$ ployed at Drum Inlet. (2) Use closer intercharge spacing and much closer inter-row separation, as necessary to achieve mound growth reinforcement and compensate for heavy fallback and washback effects in saturated sand. Closer spacing is especially indicated for shallowly buried submerged charges, for which the enhancement design technique produced less-than-satisfactory results. Enhancement factors and spacings derived from dry-land data should not be uncritically transferred to sand excavation designs. Even the small-scale model tests in unsaturated sand indicate that intercharge spacings less than $1.2 \mathrm{R}_{\mathrm{a}}$ are necessary to assure complete mound growth and avoid cusping along a single row. ${ }^{7}$ Still closer spacings would presumably be appropriate for saturated and submerged designs (to compensate for vertical fallback and washback effects). Analogous conclusions apply to the interrow separation of double rows. Established separations for alluvium, weak rock, and saturated clay shale are significantly too wide for saturated cohesionless media. (3) Use direct blasting techniques and inter-row delays to improve material ejection dynamics, increase excavated crater volume, and tailor the cut to design requirements. This very promising approach is discussed in greater detail below.

The lack of survey data renders it impossible to establish precise design parameters from the Drum Inlet results.
The following single-charge optimum crater dimensions are based on rough estimates and apply to situations resembling Drum Inlet (AANS explosive in saturated sand, crater sides above water level, crater floor submerged and subject to some liquid flow effects):

$$
\begin{aligned}
& \text { DOB (optimum) } \approx 18 \mathrm{ft} / \text { ton }^{1 / 3} \text {. } \\
& \text { Optimum apparent crater radius } \mathrm{R}_{\mathrm{a}} \\
& \quad \approx 25-26 \mathrm{ft} / \text { ton }^{1 / 3} \text {. } \\
& \text { Optimum apparent crater depth } \mathrm{D}_{\mathrm{a}} \\
& \quad \approx 10-12 \mathrm{ft} / \text { ton }^{1 / 3} \text {. } \\
& \text { Intercharge spacing } \approx 1.1 \mathrm{R}_{\mathrm{a}} . \\
& \text { Inter-row separation } \approx 1.2 \mathrm{R}_{\mathrm{a}} .
\end{aligned}
$$

Lip crest height above preshot surface is up to $6 \mathrm{ft} / \operatorname{ton}^{1 / 3}$ or higher at dryland sides of crater.

Stable crater side slopes: Very steep, up to $45^{\circ}$ or more, in wet but not submerged sand. Immediate postshot slumping is not apparent when the lip is above water level.

Underexcavation and small crater sizes in saturated sand make the designer's task quite difficult. Heavy vertical fallback and washback could create still more severe problems for very broad or extended arrays. The interrow delay technique may be used to eliminate these drawbacks by compensating for unfavorable spall dynamics, increasing the excavation efficiency of the explosive, and adding flexibility to the design options. Inter-row delays take advantage of a directed blasting effect: The earlier-detonated row produces an initial true crater surface early during its detonation history. The later-detonated row "sees" the initial crater as a free surface; thus, it ejects material laterally 
toward the first row (rather than vertically), increasing the excavation efficiency and crater volume. (The technique can also be extended to several successively-detonated rows in a broad array.) The first-detonated row must be somewhat overexcavated to accept fallback from the second row, and the delay time must be long enough to permit formation of an initial crater before the shock wave from the second row arrives. Inter-row delays are expected to be particularly effective for reducing excessive vertical fallback deposition in saturated sand. Tests conducted in a variety of media have verified the feasibility of the method and established the required delay times. Large yield tests (1-2 tons/charge) in moist rock demonstrated that delays on the order of 100 to $150 \mathrm{msec} /$ ton $^{1 / 3} \mathrm{sig}$ nificantly enhanced double-row crater dimensions and volumes relative to the dimensions for identical simultaneous events (inter-row separations used were approximately $\left.46 \mathrm{ft} / \operatorname{ton}^{1 / 3}\right)^{22}$ Smallscale double-row modeling experiments in unsaturated sand showed less effect on crater volumes, but the cross-sectional contours were greatly improved by using delays greater than $10 \mathrm{msec}$; and an inter-row mound observed for a simultaneous detonation was eliminated by using an inter-row delay ${ }^{8}$ (this phenomenon was not seen in the Drum. Inlet simultaneous models; no inter-row delays were attempted).

Inter-row delays have another beneficial side-effect: Peak ground motion amplitudes and airblast overpressures are reduced. This consideration is important in saturated sand, since ground motion may impose rigorous design restrictions near inhabited areas. Judicious use of delays can greatly increase the permissible yield and excavated volume for a single shot, thereby decreasing the total number of detonations required to accomplish a large project. Decreasing the total number of shots tends to reduce complaints and annoyance to local residents. Delays also decrease airblast overpressures, because of the greater separation between pulses from the individual rows. Airblast is most dramatically reduced in the direction perpendicular to the axis of the first-detonated row of two rows (or a series of rows). Reduc tion is greatest in this direction because the pulse from the first row propagates outward far ahead of the subsequent pulses; almost no reinforcement occurs. Perpendicular to the last-detonated row, the pulses arrive somewhat closer together, and airblast reduction may be less efficient; reinforcement may occur under certain circumstances. Generally speaking, in order to reduce airblast to single-row levels perpendicular to the first-detonated row and avoid reinforcement in other directions, the inter-row delay time should be about twice the pulse transit time (in air) between the rows (for example, $\Delta t \approx 80 \mathrm{msec}$ for 40 -ft interrow separation), . In order to minimize airblast in all directions, the delay should be approximately three times the pulse transit between rows $(\Delta t \approx 120 \mathrm{msec}$ for 40-ft separation).- These rules were established for typical events near optimum burial depth and spacing, and may not apply accurately to other configurations. Delays of the order cited above are quite acceptable from the standpoint of excavation and crater volume. Note 
that the detonation sequence should be arranged so that damage-prone structures are located off the first-detonated row, if possible. In flat terrain, the sequence may usually be selected at will so that effects are reduced in the critical direction. This option may not be available for sidehill cuts, or for complex arrays which use directed blasting to launch material toward a specific location; in these cases, the detonation sequence may be fixed by independent design requirements.

Inter-row delays have not yet been tested in saturated sand and saturated submerged sand. Qualitative tests could be carried out with small-yield modeling charges; such experiments would verify the usefulness of the technique and provide approximate design information. However, the precise delay times for large-yield rows and the effects of $L / D$ ratios on delayed row cratering cannot be determined with modeling events. It is expected that the previously used delays of 100 to $150 \mathrm{msec}$ at 1 -ton scale (optimum depth) will prove effective in saturated sand as well.

The tentative interpretation of Drum Inlet cratering results may be summarized as follows: The predominant crater formation mechanism involved strongly vertical spall launch and fallback, with slumping and liquefaction playing a subsidiary role at the submerged ends and in the interior portion of the cut. A traditional "dry-land" crater which approximately met design specifications was formed along the sides of the cut. Interactions in the center area and at the ends were more complex. The cratering mechanisms observed in submerged Tugboat coral ${ }^{2,4}$ (long-range material failure and compaction through crushing, followed by further densification during the mound collapse, washback, and settlement phases) did not occur in saturated sand. Thus, the liquefaction and washback effects extended to somewhat smaller ranges. Crater radii were therefore smaller, and the contours less flattened at long ranges. The scaled crater depths and volumes in submerged areas were also less due to the absence of substantial compaction of fallback and washback material. The center island and the shallow excavation depths in some underwater sections of the Drum Inlet cut are attributed primarily to lack of velocity reinforcement, velocity cancellation between rows, and inadequate horizontal material ejection, which caused excessive vertical fallback from lower portions of the saturated spall. The shallow burial depths of submerged ocean-end charges, stem ejection effects, ejecta disintegration, and air resistance also contributed to the occurrence of underexcavation. Heavy fallback deposition, together with slumping and liquefied flow, accounts for the flat crater-bottom contours. Closer charge spacing, decreased inter-row separation, and inter-row delays may be used to compensate for underexcavation in saturated sands. The directed blasting concept, developed for cratering in rock media, must now be applied in cohesionless and submerged materials (albeit for somewhat different reasons). 


\section{Summary and Conclusions}

The Drum Inlet Project proved the feasibility of large-charge explosive channel excavation in saturated sand, and demonstrated the highly efficient tidal flushing of an explosively excavated inlet breach. The inexpensive water jetting technique developed to emplace charges in sand was quite successful at water. depths shallower than $4 \mathrm{ft}$, but some difficulties were encountered in the surf zone. Noticeable cusping occurred within the Drum Inlet crater, and was most severe between the two charge rows. However, excess material was quickly removed by wave action and water flow. The cusping indicated that the predicted crater design dimensions were too large. The rather small apparent crater size is attributed to inefficient velocity reinforcement between charges, the preferentially vertical direction of spall launch, fallback dynamics of saturated cohesionless spall material, and washback liquefaction effects within the submerged portions of the crater. Various causative mechanisms may be implicated; these include the use of long cylindrical charges at relatively shallow burial depths; charge emplacement and stemming techniques, wide intercharge and inter-row spacings, the small shear stresses and correspondingly low horizontal, spall velocity components which occur for saturated media, and the elimination of two charge pairs at the ocean end of the row (which caused inadequate material removal and created a shallow underwater fallback area completely enclosed by a lip). The underexcavation problems encountered at Drum Inlet can probably be overcome by the use of delays between rows, together with slightly deeper burial depths and closer spacing between charges.

Fish kill and water shock effects were negligible beyond the immediate channel vicinity, and no ejecta impacts were observed at ranges greater than a few hundred feet. As indicated by camera vibrations, the seismic ground shock pulse was intense and prolonged, as expected for a saturated transmission layer overlain by less dense material. Ground motion velocity measurements were not obtained, but the authors estimate that potentially damaging peak velocities were experienced at ranges to or beyond $3000 \mathrm{ft}$. Ground shock will constitute the limiting safety factor for most excavation events in saturated sand; inter-row and intercharge delays may profitably be used to reduce this effect in some cases.

The Drum Inlet detonation excavated a navigable water channel through the Outer Banks, and permitted the interchange of ocean and Core Sound waters required to maintain favorable environmental conditions within the sound. Thus, the basic design goals of the experiment were achieved: The inlet currently has a width of 1100 to $4000 \mathrm{ft}$, and a controlling depth of about $14 \mathrm{ft}$. Maintenance dredging of the Core Sound channel was done in March 1973, providing a 7-ft-deep by $150-\mathrm{ft}$-wide approach channel for deepdraft commercial fishing craft using Drum Inlet for access to the ocean fishing grounds. In April 1973 the U. S. Coast Guard placed navigation aids marking the Drum Inlet channel for the first time since its reopening on 23 December 1971. 


\section{References}

1. B.B. Redpath, Project Pre-Gondola III, Phase III: Connection of a Row Crater to a Reservoir, U.S. Army Engineer Waterways Experiment Station Explosive Excavation Research Office, Livermore, California, EERO/TR-38 (Aug. 1971).

2. W. C. Day et al., Project Tugboat: Explosive Excavation of a Harbor in Coral, U.S. Army Engineer Waterways Experiment Station Explosive Excavation Research Laboratory, Livermore, California, EERL/TR-E-72-23 (Feb. 1972).

3. R. L. LaFrenz, Explosive Excavation for Water Environment and Road Cut Applications, U.S. Army Engineer Waterways Experiment Station Explosive Excavation Research Laboratory, Livermore, California, EERL/MP-E-72-1 (June 1972); presented to IAEA PNE Panel Meeting, Vienna, Austria, 26-30 Nov. 1972.

4. R. H. Gillespie and K. E. Sprague, Cratering in an Underwater Environment, American Nuclear Society Transactions 1972 Annual Meeting, Las Vegas, Nevada, 18-22 June 1972, Vol. 15, No. 1.

5. L. A. Dillon, The Influence of Soil and Rock Properties on the Dimensions of Explosion-Produced Craters, The Texas A\&M Research Foundation, College Station, Texas, Air Force Weapons Laboratory, Rèpt. AFWL-TR-71-144 (Feb. 1972).

6. W. W. Johnson and D. L. Nelson, Project Zulu II, Phase I: Single-Charge Calibration Series, U.S. Army Engineer Nuclear Cratering Group, Livermore, California NCG/TR-3 (Nov. 1968).

7. M. A. Novak, Project Zulu II: Laboratory-Scale Row-Charge Cratering Series, U. S. Army Engineer Nuclear Cratering Group, Livermore, California, NCG/TR-5 (Nov. 1968).

8. R. J. Meisinger, Summary of Time-Delayed Row-Charge Cratering Experiments, Site 300, 1970, U.S. Army Engineer Nuclear Cratering Group, NCG/TR-37 (May 1971).

9. K. T. Sakai and R. F. Bourque, Summary of Underwater Cratering Tests Conducted at Site 300 During 1970, U.S. Army Engineer Waterways Experiment Station Explosive Excavation Research Office, Livermore, California, EERO/TM-70-11 (Aug. $1971)$.

10. E. H. Kleist and M. R. Florey, Underwater Explosive Excavation Modeling Tests, U.S. Army Engineer Waterways Experiment Station Explosive Excavation Research Office, Livermore, California, EERO/TM-71-9 (Jan. 1972).

11. C. M. Snell, Shock Wave Interaction and Near-Surface Cavitation, Project Tugboat, U.S. Army Engineer Waterways Experiment Station Explosive Excavation Research Laboratory, Livermore, California, EERL/TM-71-17 (Apr. 1972).

12. C.S. Mill, Jr., Explosive Excavation of Drum Inlet, U.S. Army Engineer District, Wilmington, Corps of Engineers, Wilmington, North Carolina (1972); draft article prepared for submission to the journal Military Engineer. 
13. Water Spectrum, Office of the Chief of Engineers, Department of the Army, Washington, D.C., published by Dept. of the Army, Corps of Engineers, Spring Issue (1972), pp. 44-46.

14. Manteo (Shallowbag) Bay, North Carolina, Review Report, U.S. Army Engineer District, Wilmington, Corps of Engineers, Wilmington, North Carolina (1968).

15. Drum Inlet, North Carolina, Detailed Project Report, U.S. Army Engineer District, Wilmington, Corps of Engineers, Wilmington, North Carolina (1965).

16. S. M. Johnson, Explosive Excavation Technology, U.S. Army Engineer Nuclear Cratering Group, Livermore, California, NCG/TR-21, AD-727651 (June 1971).

17. B. B. Redpath, "A Concept of Row Crater Enhancement," in Proceedings of Symposium on Engineering with Nuclear Explosives, American Nuclear Society Meeting, Las Vegas, Nevada, January 14-16, 1970, CONF-700101, Vol. 1 (1970), p. 1679.

18. B.B. Redpath, Explosive Excavation Research Laboratory, Livermore, California, private communication (Nov. 1972).

19. L. K. Davis and A. D. Roode, High-Explosive Cratering Experiments in Shallow Water, U.S. Army Engineer Waterways Experiment Station, Vicksburg, Mississippi, Miscellaneous Paper No. 1-946 (Dec. 1968).

20. J. N. Strange, Effects of Explosions in Shallow Water, U.S. Army Engineer Waterways Experiment Station, Vicksburg, Mississippi, Technical Memorandum No. 2-406 (Apr. 1955).

21. B. B. Redpath, Project Trinidad: Explosive Excavation Tests in Sandstone and Shale, U.S. Army Engineer Waterways Experiment Station Explosive Excavation Research Laboratory, Livermore, California, EERL/TR-E-73-1 (1973).

22. J.E. Lattery, Project Trinidad: Railroad Relocation, Cuts RR-2 and RR-3, U.S. Army Engineer Waterways Experiment Station Explosive Excavation Research Laboratory, Livermore, California, technical report to be published (1973).

23. D. L. Oltmans, E. J. Leahy, C. M. Snell, T. Donlan, and W. B. Lane, Fallout Simulation: Nuclear Cratering Device Simulation (Project Diamond Ore) (2), U. S. Army Engineer Waterways Experiment Station Explosive Excavation Research Laboratory, Livermore, California, technical report to be published (1973).

24. Young, G. A., The Physical Effects of Conventional Explosions on the Ocean Environment, U.S. Naval Ordnance Laboratory, White Oak, Silver Spring, Maryland, NOL-TR-71-120 (Aug. 1971).

25. R. H. Cole, Underwater Explosions (Dover Publications, New York, 1948).

26. W. G. Christopher and J. E. Lattery, Project Pre-Gondola I, Crater Studies: Surface Motion, U.S. Army Engineer Nuclear Cratering Group, Livermore, California, PNE-1107 Part II (Feb. 1969).

27. D. N. Montan, "Source of Airblast from the Underground Explosion," Trans. Amer. Nuc1. Soc. 2, 541 (1968).

28. C. M. Snell and D. L. Oltmans, Prediction of Ground-Shock-Induced Airblast Overpressures for Subsurface Explosions from Peak Vertical Spall Velocity, U.S. 
Army Engineer Waterways Experiment Station Explosive Excavation Research Office, Livermore, California, EERO/TR-40 (Nov. 1971).

29. C. M. Snell, Estimating Water-Shock-Induced Airblast from Detonations in a Medium Overlain with Water, U.S. Army Engineer Waterways Experiment Station Explosive Excavation Research Laboratory, Livermore, California, EERL/TR-E72-16 (1972).

30. A.S. Vesic et al., Duke University School of Engineering, Cratering in Layered Media, U. S. Army Engineer Waterways Experiment Station Explosive Excavation Research Laboratory, Livermore, California, EERL/TR-E-72-31 (Aug. 1971). 


\section{Distribution}

\section{LLL Internal Distribution}

Roger E. Batzel

T. A. Gibson

M. A. Harrison

A. C. Haussmann

G. H. Higgins

A. Holzer

V. N. Karpenko

J. B. Knox

C.A. McDonald

M. D. Nordyke

H. L. Reynolds

J.W. Rosengren

D. C. Sewell

R. W. Terhune

H. A. Tewes

J. Toman

G. C. Werth

LBL Library

TID File

\section{External Distribution}

E. Teller

University of California

Berkeley, California

HQDA (DARD-NSN)

Washington, D. C.

HQDA (DAEN-CWZ-R)

Washington, D.C.

HQDA (DAEN-CWE-G)

Washington, D. C.

HQDA (DAEN-MER-D)

Washington, 'D.C.

HQDA (DAEN-MCE-D)

Washington, D. C.

HQDA (DARD-MSN)

Washington, D. C.

U.S. Army Engineer Waterways Experiment Station

Vicksburg, Mississippi
U.S. Army Engineer Division, Huntsville

Huntsville, Alabama

U.S. Army Engineer District, - Memphis

Memphis, Tennessee

U. S. Army Engineer District, New Orleans

New Orleans, Louisiana

U.S. Army Engineer District, St. Louis

St. Louis, Missouri

U.S. Army Engineer Division, Lower Mississippi Valley

Vicksburg, Mississippi

U.S. Army Engineer District, Vicksburg

Vicksburg, Mississippi

U.S. Army Liaison Detachment

New York, New York

U. S. Army Engineer Division, Missouri River

Omaha, Nebraska

U.S. Army Engineer District, Kansas City

Kansas City, Missouri

U.S. Army Engineer District, Omaha

Omaha, Nebraska

U.S. Army Engineer Division, New England

Waltham, . Massachusetts

U.S. Army Engineer Division, North Atlantic

New York, New York

U.S. Army Engineer District, Baltimore

Baltimore, Maryland

U.S. Army Engineer District, New York

New York, New York

5

U.S. Army Engineer District, Norfolk

Norfolk, Virginia 
External Distribution Continued

U.S. Army Engineer District, Philadelphia

Philadelphia, Pennsylvania

U.S. Army Engineer Division, North Central

Chicago, Illinois

U.S. Army Engineer District, Buffalo

Buffalo, New York

U.S. Army Engineer District, Chicago

Chicago, Illinois

U.S. Army Engineer District, Detroit

Detroit, Michigan

U.S. Army Engineer District, Rock Island

Rock Island, Illinois

U. S. Ärmy Engineer District, St. Paul

St. Paul, Minnesota

U.S. Army Engineer Division, North Pacific

Portland, Oregon

U.S. Army Engineer District, Alaska

Anchorage, Alaska

U.S. Army Engineer District, Portland

Portland, Oregon

U.S. Army Engineer District, Seattle

Seattle, Washington

U.S. Army Engineer District, Walla Walla

Walla Walla, Washington

U.S. Army Engineer Division, Ohio River

Cincinnati

U.S. Army Engineer District, Huntington

Huntington, West Virginia

U. S. Army Engineer District, Louisville

Louisville, Kentucky
U.S. Army Engineer District, Nashville

Nashville, Tennessee

U. S. Army Engineer District, Pittsburgh

Pittsburgh, Pennsylvania

U.S. Army Engineer Division, Pacific Ocean

Honolulu, Hawaii

U.S. Army Engineer Division, South Atlantic

Atlanta, Georgia

U. S. Army Engineer District, Charleston

Charleston, South Carolina

U.S. Army Engineer District, Jacksonville

Jacksonville, Florida

U. S. Army Engineer District, Mobile

Mobile, Alabama

U. S. Army Engineer District, Savannah

Savannah, Georgia

U. S. Army Engineer District, Wilmington

ATTN: D. Carmen

Wilmington, North Carolina

U.S. Army Engineer Division, South Pacific

San Francisco, California

U.S. Army Engineer District, Los Angeles

Los Angeles, California

U.S. Army Engineer District, Sacramento

Sacramento, California

U.S. Army Engineer District, San Francisco

San Francisco, California

U. S. Army Engineer Division, Southwestern

Dállas, Texas

U. S. Army Engineer District, Albuquerque

Albuquerque, New Mexico 
External Distribution Continued

U.S. Army Engineer District, Fort Worth

Fort Worth, Texas

U.S. Army Engineer District, Galveston

Galveston, Texas

U.S. Army Engineer District, Little Rock

Little Rock, Arkansas

U.S. Army Engineer District, Tulsa

Tulsa, Oklahoma

U.S. Army Coastal Engineering Research Center

Washington, D. C.

U.S. Army Engineer Topographic Command

Washington, D. C.

U.S. Army Engineer Topographic Laboratories

Fort Belvoir, Virginia

U. S. Army Engineer Center

Fort Belvoir, Virginia

Commandant

U.S. Army Engineer School

ATTN: ATSEN-DD

Fort Belvoir, Virginia

NBC Division

U.S. Army Engineer School

Fort Belvoir, Virginia

U.S. Army Engineer Power Group

Fort Belvoir, Virginia

U. S. Army Engineer Training Center

Fort Leonard Wood, Missouri

Director

Development Center (FS Div.)

Marine Corps Development of Education Command

Quantico, Virginia

U.S. Army Cold Region Research and Engineering Laboratory

Hanover, New Hampshire

$\mathrm{WEC} / \mathrm{rt}$

\section{U.S. Army Construction Engineering} Research Laboratory

Champaign, Illinois

Commander of the Marine Corps

Department of the Navy

Washington, D. C.

Commander

Kirtland AFB

Albuquerque, New Mexico

Commander

Air Force Weapons Laboratory

ATTN: R. W. Henny/WLDC

Kirtland A FB

Albuquerque, New Mexico

Commander

Department of the Navy

Washington, D. C.

U.S. Army Engineer School

Library

ATTN: R. M. Hannholm

Fort Belvoir, Virginia

Defense Documentation Center

Cameron Station

Alexandria, Virginia

U.S. Army Ballistics Research Laboratories

Aberdeen Proving Ground,

Maryland

Commander

Command and General Staff College

Fort Leavenworth, Kansas

Naval Ordnance Laboratory

White Oak, Maryland

Commander

Naval Weapons Evaluation Facility (SW)

Kirtland AFB

Albuquerque, New Mexico

Sandia Laboratories

ATTN: Technical Library

ATTN: L.J. Vortman

Albuquerque, New Mexico

U.S. Army Engineer Explosive Excavation Research Laboratory

Livermore, California

TID-4500 Distribution, UC-35

Peaceful Applications

of Explosions 
Printed in the United States of America Available from

National Technical Information Service

U.S. Department of Commerce 5285 Port Royal Road

Springfield, Virginia 22151

Price: Printed Copy $\$ 10.60$; Microfiche $\$ 1.45$

NOTICE

"This report was prepared as an account of work sponsored by the United States Government. Neither the United States nor the United States Atomic Energy Commission, nor any of their employees, nor any of their contractors, subcontractors, or their employees, makes any warranty, express or implied, or assumes any legal liability or responsibility for the accuracy, completeness or usefulnes of any information, apparatus, product or process would not infringe privately. disclosed, or reped rights." 
DOCUMENT CONTROL DATA - R \& D

(Security classification of tillo, body of abstract and indening annotetion must be entered when the overall report is clasaified) 1. ORIGINATING ACTIVITY (Corporate author)" 2G. REPORT SECURITY CLASSIFICATION

U. S. Army Engineer Waterways Experiment Station Explosive Excavation Research Laboratory Unclassified

3. REPOAT TITLE

Project DRUM INLET: Explosive Excavation in Saturated Sand

4. DESCRIPTIVE NOTES (TYPe of roport and inclusive dates)

Final Technical Report

5. AU THOR(S) (Flret neme, middlo Initial, last namo)

Charles M. Snell, MAJ Richard H. Gillespie

\begin{tabular}{|c|c|c|}
\hline $\begin{array}{l}\text { 6. AEPORT OATE } \\
\text { August } 1973\end{array}$ & $\begin{array}{l}\text { 76. TOTAL NO. OF PAGES } \\
{ }_{3}\end{array}$ & $\begin{array}{c}\text { 7b. NO. OF REFS } \\
30\end{array}$ \\
\hline $\begin{array}{l}\text { QA. CONTRACT OR GRANT NO. } \\
\text { b. PROJECT NO. }\end{array}$ & \multicolumn{2}{|c|}{$\begin{array}{l}\text { 90. ORIGINA TOR.S REPORT NUMBER(S) } \\
\text { TR-E-73-5 }\end{array}$} \\
\hline c. & \multicolumn{2}{|c|}{$\begin{array}{l}\text { 9b. OTHER REPORT NO(S) (ANy Other numbers that may bo AEslened } \\
\text { this roport) }\end{array}$} \\
\hline
\end{tabular}

10. DISTR1BUTION STATEMENT

Approved for public release; distribution unlimited.

\begin{tabular}{|l|l|}
\hline 11. SUPPLEMENTARY NOTES & 12. SPONSORING MILITARY ACTIVITY \\
\hline $\begin{array}{c}\text { 13. ABSTACT } \\
\text { Seasonal storms during February of } 1971 \text { completely closed the DRUM INLETT }\end{array}$
\end{tabular}

Seasonal storms during February of 1971 completely closed the DRUM INLET navigation channel through the Outer Banks off the North Carolina Coast. This channel is highly useful to commercial and sport fishing industries in the Carteret County vicinity of North Carolina, and is vital to maintenance of the ecological balance in the inland Core Sound waters. To reopen DRUM INLET, an alignment about 2.1 miles south of the original location was selected. A contract dredge excavated a channel from the inland Core Sound waterway to and partway through the Outer Banks. The final 385-ft-long section of sand separating the Core Sound from the Atlantic Ocean was excavated with large explosive charges. This report describes the explosive excavation of that portion of the channel. Twenty-two separate canisters, each containing 1 ton of aluminized ammoniumnitrate slurry blasting agent, were emplaced in two rows. All charges were detonated simul taneously at 1327 hours, 23 Decenber 1971. The detonation successfully removed the sand barrier, forming a continuous channel over $80 \mathrm{ft}$ in width. This channel subsequently washed out to a. width of about $1000 \mathrm{ft}$ and was used as an access route to the Raleigh Bay fishing grounds. The DRUM INLET Project demonstrated the practicality of explosive channel excavation in saturated sand under the special conditions encountered at this site. 
UNCLASSIFIED

Security Classification

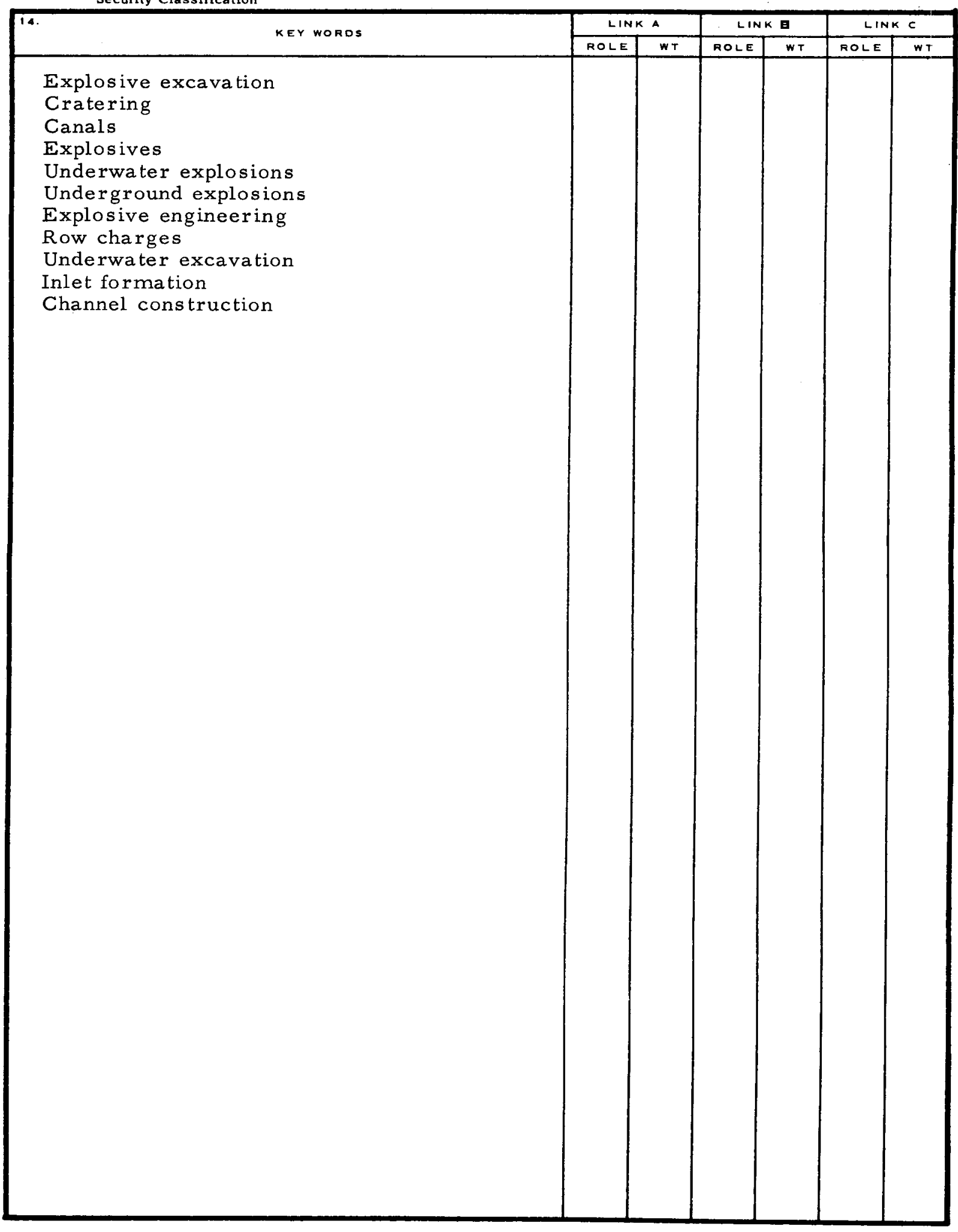

UNCLASSIFIED

น GPO 791.726

Security Classification 
0 
0 